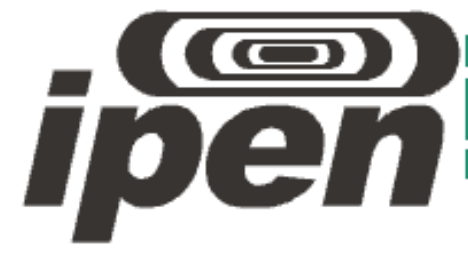

AUTARQUIA ASSOCIADA À UNIVERSIDADE DE SÃO PAULO

\title{
PROJETO E CONSTRUÇÃO DE PLACAS ESPALHADORAS E DEGRADADORAS DE ENERGIA PARA USO EM RADIOTERAPIA COM FEIXES DE ELÉTRONS PARA DOENÇAS DE PELE
}

\section{Gabriel Paiva Fonseca}

Dissertação apresentada como parte dos requisitos para obtenção do Grau de Mestre em Ciências na Área de Tecnologia Nuclear - Reatores

Orientador:

Prof. Dr. Hélio Yoriyaz 
PROJETO E CONSTRUÇÃO DE PLACAS ESPALHADORAS E DEGRADADORAS DE ENERGIA PARA USO EM RADIOTERAPIA COM FEIXES DE ELÉTRONS PARA DOENÇAS DE PELE

GABRIEL PAIVA FONSECA

Dissertação apresentada como parte dos requisitos para obtenção do Grau de Mestre em Ciências na Área de Tecnologia Nuclear Reatores 


\section{DEDICATÓRIA}

Dedico este trabalho aos meus pais

Carlos e Madalena, pela confiança e apoio incondicional. 
"Tantum homo habet de scientia quantum operatur $(\mathrm{O}$ conhecimento que o homem possui é só aquele que aplica)"

São Francisco 


\section{AGRADECIMENTOS}

Gostaria de agradecer, sobretudo, ao Dr. Hélio Yoriyaz, por me orientar desde 2006, e por dedicar o seu tempo à conclusão deste trabalho e a minha formação.

Ao Dr. Paulo de Tarso pelo interesse e auxílio ao longo de todo o trabalho desenvolvido.

A toda equipe do Serviço de Radioterapia do Hospital das Clínicas da Universidade de São Paulo, em especial à Dra. Esmeralda, idealizadora do projeto. À Gabriela e à Laura Furnari pelas diversas noites realizando medidas experimentais, além do apoio prático e teórico.

À minha namorada Louise pela compreensão, pela consultoria na área médica e, sobretudo, pelo incentivo pessoal e profissional ao longo de oito anos.

Aos meus pais, Carlos e Madalena, à minha tia Tereza, aos meus irmãos Juliana, Rodrigo e Roberta, e aos queridos agregados Hudson, Antônio Flavio e Maraysa, que me apoiaram e incentivaram em todos os momentos da minha vida.

Aos meus colegas de república e aos meus amigos, Yan, Carlos, Gregório, Arthur, César, Thiago, Leonardo e Rodrigo, muitos dos quais amigos da graduação e hoje colegas de Mestrado, pelo tempo dedicado a ouvir as apresentações e pelos artigos, que leram inúmeras vezes. Em especial gostaria de agradecer à Paula por acompanhar-me em todas as medidas experimentais e em todas as fases deste projeto, contribuindo para o seu êxito, e principalmente pela amizade.

Aos colegas de trabalho do IPT, pela compreensão, incentivo e pela disponibilidade necessária a conclusão deste trabalho. Agradeço especialmente, ao Me. Antonio Gentil e ao Dr. Julio Teixeira, pela amizade, interesse e pelo apoio no desenvolvimento deste projeto. À Ariane Tada, companheira de trabalho, de mestrado e amiga, pelo apoio e pelas inúmeras discussões pessoais e profissionais, ao longo de mais de 2 anos. 


\title{
PROJETO E CONSTRUÇÃO DE PLACAS ESPALHADORAS E DEGRADADORAS DE ENERGIA PARA USO EM RADIOTERAPIA COM FEIXES DE ELÉTRONS PARA DOENÇAS DE PELE
}

\author{
Gabriel Paiva Fonseca
}

\section{RESUMO}

Há diversas enfermidades radiossensíveis epidermotrópicas, como a micose fungóide e a síndrome de Sézary, neoplasias cutâneas originadas de linfócitos do tipo $\mathrm{T}$, que apresentam grande possibilidade de erradicação quando tratadas com feixes de elétrons com energia entre 4 e $10 \mathrm{MeV}$, conforme apontam diversos estudos. No entanto, esta técnica de tratamento apresenta inúmeras dificuldades práticas, pois a doença dissemina-se por todo o corpo do paciente tornando necessário um grande campo de radiação e deposição de energia limitada à profundidade da pele. A fim de obter uma distribuição de dose uniforme, muitas técnicas já foram desenvolvidas. Com base em estudos anteriores e guiados pelo protocolo $n^{\circ} .23$ da American Association of Physicists in Medicine (AAPM), o presente trabalho desenvolveu placas espalhadoras e degradadoras de energia e realizou toda a dosimetria (computacional e experimental), a fim de fornecer subsídios para a implementação da técnica de tratamento Total Skin Electron Therapy (TSET) no Serviço de Radioterapia do Hospital das Clínicas de São Paulo. O programa MCNP4C baseado no método de Monte Carlo foi utilizado para reconstruir o espectro energético do acelerador Varian Clinac 2100C, por meio de medidas experimentais de percentual de dose em profundidade (PDP) e perfis radiais de dose. Com estes dados, foi possível efetuar simulações computacionais para a seleção de materiais, mediante análise da distribuição radial e axial de dose, produção de raios-X e a atenuação do feixe, além da simulação de placas espalhadoras e degradadoras de energia, a serem posicionadas na saída do acelerador. Os resultados das simulações foram validados por meio de medidas experimentais a fim de obter um grande campo de radiação com $200 \mathrm{~cm} \times 80 \mathrm{~cm}$ que atendesse as especificações do protocolo da AAPM. 


\title{
PROJECT AND CONSTRUCTION OF ENERGY DEGRADING AND SCATTERING PLATES FOR ELECTRON BEAM RADIOTHERAPY FOR SKIN DISEASES
}

\author{
Gabriel Paiva Fonseca
}

\begin{abstract}
There are many radiosensitive epidermotropics diseases such as mycosis fungoids and the syndrome of Sézary, coetaneous neoplasics originated from type $T$ lymphocytes. Several studies indicate the eradication of the disease when treated with linear accelerators emitting electron beams with energies between 4 to 10 MeV. However, this treatment technique presents innumerable technical challenges since the disease in general reaches all patient's body, becoming necessary not only a very large field size radiation beam, but also deliver superficial doses limited to the skin depth. To reach the uniformity in the dose distribution, many techniques had already been developed. Based on these previous studies and guided by the report $n^{\circ} .23$ of the American Association of Physicists in Medicine (AAPM), the present study developed an energy scattering and degrading plates and made dosimetry (computational and experimental), supplying subsidies for a future installation of Total Skin Electron Therapy (TSET) at the Serviço de Radioterapia do Hospital das Clínicas de São Paulo. As part of the plates design, first of all, the energy spectrum of the $6 \mathrm{MeV}$ electron beam of the VARIAN $2100 \mathrm{C}$ accelerator was reconstructed through Monte Carlo simulations using the MCNP4C code and based on experimental data. Once the spectrum is built, several materials were analyzed for the plates design based on radial and axial dose distribution, production of rays- $x$ and dose attenuation. The simulation results were validated by experimental measurements in order to obtain a large field of radiation with $200 \mathrm{~cm} \times 80 \mathrm{~cm}$ that meets the specifications of the AAPM protocol.
\end{abstract}




\section{SUMÁRIO}

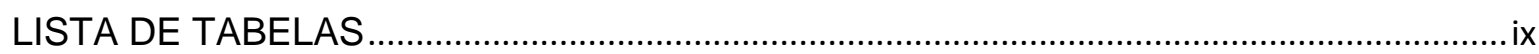

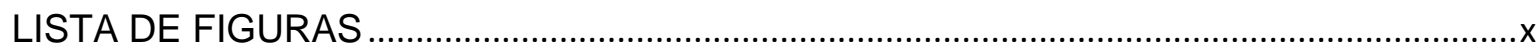

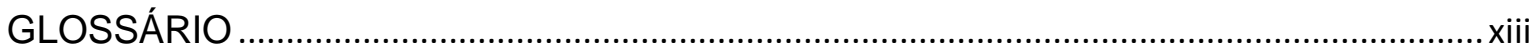

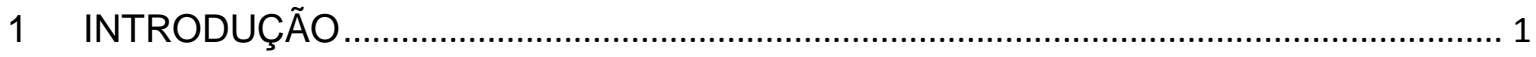

2 FUNDAMENTOS TEÓRICOS ................................................................................... 4

2.1 Fundamentos de radioterapia ................................................................................ 4

2.1.1 Aceleradores lineares ................................................................................... 4

2.2 Fundamentos de dosimetria..................................................................................

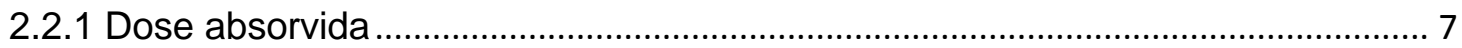

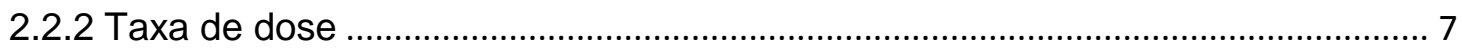

2.2.3 Parâmetros clínicos da PDP ......................................................................... 8

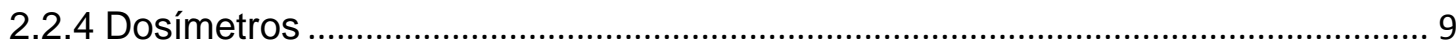

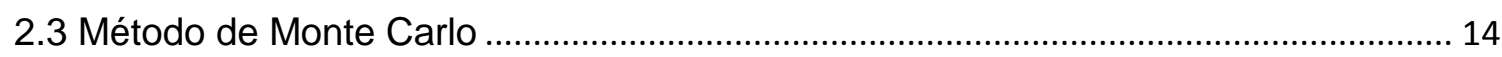

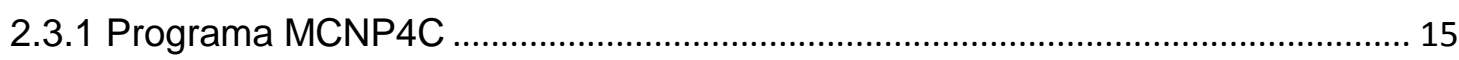

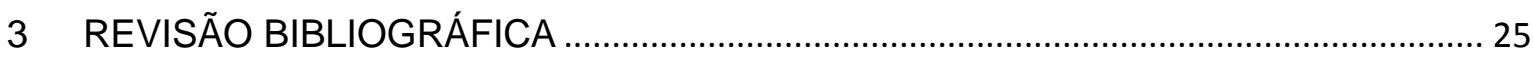

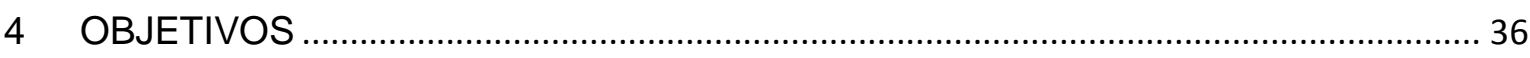

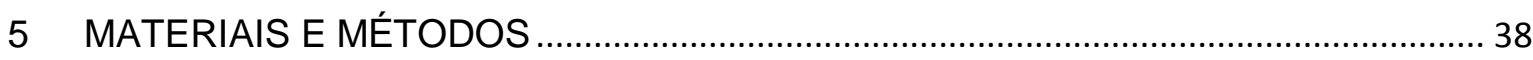

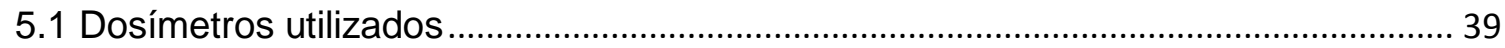



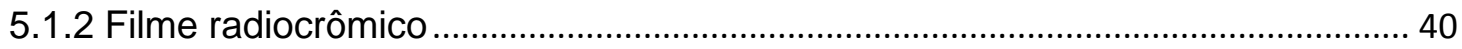

5.1.3 Dosímetro termoluminescente (TLD 100) ........................................................... 40

5.2 Medidas experimentais "Acelerador Linear Varian Clinac 2100C" ............................ 43

5.2.1 Caracterização do feixe de elétrons ..................................................................... 43

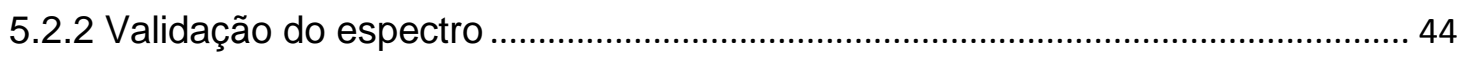

5.2.3 Validação das simulações com materiais .............................................................. 45

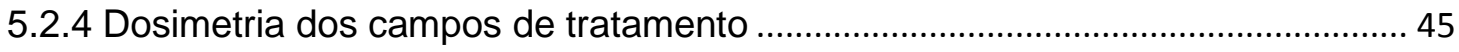

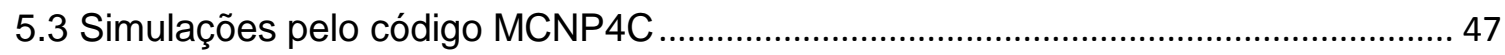

5.3.1 Comparação entre feixes monoenergéticos de 4, 6, 9 e $12 \mathrm{MeV}$......................... 48

5.3.2 Fonte de elétrons .................................................................................................... 48 
5.3.3 Seleção de materiais 51

5.3.4 Placas espalhadoras e degradadoras de energia............................................... 52



6.1 Avaliação dos dosímetros termoluminescentes LiF-100 ............................................. 55

6.2 Comparação entre feixes monoenergéticos de 4, 6, 9 e $12 \mathrm{MeV}$................................ 59



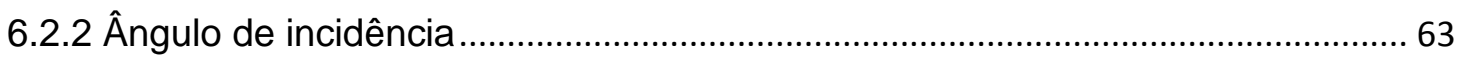



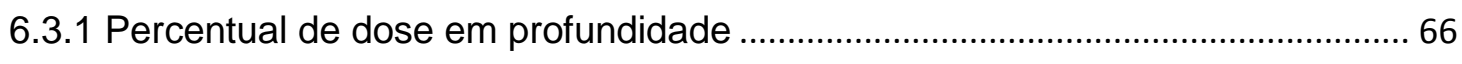

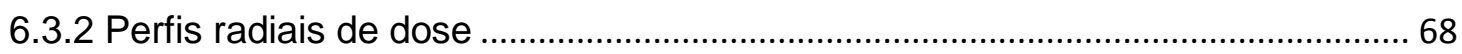

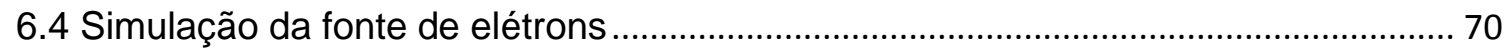

6.4.1 Percentual de dose em profundidade ................................................................. 70

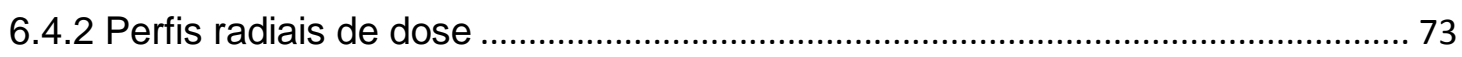

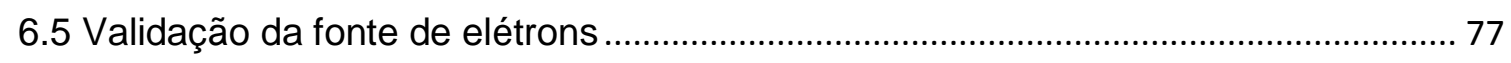

6.5.1 Percentual de dose em profundidade ................................................................... 77

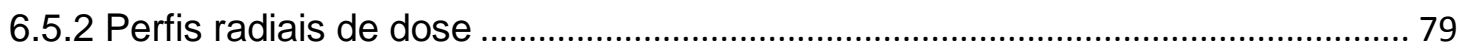

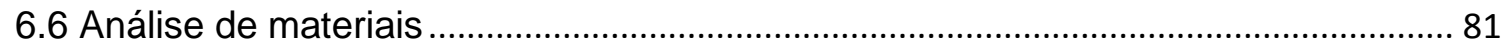

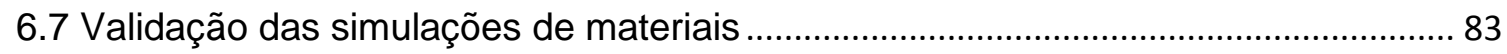

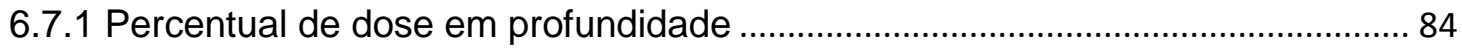

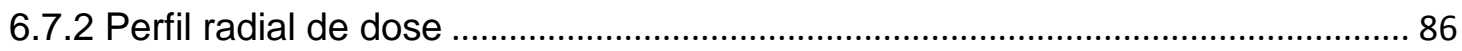

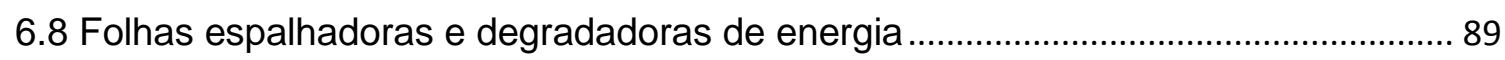

6.8.1 Feixe único de tratamento para lesões de até $60 \mathrm{~cm}$ (DFS 1,3 m) ..................... 89

6.8.2 Feixe único de tratamento para TSET ………………........................................... 92

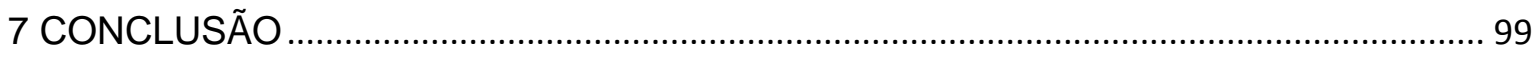

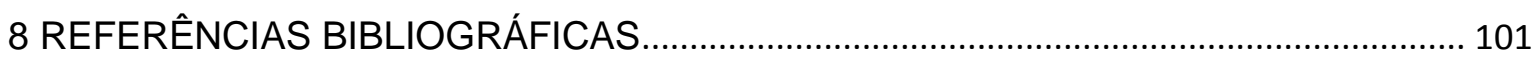




\section{LISTA DE TABELAS}

TABELA 1: Tratamentos mais utilizados nos diferentes estágios da doença. 26

TABELA 2: Fatores de correção (F.C) e desvio padrão (\%) dos fatores de correção de cada dosímetro, obtidos pela resposta normalizada em cada uma das seis irradiações. .58 TABELA 3: Desvio padrão da média em porcentagem, para 110 dosímetros sem fator de correção em comparação ao desvio padrão dos dados corrigidos.

TABELA 4: Parâmetros clínicos simulados para feixes de elétrons monoenergéticos com energias de 4, 6, 9 e $12 \mathrm{MeV}$.

TABELA 5: Profundidade da região de tratamento para feixes monoenergéticos de 4, 6, 9 e $12 \mathrm{MeV}$, em função do ângulo de inclinação do feixe.

TABELA 6: Parâmetros clínicos obtidos mediante PDP experimental, realizada com a bandeja de TSET, sem nenhuma folha espalhadora, a DFS 0,7 m

TABELA 7: Comparação entre os parâmetros obtidos, mediante PDP experimental (referência) e simulada, em um objeto simulador de água a DFS 0,7 m.

TABELA 8: Comparação entre os parâmetros obtidos, mediante PDP experimental e simulada, em um objeto simulador de água a DFS $1 \mathrm{~m}$.

TABELA 9: Comparação de parâmetros entre placas espalhadoras e degradadoras de energia quadradas com $20 \mathrm{~cm}$ de lado e $1 \mathrm{~mm}$ de espessura para diferentes materiais, simulados na saída do acelerador a DFS $1 \mathrm{~m}$. 


\section{LISTA DE FIGURAS}

FIGURA 1: Representação de um tratamento com dois campos de radiação. 2

FIGURA 2: Foto do acelerador linear Varian Clinac 2100C do Hospital das Clínicas da Universidade de São Paulo.

FIGURA 3: Percentual de dose em profundidade no eixo central, a $1 \mathrm{~m}$ de distância fonte superfície, para: (a) elétrons com energias de 6, 9, 12 e $18 \mathrm{MeV}$; (b) fótons com energias de 6 e 15 MV (PODGORSAK, 2005).

FIGURA 4: Representação dos parâmetros de PDP, construída com base nos resultados obtidos experimentalmente.

FIGURA 5: Modelo de uma câmara de ionização cilíndrica tipo Farmer (PODGORSAK, 2005).

FIGURA 6: Processo de excitação e emissão termoluminescente..........................................12

FIGURA 7: Picos de emissão do TLD tipo LiF 100

FIGURA 8: Ilustração do tempo necessário para resolução problemas pelo método de Monte Carlo em comparação com o método analítico (BIELAJEW, 2001)..........................14

FIGURA 9: Imagem construída utilizando o recurso de estruturas repetidas. ........................16

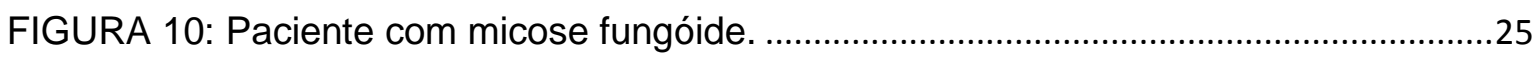

FIGURA 11: Posições de tratamento, baseadas no protocolo $n^{\circ} 23$ da AAPM. ...................30

FIGURA 12: Tratamento com um único feixe espalhado (CHEN et al., 2004).....................31

FIGURA 13: Tratamento com dois feixes espalhados (CHEN et al., 2004). ..........................32

FIGURA 14: Distribuição de dose para um feixe (esquerda) e dois feixes (direita)

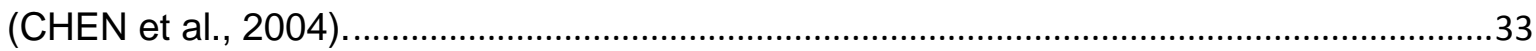

FIGURA 15: Distribuição de dose na pele, obtida simulando um feixe de fótons. ................35

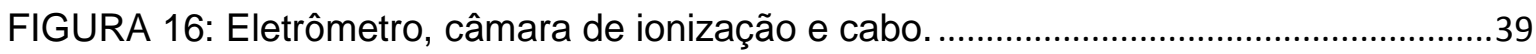

FIGURA 17: Filme Gafchromic da ISP, posicionado sobre placas de água sólida. .............40

FIGURA 18: Dosímetros termoluminescentes do tipo LiF 100 ...............................................40

FIGURA 19: Estufa Fisher Scientific, utilizada no tratamento térmico dos dosímetros. .....41

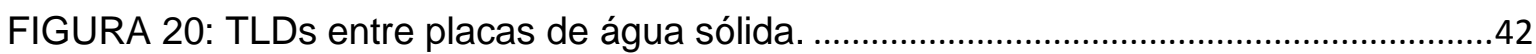

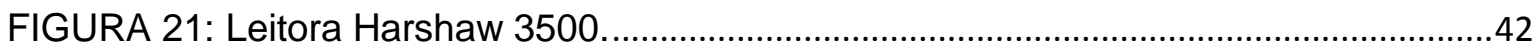

FIGURA 22: Acelerador linear Varian Clinac $2100 \mathrm{C}$ e objeto simulador de água automatizado utilizados nas medidas experimentais. .........................................................4

FIGURA 23: Bandeja de suporte para placas espalhadoras e degradadoras de

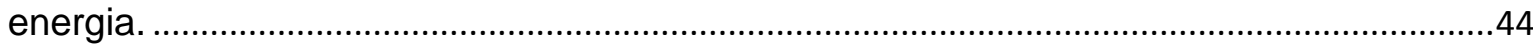

FIGURA 24: Câmara de ionização entre placas de água sólida. ..........................................46

FIGURA 25: Acelerador linear Varian Clinac 2100C, filmes radiocrômicos e dosímetros termoluminescentes (LiF 100), utilizados na medida de perfil radial a DFS 2,95 m. .........47

FIGURA 26: Geometria utilizada na simulação da fonte a DFS 0,7 m................................49

FIGURA 27: Representação da subdivisão da fonte no código MCNP4C. ............................50 
FIGURA 28: Ilustração de um campo circular delimitado, obtido com uma fonte pontual.

FIGURA 29: Representação da geometria utilizada nas simulações de materiais.

FIGURA 30: Número de dosímetros em função da faixa da resposta, em cada uma das 8 irradiações realizadas.

FIGURA 31: Número de dosímetros em função da faixa da resposta normalizada, em cada uma das 8 irradiações realizadas.

FIGURA 32: a) dispersão da resposta termoluminescente normalizada pela média; b) dispersão da resposta termoluminescente corrigida e normalizada pela média.

FIGURA 33: Comparação entre as PDPs obtidas pelo método de Monte Carlo, para as energias de 4, 6, 9 e $12 \mathrm{MeV}$, em um objeto simulador de água a DFS 2,5 m

FIGURA 34: Comparação entre os perfis radiais obtidos pelo método de Monte Carlo, para as energias de 4, 6, 9 e $12 \mathrm{MeV}$ em um dos lados do campo de tratamento.

FIGURA 35: Representação das simulações realizadas com feixes inclinados, em relação à reta normal a superfície do objeto simulador.

FIGURA 36: PDP em um objeto simulador de água, com ângulos de incidência do feixe entre 0 e $75^{\circ}$, para feixes de elétrons com energia: a) $4 \mathrm{MeV}$; b) $6 \mathrm{MeV}$.

FIGURA 37: PDP em um objeto simulador de água, com ângulos de incidência do feixe entre 0 e $75^{\circ}$, para feixes de elétrons com energia: a) $9 \mathrm{MeV}$; b) $12 \mathrm{MeV}$.................65

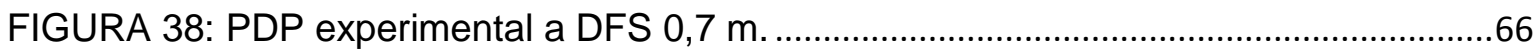

FIGURA 39: Perfis radiais em um objeto simulador de água a DFS $0,7 \mathrm{~m}$.......................68

FIGURA 40: Comparação entre os perfis radiais de dose nos eixos $x$ e y a $12,8 \mathrm{~mm}$ profundidade, obtidos a DFS $0,7 \mathrm{~m}$.

FIGURA 41: Distribuição energética utilizada nas simulações pelo MCNP4C. .....................70

FIGURA 42: Comparação entre a PDP obtida pelo método de Monte Carlo e o resultado obtido experimentalmente a DFS $0,7 \mathrm{~m}$, para o feixe de $6 \mathrm{MeV}$. .

FIGURA 43: Representação geométrica da fonte, da janela simulada e do feixe de elétrons.

FIGURA 44: Distribuição angular dos elétrons emitidos pela fonte utilizada nas simulações pelo código MCNP4C.

FIGURA 45: Comparação do perfil radial experimental e simulado, no eixo central e fora do eixo, a 12,8 $\mathrm{mm}$ profundidade (DFS 0,7 $\mathrm{m}$ ).

FIGURA 46: Comparação do perfil radial experimental e simulado, no eixo central e fora do eixo, a 13,2 $\mathrm{mm}$ profundidade (DFS 0,7 $\mathrm{m}$ ).

FIGURA 47: Comparação do perfil radial experimental e simulado, no eixo central e fora do eixo, a 18,4 $\mathrm{mm}$ profundidade (DFS 0,7 $\mathrm{m}$ ).

FIGURA 48: Comparação do perfil radial experimental e simulado, no eixo central e fora do eixo, a $23 \mathrm{~mm}$ profundidade (DFS 0,7 m) ............................................................. FIGURA 49: Comparação entre a PDP obtida pelo método de Monte Carlo e o resultado obtido experimentalmente a DFS $1 \mathrm{~m}$, para o feixe de $6 \mathrm{MeV}$.............................77 FIGURA 50: Comparação do perfil radial experimental e simulado, no eixo central e

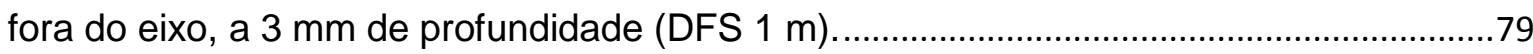
FIGURA 51: Comparação do perfil radial experimental e simulado, no eixo central e fora do eixo, a $7 \mathrm{~mm}$ de profundidade (DFS $1 \mathrm{~m}$ )... 
FIGURA 52: Comparação do perfil radial experimental e simulado, no eixo central e fora do eixo, a $11 \mathrm{~mm}$ de profundidade (DFS $1 \mathrm{~m}$ )...

FIGURA 53: Comparação do perfil radial experimental e simulado no eixo central e fora do eixo a $15 \mathrm{~mm}$ de profundidade (DFS $1 \mathrm{~m}$ ).

FIGURA 54: PDP (DFS $1 \mathrm{~m}$ ) com uma placa de alumínio com $1 \mathrm{~mm}$ de espessura posicionada na janela do acelerador.

FIGURA 55: PDP (DFS $1 \mathrm{~m}$ ) com uma placa de alumínio com $3 \mathrm{~mm}$ de espessura posicionada na janela do acelerador.

FIGURA 56: PDP (DFS $1 \mathrm{~m}$ ) com uma placa de alumínio com $5 \mathrm{~mm}$ de espessura posicionada na janela do acelerador.

FIGURA 57: PDP (DFS 0,7 m) com uma placa de cobre com 0,8 $\mathrm{mm}$ de espessura posicionada na janela do acelerador.

FIGURA 58: Perfil radial (DFS $1 \mathrm{~m}$ ) a $11 \mathrm{~mm}$ de profundidade, com uma placa de alumínio com $1 \mathrm{~mm}$ de espessura posicionada na janela do acelerador.

FIGURA 59: Perfil radial (DFS $1 \mathrm{~m}$ ) a $11 \mathrm{~mm}$ de profundidade, com uma placa de alumínio com $3 \mathrm{~mm}$ de espessura posicionada na janela do acelerador.

FIGURA 60: Perfil radial (DFS $1 \mathrm{~m}$ ) a $11 \mathrm{~mm}$ de profundidade, com uma placa de alumínio com $5 \mathrm{~mm}$ de espessura posicionada na janela do acelerador.

FIGURA 61: Perfil radial (DFS $1 \mathrm{~m}$ ) a $11 \mathrm{~mm}$ de profundidade, com uma placa de cobre com $0,8 \mathrm{~mm}$ de espessura posicionada na janela do acelerador.

FIGURA 62: Comparação entre o perfil radial obtido pelo método de Monte Carlo e os perfis experimentais, nos dois eixos do campo de tratamento, a $11 \mathrm{~mm}$ de profundidade (DFS $1 \mathrm{~m}$ )

FIGURA 63: PDP (DFS 1,3 m) com uma placa espalhadora de cobre, posicionada 11 $\mathrm{cm}$ abaixo da bandeja de suporte.

FIGURA 64: Comparação entre o perfil radial simulado e experimental em um dos lados do eixo central, utilizando uma folha espalhadora de cobre, a DFS 1,3 m.

FIGURA 65: PDP utilizando placas espalhadoras de cobre, cobre e acrílico, zinco e estanho.

FIGURA 66: Perfil radial de dose simulado, em um dos lados do eixo central, com placas espalhadoras de cobre, zinco e estanho, a DFS 2,95 m. .95 FIGURA 67: Perfil radial de dose em um dos lados do eixo central (DFS 2,95 m), obtido com TLDs, filmes radiocrômicos e simulado pelo MCNP4C. 


\section{GLOSSÁRIO}

PUVA Modalidade terapêutica que utiliza medicamentos para aumentar a sensibilidade à luz, os psoralenos $(\mathrm{P})$, associados à luz ultravioleta A (UVA).

MCNP4C Monte Carlo N-Particle Transport Code, versão 4C. Programa desenvolvido pelo laboratório de Los Alamos, que simula o transporte de radiação por meio do método estatístico de Monte Carlo.

Tally

Cartão de saída do programa MCNP4C, que define quais parâmetros devem ser calculados, por exemplo, o fluxo de elétrons.

AAPM American Association of Physicists in Medicine.

TG23

Relatório $\mathrm{n}^{\circ} 23$ da AAPM, denominado Total Skin Electron Therapy: Technique and Dosimetry.

PDP Percentual de Dose em Profundidade. Utilizado para caracterizar a distribuição de dose em função da profundidade em um determinado meio material.

DFS Distância Fonte Superfície.

TSET

Total Skin Electron Therapy.

LET

Linear Energy Transfer. Energia media depositada por uma partícula, ao atravessar um meio absorvedor com espessura determinada. 
TLD

Termo Luminescence Dosimetry. Dosímetros sensíveis à radiação, com resposta estimulada termicamente.

TLD100/LiF 100 Dosímetro termoluminescente de fluoreto de lítio, dopados com titânio e magnésio (LiF:Mg:Ti), com sensibilidade a fótons e elétrons.

SALT

FDP

FDC
Skin Associated Lymphoid Tissue.

Função Densidade de Probabilidade

Função Densidade Cumulativa 


\section{INTRODUÇÃO}

A pele é o maior órgão do corpo humano, representa de 15 a $16 \%$ da massa corporal; reveste praticamente toda sua superfície; protege os tecidos subjacentes; é responsável pela regulação da temperatura somática; efetor imunológico com população linfocitária T (SALT - skin associated lymphoid tissue) e é constituída de três camadas: epiderme, derme e hipoderme (SAMPAIO, 2007).

São inúmeras as doenças que podem acometer o tecido cutâneo (AGUIAR, 2009), cuja etiologia varia desde causas inflamatórias a neoplásicas. Dentre essas diversas enfermidades destaca-se a micose fungóide e a síndrome de Sézary (LANSIGAN et al., 2008), variedades epidermotrópicas dos linfomas cutâneos de células $T$. Estas desordens linfoproliferativas fazem com que os linfócitos $T$, formados no timo e responsáveis pela defesa da pele, tornem-se malignos, resultando em lesões no tecido.

A incidência de micose fungóide aumenta com a idade e ocorre sobretudo na faixa etária de 45 a 69 anos com prevalência no sexo masculino. No entanto, pode inclusive ocorrer na infância.

Dentre as modalidades de tratamento destaca-se, a radioterapia e a aplicação de materiais radioativos (BECKER et al., 1995). A Total Skin Electron Therapy (TSET) é uma modalidade terapêutica comumente utilizada em neoplasias radiossensíveis, apresentando remissão completa da doença em até $95 \%$ dos casos tratados em estágios iniciais (SAMPAIO, 2007).

Diversos ensaios clínicos (JONES et al., 1999) indicam a erradicação da doença quando tratados com aceleradores lineares emitindo feixes de elétrons com energias entre 4 e $10 \mathrm{MeV}$. Entretanto, os desafios técnicos para a elaboração de um arranjo clínico eficaz, tornam esta modalidade de radioterapia um objeto de vários estudos dosimétricos e clínicos. Isto decorre, sobretudo, em razão do 
tamanho da região afetada, uma vez que as células neoplásicas estão presentes em toda superfície corporal e, quando não tratadas a tempo, sofrem metástase.

Por se tratar de uma doença superficial, a técnica desenvolvida precisa depositar uma dose uniforme em toda a pele, em determinada profundidade, a qual deve ser limitada escolhendo-se feixes de elétrons de baixa energia ou por meio de placas degradadoras de energia.

Para atingir a uniformidade na distribuição de dose, muitas técnicas já foram desenvolvidas, em geral envolvendo a rotação da fonte de radiação em torno do paciente, ou então, o movimento contínuo dos pacientes (figura 1), utilizando um ou mais campos de radiação (KHATIB et al., 1995).

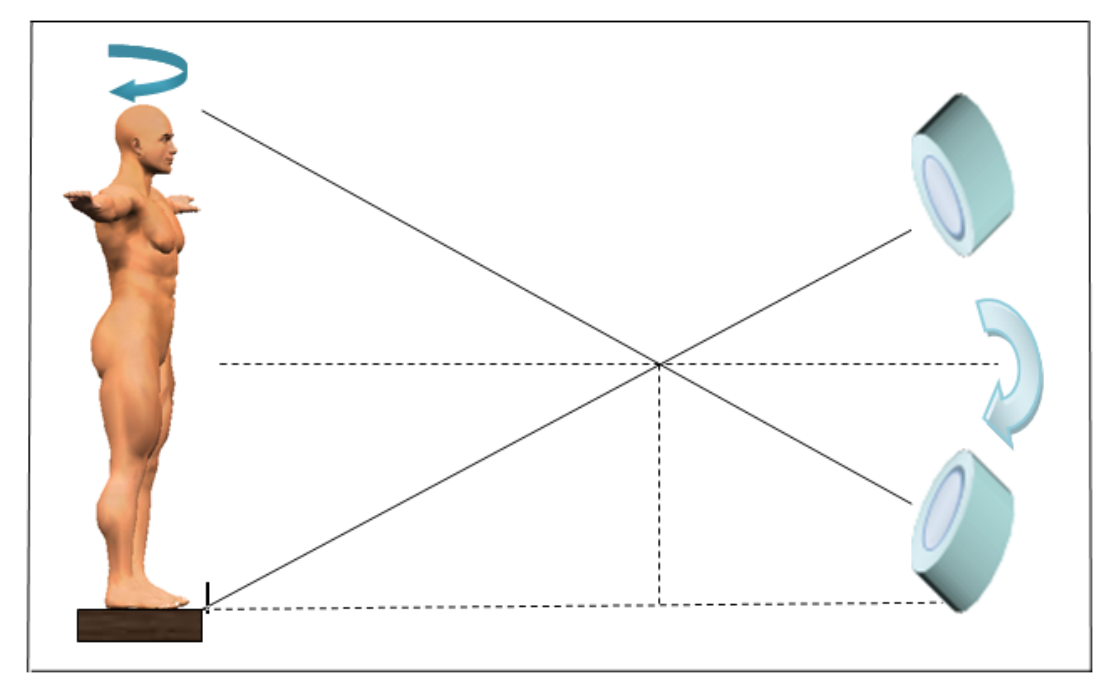

FIGURA 1: Representação de um tratamento com dois campos de radiação.

A modalidade radioterápica TSET é descrita pelo relatório $n^{\circ} .23$ da AAPM (AAPM, 1987) que fornece as diretrizes principais para a elaboração de técnicas para irradiação de corpo inteiro com feixes de elétrons. Neste relatório também estão descritos métodos para obtenção de feixes com tamanhos de campo de até $200 \mathrm{~cm} \times 80 \mathrm{~cm}$, necessários para este tipo de tratamento.

O método de tratamento adotado neste trabalho em consequência dos bons resultados obtidos em diversos centros de tratamento e da viabilidade da implementação em um hospital público, consiste na utilização de placas espalhadoras e degradadoras de energia posicionadas entre a saída do acelerador e 0 paciente, espalhando o feixe e ampliando a região de tratamento. A degradação 
energética também possibilita uma deposição de energia superficial de acordo com a gravidade da lesão.

A implementação desta técnica é complexa e envolve o estudo de diversos parâmetros como o tamanho e uniformidade do campo, contaminação por raios- $X$, taxa de dose, materiais, geometria das placas e distribuição de dose em profundidade.

A análise teórica destes parâmetros torna-se inviável em conseqüência da complexidade das interações e do grande número de partículas. Para realizar tal análise foi utilizado o programa MCNP4C (BRIESMEISTER, 2000) baseado no método de Monte Carlo que simula o transporte de radiação e interação de partículas por meio de um processo estocástico, fundamentado em princípios físicos e estatísticos, apresentando uma vasta área de aplicação, inclusive na terapêutica hospitalar (WIESLANDER et al., 2007).

O programa foi utilizado para a análise da energia mais adequada a este tipo de tratamento, para a simulação de blindagens, e para simular o feixe de elétrons do acelerador linear Varian Clinac $2100 \mathrm{C}$ do Serviço de Radioterapia do Hospital das Clínicas de São Paulo, permitindo a simulação das placas espalhadoras e degradadoras de energia e a análise dos parâmetros clínicos relevantes à modalidade terapêutica. 


\section{FUNDAMENTOS TEÓRICOS}

\subsection{Fundamentos de radioterapia}

A descoberta dos raios-X por Röntgen em 1895 e a descoberta da radioatividade por Bequerel, Pierre e Marie Curie entre 1896 e 1898 (SEGRÉ, 1980), estabeleceram a base da radioterapia. Logo no início dos trabalhos Bequerel e o casal Curie sofreram lesões provocadas pelo rádio, em pouco tempo espalhou-se a idéia que a nova substância poderia ser utilizada para controlar tumores.

A radioterapia é um método de tratamento utilizado para destruir células tumorais, mediante o uso de radiações ionizantes, geralmente empregada no tratamento de lesões radiossensíveis locais, aplicada em conjunto com outras técnicas de tratamento, em procedimentos pré-operatórios no caso da necessidade de redução de tumor antes da cirurgia, em procedimentos pós-operatórios para garantir a eliminação de todas as células tumorais, ou de forma curativa no caso onde é possível eliminar todas as células de um tumor sem ultrapassar os limites de dose dos tecidos sadios.

São várias as fontes de energia utilizadas na radioterapia, como os aceleradores lineares de partículas pesadas, os aceleradores lineares que produzem fótons ou elétrons com diferentes energias e isótopos radioativos, como, por exemplo, as pastilhas de cobalto, as quais geram raios gama.

\subsubsection{Aceleradores lineares}

Um acelerador de partículas (figura 2) consiste em uma fonte de partículas carregadas, expostas a campos elétricos que as aceleram mediante uma diferença de potencial que chega a ordem de milhões de volts.

Nos aceleradores clínicos convencionais são utilizados elétrons, que após acelerados são direcionados por meio de um campo magnético, produzindo feixes de fótons ou elétrons, de acordo com as configurações do acelerador. 


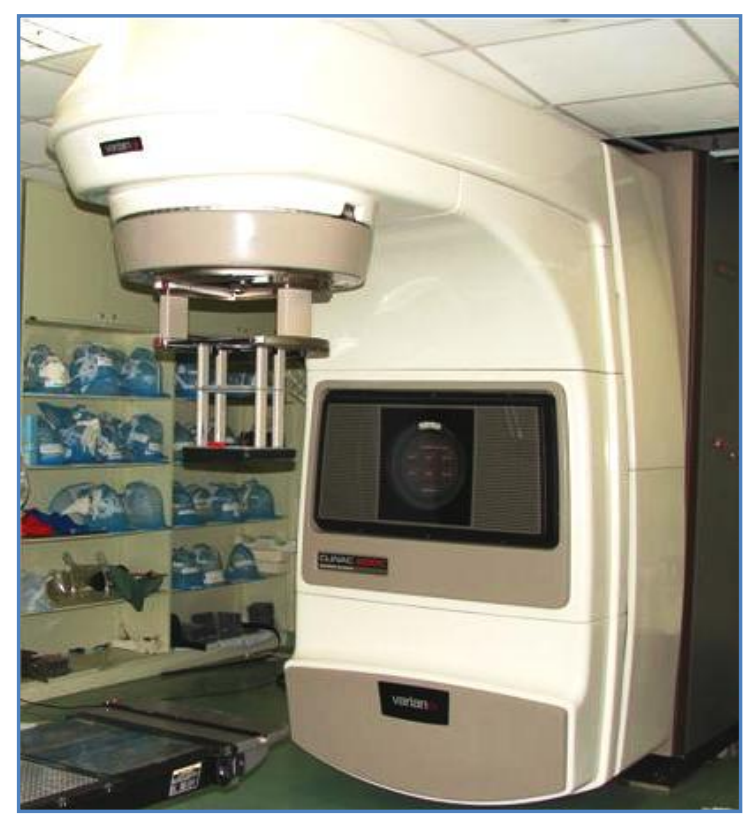

FIGURA 2: Foto do acelerador linear Varian Clinac 2100C do Hospital das Clínicas da Universidade de São Paulo.

\subsubsection{Feixe de elétrons}

Após serem acelerados os elétrons são direcionados por meio de um campo magnético e colidem com uma placa espalhadora, produzindo o campo de radiação espalhado, cujo tamanho é definido pelo espalhamento e pela abertura dos colimadores do acelerador.

Elétrons são partículas de baixo LET (Transferência Linear de Energia), uma partícula com energia da ordem de 0,5 MeV sofre aproximadamente 29.000 interações antes de transferir 0,25 MeV de energia para um meio material como o alumínio. Possuem também alta seção de choque de espalhamento mesmo para interações com o ar, tornando necessário o uso de aplicadores (utilizados para reduzir o espalhamento dos elétrons e delimitar o campo de tratamento) para delimitar o campo de tratamento.

Em virtude do alto espalhamento os elétrons também possuem alcance limitado, um feixe com $4 \mathrm{MeV}$, por exemplo, possui alcance terapêutico de aproximadamente $1,1 \mathrm{~cm}$, com aplicação restrita ao tratamento de lesões pouco profundas, como determinados tipos de cânceres de pele (PODGORSAK, 2005). 


\subsubsection{Feixes de fótons}

Após os elétrons serem acelerados por uma diferença de potencial e direcionados por meio de um campo magnético, estes colidem com um alvo metálico, onde produzem raios- $X$ mediante o processo de freamento (bremsstrahlung), em consequência da interação com o campo eletromagnético do núcleo.

O espectro energético do feixe produzido apresenta uma curva contínua, proveniente do freamento dos elétrons e dois picos de emissão mais intensos provenientes da excitação e posterior desexitação dos elétrons mais internos do material alvo.

Assim como os elétrons, os fótons são amplamente empregados em tratamentos radioterápicos. No entanto, apresentam características muito diferentes, seu alcance terapêutico é superior, em virtude do maior caminho livre médio.

$\mathrm{Na}$ figura 3 é apresentada a comparação entre a distribuição de dose em profundidade para feixes de fótons e elétrons com diferentes energias. No eixo das ordenadas é apresentada a dose relativa (todos os valores são normalizados pela energia máxima depositada) em porcentagem e no eixo das abscissas a profundidade em centímetros de água.
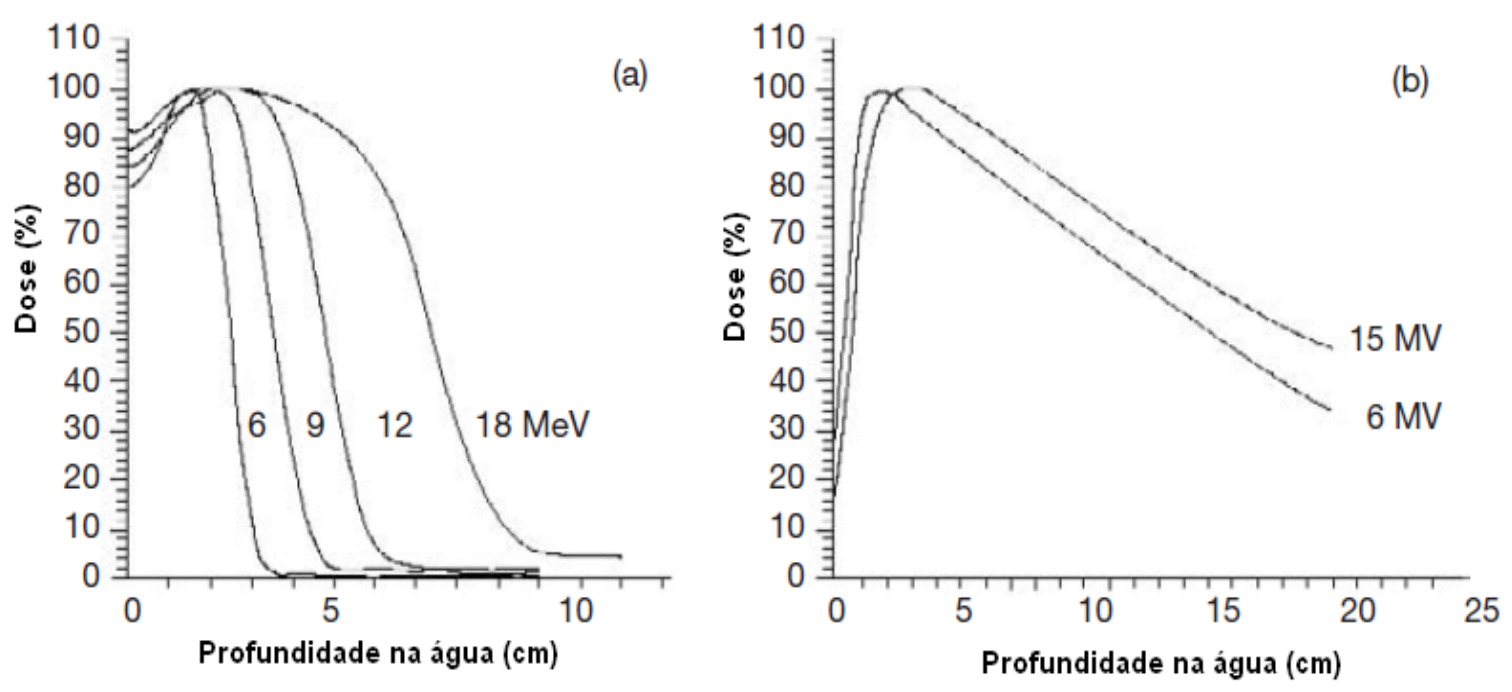

FIGURA 3: Percentual de dose em profundidade no eixo central, a $1 \mathrm{~m}$ de distância fonte superfície, para: (a) elétrons com energias de 6, 9, 12 e $18 \mathrm{MeV}$; (b) fótons com energias de 6 e $15 \mathrm{MV}$ (PODGORSAK, 2005). 
Elétrons apresentam alta deposição de dose na superfície, o alcance terapêutico máximo é da ordem de $6 \mathrm{~cm}$ (feixe com $18 \mathrm{MeV}$ ) e um grande gradiente de dose após a região de tratamento, ao passo que o feixe de fótons possui baixa deposição energética superficial, maior alcance terapêutico e um baixo gradiente de dose. Eventual desvantagem, pois, a energia depositada nas regiões adjacentes ao tumor é superior à depositada no tratamento com elétrons.

É impossível realizar tratamentos com elétrons sem a presença de fótons, que são produzidos nas interações dos elétrons com os materiais do acelerador e com o ar da sala de tratamento. Esta contaminação é altamente indesejável, em razão do caráter altamente penetrante dos fótons de alta energia que depositam energia em regiões sadias, além da profundidade do tumor.

Tratamentos que envolvem o uso de folhas espalhadoras e degradadoras de energia aumentam consideravelmente a produção de fótons, em razão da interação das folhas com o feixe de elétrons. A contaminação por raios-X é um parâmetro extremamente crítico, que limita a composição e a espessura das folhas utilizadas, uma vez que folhas com grande espessura ou compostas por materiais de alto número atômico podem produzir uma contaminação por raios- $X$ inaceitável em tratamentos de lesões superficiais e que em geral envolvem altas doses.

\subsection{Fundamentos de dosimetria}

\subsubsection{Dose absorvida}

A dose absorvida é a quantidade de energia depositada pelos elétrons ou outras partículas ionizantes, por unidade de massa.

$$
D=\frac{d e}{d m}
$$

A dose absorvida é usualmente medida em joules por quilograma $(\mathrm{J} / \mathrm{kg})$, equivalente a unidade de medida Gray (Gy).

\subsubsection{Taxa de dose}

A taxa de dose corresponde à variação de dose no tempo. Usualmente expressa em grays por minuto (Gy/min). 


\subsubsection{Parâmetros clínicos da PDP}

A partir de uma medida experimental de PDP é possível determinar diversos parâmetros clínicos (PODGORSAK, 2005), relevantes para caracterização do feixe e planejamento de tratamentos clínicos. Na figura 4 é apresentada uma PDP experimental onde são indicados alguns parâmetros clínicos.

\section{Parâmetros clínicos:}

- $R_{100}$ - Profundidade de dose máxima;

- $R_{90}$ - Profundidade onde a dose é $90 \%$ da dose máxima;

- $R_{80}$ - Profundidade onde a dose é $80 \%$ da dose máxima;

- $R_{50}$ - Profundidade onde a dose é $50 \%$ da dose máxima;

- $R_{q}$ - Profundidade do ponto de inflexão, onde a tangente da região aproximadamente linear, separa-se da PDP;

- $R_{p}$ - Alcance prático. Ponto onde a tangente da região aproximadamente linear intercepta perpendicularmente a extrapolação linear dos pontos finais da PDP, região com deposição energética proveniente dos raios- $X$.

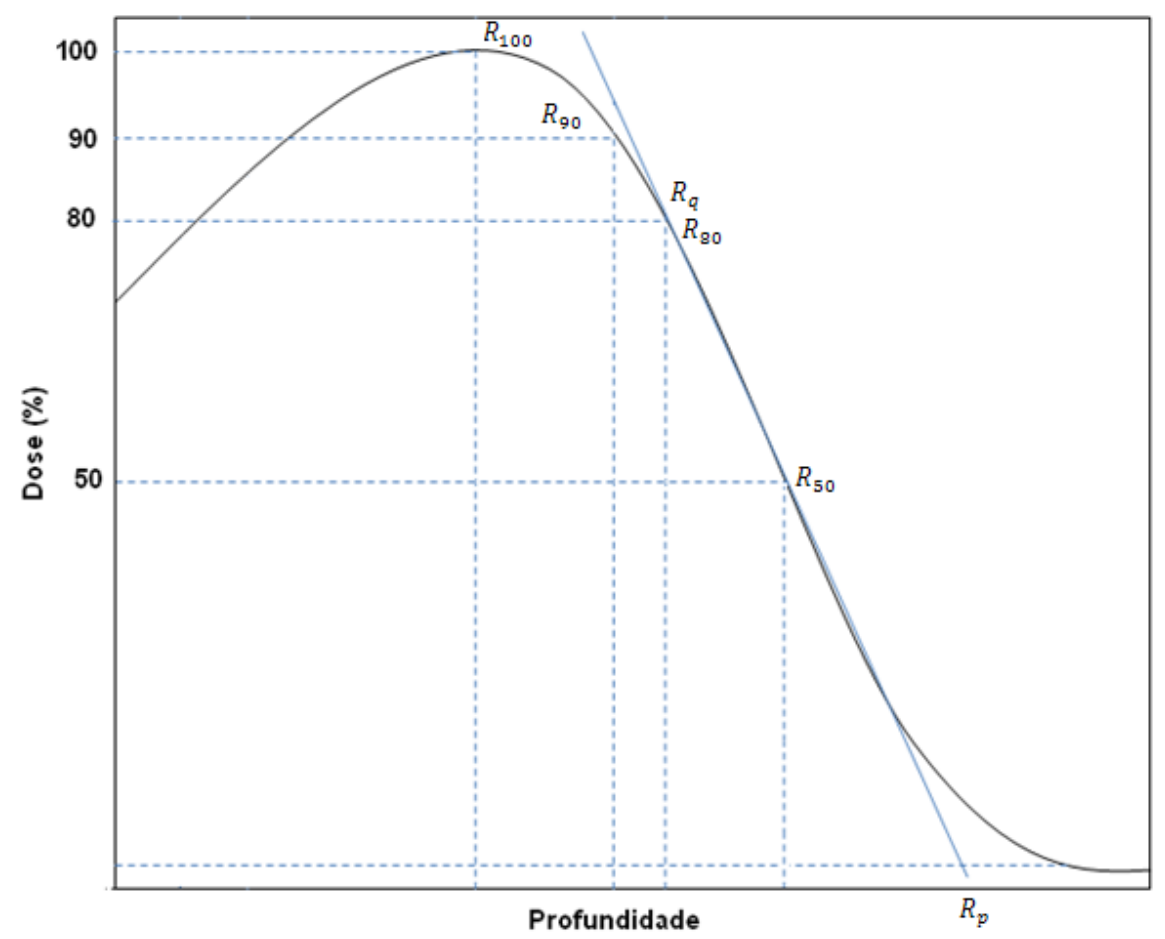

FIGURA 4: Representação dos parâmetros de PDP, construída com base nos resultados obtidos experimentalmente. 
Os parâmetros obtidos a partir da PDP experimental, também são utilizados para calcular outros parâmetros do feixe, como:

- Energia mais provável na superfície do objeto simulador, calculada pela equação:

$$
\bar{\epsilon}_{p, 0}=0,0025 R_{p}^{2}+1,98 R_{p}+0,22
$$

Onde:

$\bar{\epsilon}_{p, 0}=$ energia mais provável na superfície do objeto simulador em MeV;

- Energia média na superfície do objeto simulador, calculada pela equação:

$$
\bar{\epsilon}_{0}=2,33 R_{50}
$$

Onde:

$\bar{\epsilon}_{0}=$ energia média na superfície do objeto simulador em MeV

Gradiente de dose $(G)$, calculado pela equação:

$$
G=\frac{R_{p}}{R_{p}-R_{q}}
$$

Refere-se à região após a profundidade de dose máxima da PDP, que apresenta um grande gradiente de dose.

\subsubsection{Dosímetros}

Dosímetros são instrumentos capazes de medir direta ou indiretamente parâmetros dosimétricos de radiação ionizante como dose absorvida, exposição, kerma, taxa de dose ou outros parâmetros relacionados à radiação ionizante (TAUHATA, 2002).

Neste trabalho foram utilizados três tipos de dosímetros, amplamente empregados na dosimetria clínica, sendo eles: câmara de ionização, filmes radiográficos e dosímetros termoluminescentes do tipo LiF-100. 


\subsubsection{Câmara de ionização}

As câmaras de ionização são os dosímetros mais utilizados na prática clínica por apresentarem grande precisão, rastreabilidade (calibração através de padrões nacionais e internacionais) e grande variedade, o que possibilita sua utilização na dosimetria de campos de radiação com diferentes tamanhos em uma ampla faixa energética.

Uma câmara de ionização (figura 5) consiste basicamente em um eletrodo coletor central imerso em um meio gasoso, circundado por uma parede (eletrodo externo), isolado do meio por um material isolante de alta qualidade, chamado de eletrodo de "guarda", utilizado para limitar a corrente de fuga.

O feixe de radiação ao incidir sobre a câmara ioniza os átomos do ar dentro da mesma e induz uma corrente ou carga nos eletrodos, as quais são quantificadas por equipamentos com grande sensibilidade, conhecidos como eletrômetros.

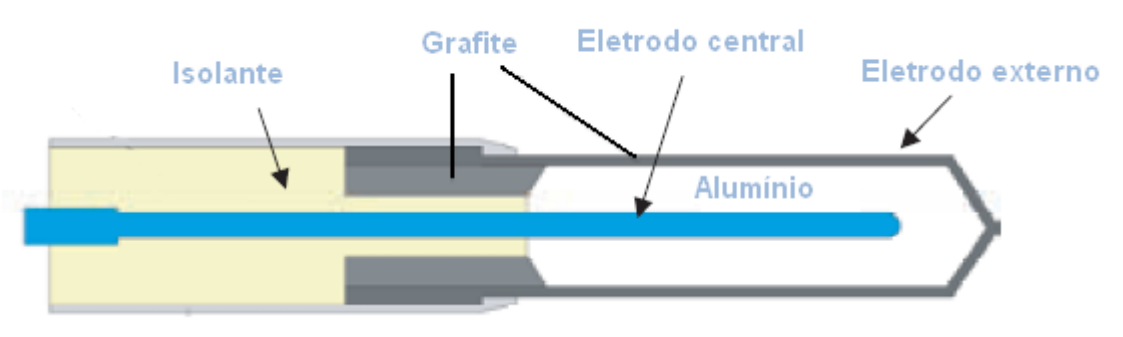

FIGURA 5: Modelo de uma câmara de ionização cilíndrica tipo Farmer (PODGORSAK, 2005).

As câmaras de ionização podem ser utilizadas tanto para dosimetria relativa quanto para dosimetria absoluta, em razão da proporcionalidade entre o sinal produzido e a energia depositada. É possível obter a dose absorvida na água $\left(D_{w, Q}\right)$ com uma câmara calibrada por meio da seguinte equação (IAEA, 2000):

$$
D_{w, Q}=M_{Q} N_{D, w, Q_{o}} K_{Q_{o}}
$$

Onde:

$N_{D, w, Q_{o}}=$ fator de calibração em termos de dose absorvida na água com um feixe de referência com qualidade $Q_{0}$, obtido em um laboratório de calibra- 
ção ou por meio de calibrações cruzadas, mediante irradiações em campos conhecidos e comparações com câmaras padrões calibradas de maior precisão;

$M_{Q}=$ sinal da câmara coletado pelo eletrômetro.

$K_{Q_{o}}=$ fator de correção entre a qualidade do feixe de referência $\left(Q_{0}\right)$ e a qualidade do feixe atual $Q$.

\subsubsection{Filme radiográfico}

A estrutura básica de um filme radiográfico consiste em um composto de base, uma emulsão e uma camada protetora. A base é feita geralmente de material plástico transparente (em geral de poliéster) ou acetato de celulose e serve para dar suporte à emulsão.

A emulsão é a parte principal do filme, consiste em uma mistura homogênea de gelatina e sais, como o brometo de prata. A interação da radiação causa a ionização do $\mathrm{AgBr}$ em grãos formando uma imagem latente que só pode ser observada após a revelação, quando os cristais se reduzem à prata metálica.

A luz transmitida depende da opacidade do filme e pode ser medida em termo da densidade óptica $(O D)$ por meio de um densitômetro ou por um scanner. A densidade óptica é proporcional à intensidade da energia depositada, sendo definida como:

$$
O D=\log _{10}\left(I_{0} / I\right)
$$

Onde:

$I_{0}=$ intensidade inicial sem o filme ou em um ponto não sensibilizado do filme;

$I$ = intensidade transmitida através do filme.

Os filmes radiográficos apresentam uma série de aplicações por possuírem grande resolução espacial em duas dimensões. Atualmente já estão disponíveis filmes radiocrômicos que não precisam ser revelados, eliminando as variáveis 
deste processo, além de apresentar uma série de vantagens (PODGORSAK, 2005):

- Baixa dependência da taxa de dose;

- Grande resolução, podendo ser usado em regiões com alto gradiente de dose;

- Baixa sensibilidade a luz visível;

- Material equivalente ao tecido humano.

\subsubsection{Dosímetros termoluminescentes}

Os dosímetros termoluminescentes (TLD) são utilizados na dosimetria de radiações ionizantes, em virtude do fenômeno da radiotermoluminescência.

Em materiais, como o LiF e o $\mathrm{CaF}$, a radiação incidente excita os elétrons do material que passam para a banda de condução, em seguida estes elétrons decaem para o estado metaestável (armadilhas).

Os elétrons permanecem no estado metaestável, região conhecida como banda proibida, em razão de alterações na estrutura cristalina do material, ocasionada pela adição de impurezas aos materiais, que formam as "armadilhas".

Com o aquecimento do material os elétrons no estado metaestável vão para o estado excitado (banda de condução) e depois decaem para o estado fundamental emitindo luz. Na figura 6 é representado o processo de excitação e emissão termoluminescente.

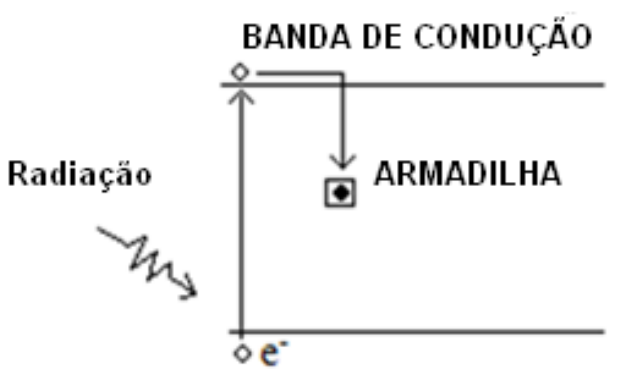

BANDA DE VALÊNCIA

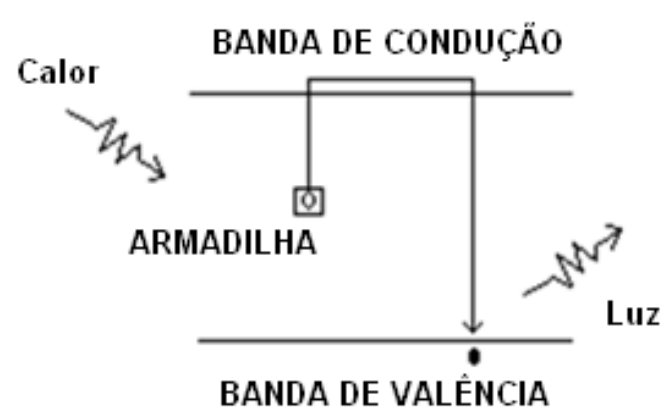

FIGURA 6: Processo de excitação e emissão termoluminescente.

A resposta termoluminescente é proporcional a energia depositada e pode ser convertida em corrente elétrica ou carga por uma válvula fotomultiplicadora. 
$\mathrm{Na}$ figura 7 é apresentada a intensidade da emissão termoluminescente, aquisitada por uma fotomultiplicadora multi-canais e processadas por programa auxiliar. Os cinco picos de emissão termoluminescente estão indicados na figura, que apresenta à corrente $(n A)$ no eixo das ordenadas do lado esquerdo e a temperatura (linha vermelha) no lado direito, no eixo das abscissas são apresentados os canais de leitura da fotomultiplicadora.

O número de picos de emissão, suas intensidades e a temperatura em que ocorrem depende do tipo de dosímetro. No caso do LiF 100 os picos 4 e 5 são utilizados em muitos trabalhos, em razão da sua maior intensidade, por não decaírem em baixas temperaturas e apresentarem um tempo de meia-vida longo, não apresentando variação significativa mesmo após 20 dias da irradiação (MCKEEVER, 2005) .

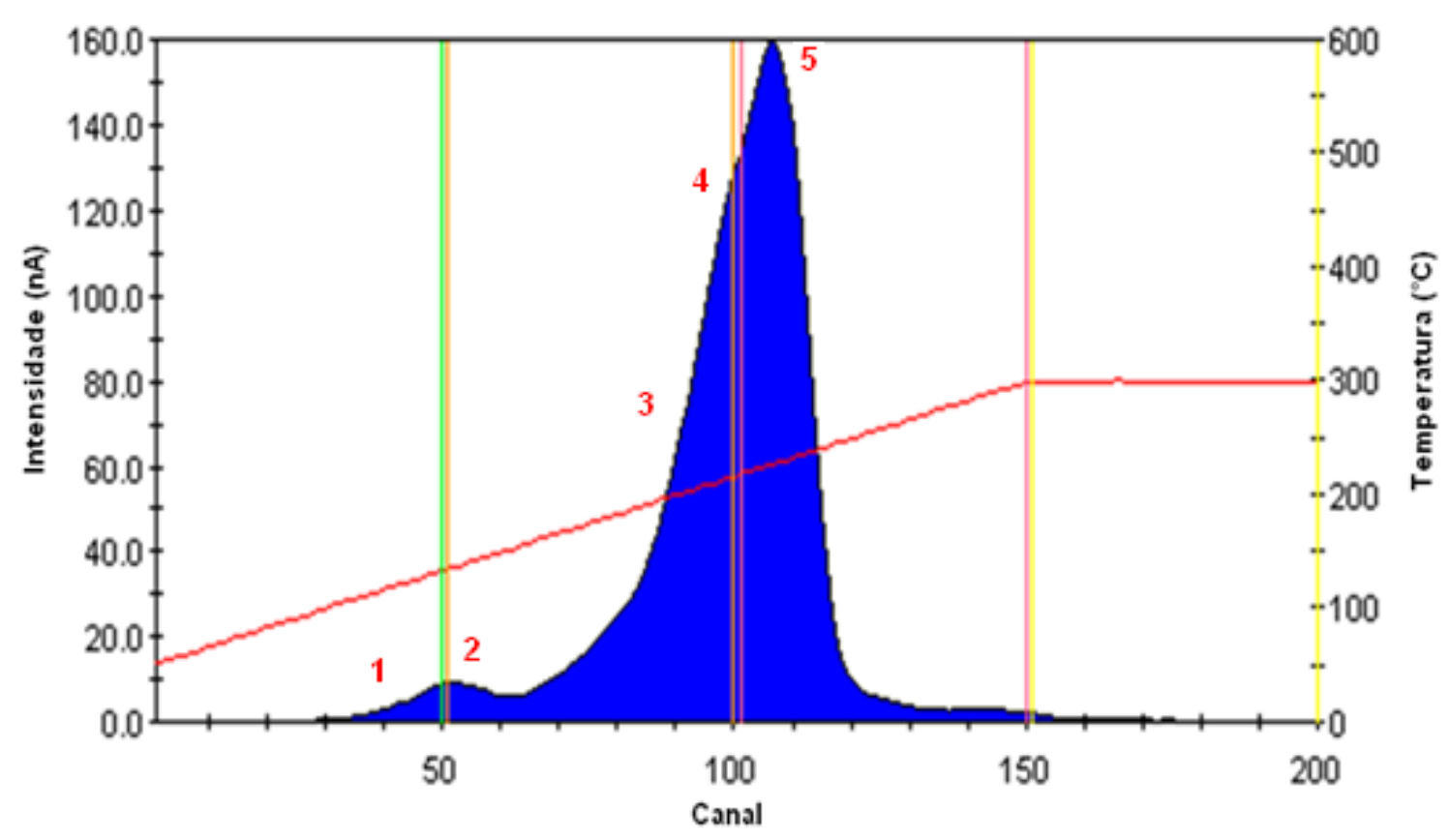

FIGURA 7: Picos de emissão do TLD tipo LiF 100.

Este tipo de dosímetro apresenta inúmeras aplicações, em virtude do baixo custo e tamanho reduzido, que permite até mesmo medições internas de dose, em pacientes em tratamento. Atualmente, encontramos dosímetros termoluminescentes utilizados na dosimetria pessoal, em áreas sujeitas à radiação, em procedimentos médicos como a radiocirurgia, entre outras aplicações. 


\subsection{Método de Monte Carlo}

O método de Monte Carlo é um método numérico utilizado na resolução de problemas macroscópicos e microscópicos, com aplicações em diversas áreas como previsões meteorológicas, estimativas de fluxo de veículos e até mesmo em simulações de tratamento clínicos com partículas de alta energia.

Em muitos casos existem métodos determinísticos para resoluções de problemas que não necessitam de grande esforço, no entanto, em situações reais os fenômenos podem ser tão complexos ou apresentar tantas variáveis, que um método determinístico se torna inviável. Na figura 8 é apresentada uma ilustração representando as situações onde o método de Monte Carlo passa a ser mais vantajoso que os métodos determinísticos.

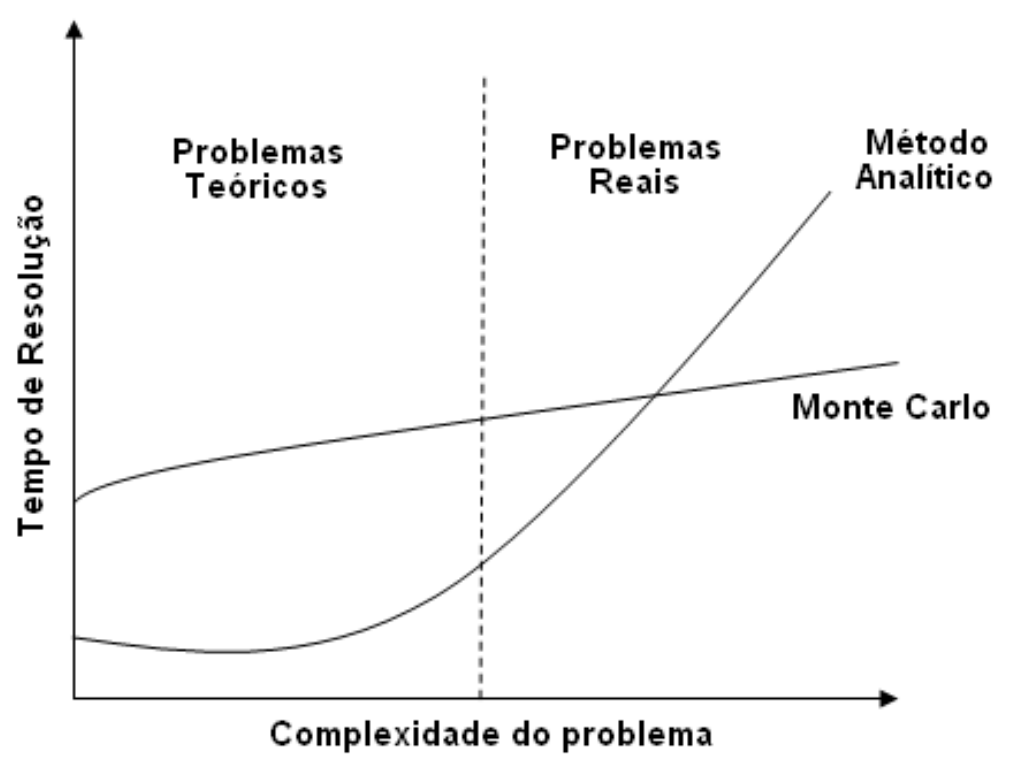

FIGURA 8: llustração do tempo necessário para resolução problemas pelo método de Monte Carlo em comparação com o método analítico (BIELAJEW, 2001).

Planejamentos de tratamentos radioterápicos envolvem interações da radiação com a matéria, partículas de altas energias, modelagem e grande precisão no cálculo de parâmetros clínicos de tratamento, o que torna o método de Monte Carlo uma importante ferramenta nesta área (VIEIRA, 2008). 


\subsubsection{Programa MCNP4C}

O programa MCNP4C que utiliza o método de Monte Carlo para simular o transporte de radiação, foi desenvolvido pelo laboratório de Los Alamos durante a segunda guerra mundial. A primeira versão foi lançada em 1977 e continua sendo aprimorada até os dias atuais. O método simula o transporte de radiação e a interação de partículas por meio de um processo estocástico baseado em princípios físicos e estatísticos, utilizando um gerador de números aleatórios para amostrar diversos fenômenos com base em distribuições de probabilidades conhecidas (BRIESMEISTER, 2000).

O programa é amplamente utilizado em diversas áreas, pois permite a simulação de elétrons, fótons e nêutrons em uma grande faixa energética, além de permitir modelagens tridimensionais complexas.

$\mathrm{Na}$ área radiológica o número de artigos publicados vem aumentando desde 1983. Este aumento está relacionado ao avanço da capacidade computacional que vem reduzindo drasticamente o tempo de simulação e possibilitando simulações mais complexas (ROGERS, 2006).

\subsubsection{Modelagem de problemas utilizando o MCNP4C}

A estrutura de um arquivo de entrada é composta basicamente de três blocos:

- $1^{\circ}$ Bloco - Geometria Modelagem geométrica constituída pela parte interna, externa, união ou intersecções de diferentes superfícies como cilindros, cones, elipsóides e planos.

- $2^{\circ}$ Bloco - Superfícies

Descrição das superfícies geométricas, realizada por meio de mnemônicos correspondentes a superfícies pré-estabelecidas pelo programa. As superfícies são definidas por parâmetros matemáticos que definem as equações que representam as respectivas superfícies.

- $3^{\circ}$ Bloco - Fonte, Materiais e Parâmetros de Simulação 
Nesta seção são definidos os parâmetros da fonte, os materiais e os parâmetros como o tempo de simulação e o corte energético.

O código pode gerar elétrons, fótons e nêutrons com uma ampla faixa energética, além de permitir ao usuário a atribuição de distribuições independentes, sendo elas discretas ou contínuas, para os parâmetros da fonte como a energia, geometria, posição e direção.

Os materiais são definidos utilizando referências a bibliotecas de seção de choque de interações, como a utilizada no código ITS (Halbleid et al., 1992) e poder de frenagem similar aos definidos pelo ICRU-37, sendo possível utilizar bibliotecas especificadas pelo usuário.

O programa ainda possui uma série de recursos, como o de estruturas repetidas, através do qual é possível, por exemplo, reconstruir o corpo humano, segmentando estruturas que podem ser preenchidas com diferentes materiais (BRIESMEISTER, 2000).

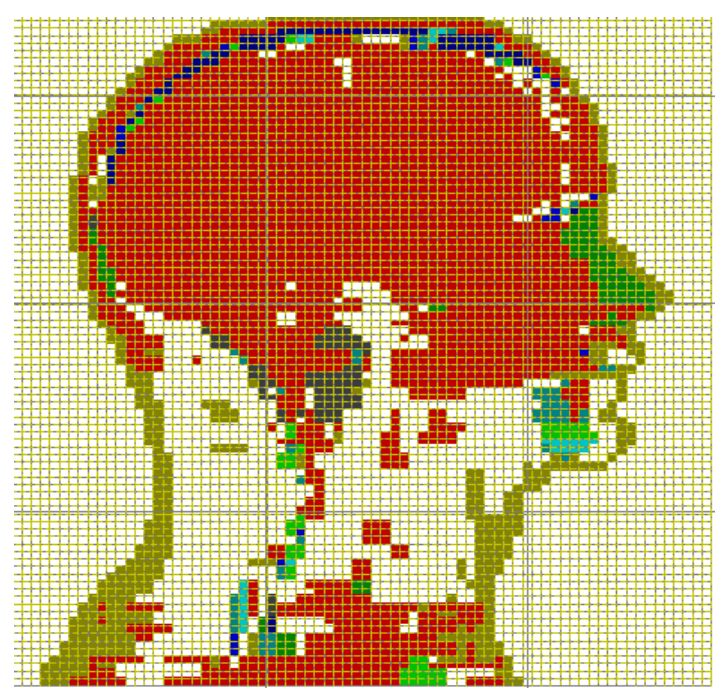

FIGURA 9: Imagem construída utilizando o recurso de estruturas repetidas.

Como pode ser observado na figura 9 (ANTUNES et al., 2009), a geometria pode ser construída a partir de uma imagem de tomografia computadorizada processada por um programa auxiliar, que fornece a posição e a composição dos materiais em um formato reconhecido pelo MCNP. 
Este recurso permite construir geometrias complexas e simular distribuições de dose em pontos específicos, como a pele. Considerando as características específicas de cada paciente.

\subsubsection{Amostragem}

O processo de amostragem utiliza a geração de números aleatórios e o processo probabilístico de interação da radiação com a matéria para descrever os feixes produzidos pelos aceleradores lineares, utilizando funções de densidade de probabilidade conhecidas (BRIESMEISTER, 2000).

Sendo $x$ uma variável aleatória contínua que representa a posição onde um fóton interage, por exemplo, pelo processo de produção de pares e $f(x)$ a função densidade de probabilidade (fdp) de um sistema (caso unidimensional) determinada pela seção choque de fótons. Então $f\left(x_{0}\right) d x$ descreve a probabilidade de ocorrer um valor $x_{0}$ tal que $x<x_{0}<x+d x$.

Com $x \in[a, b]$ a fdp normalizada que representa todo o sistema pode ser dada por:

$$
\int_{a}^{b} f(x) d x=1
$$

A função densidade cumulativa (fdc), associada às funções de distribuição de probabilidade em um caso unidimensional é dada por:

$$
F(x)=\int_{a}^{x} f(x) d x^{\prime}
$$

É possível associar funções do tipo fdc a números aleatórios (६) distribuídos uniformemente no intervalo $[0,1]$, pela relação:

$$
\xi=F(x)
$$

Invertendo a função temos:

$$
x=F^{-1}(\xi)
$$


Desta forma é possível amostrar as funções utilizando um gerador de números aleatórios, de forma que os valores de probabilidade tendam ao valor da probabilidade real, como descrito pela lei dos grandes números.

\subsubsection{Cálculo de fluxo e dose.}

O usuário pode utilizar diversos cartões de saída (tallies) relacionados à corrente, ao fluxo de partículas e a deposição energética, em um total de 7 tipos de tallies pré definidos, dos quais sete são aplicados a nêutrons, seis aplicados a fótons e quatro aplicados a elétrons (BRIESMEISTER, 2000).

Os tallies são utilizados para calcular o fluxo de partículas (F4), a energia depositada por fótons e elétrons ( ${ }^{*} \mathrm{~F} 8$ ) e a energia depositada apenas por fótons (F6). Associando estes cartões de saída as letras e, p e n o usuário determina para qual ou quais tipos de partículas os parâmetros devem ser calculados, por exemplo, o tally F4:e calcula o fluxo de elétrons e o cartão F4:p,n calcula o fluxo de fótons e nêutrons.

\subsection{Fluxo (F4)}

O fluxo médio de partículas em uma determinada célula (volume ou superfície definida no MCNP), pode ser obtido pela seguinte equação:

$$
\bar{\Phi}_{v}=\frac{1}{V} \int d E \int d t \int d V \int d \Omega \psi(\vec{r}, \Omega, E, t)
$$

Onde:

$$
\begin{array}{ll}
\bar{\Phi}_{v} & =\text { fluxo médio na célula }\left(\text { partículas } / \mathrm{cm}^{2}\right) ; \\
V & =\text { volume da célula }\left(\mathrm{cm}^{3}\right) ; \\
d E & =\text { energia }(\mathrm{MeV}) \\
d t & =\text { tempo }(\text { seg. }) ; \\
d \Omega & =\text { ângulo (sr); } \\
\psi(\vec{r}, \Omega, E, t) & \left.=\text { fluxo angular (partículas } / \mathrm{sr} . \mathrm{cm}^{2} . \mathrm{MeV} . \mathrm{seg}\right) .
\end{array}
$$


Considerando:

$$
\psi(\vec{r}, \Omega, E, t)=n v(\vec{r}, \Omega, E, t)
$$

Onde:

$n$ = é a densidade de partículas (partículas $/ \mathrm{sr} . \mathrm{cm}^{3} \cdot \mathrm{MeV}$ )

$v=$ é a velocidade $(\mathrm{cm} / \mathrm{sh})$

e

$$
N(\vec{r}, E, t)=\int d \Omega n(\vec{r}, \Omega, E, t)
$$

Onde:

$N(\vec{r}, E, t)=$ número de partículas independente de sua trajetória.

Podemos escrever

$$
\bar{\Phi}_{v}=\frac{1}{V} \int d E \int d t \int d V \int d t \cdot v \cdot N(\vec{r}, E, t)
$$

Onde:

$$
d t . v=d s
$$

$d s$ = unidade diferencial do track lenght .

A quantidade $N(\vec{r}, E, t) d s$ pode ser considerada a densidade de track lenght, e o fluxo estimado pela soma das trajetórias. O MCNP estima o fluxo médio $\left(\bar{\Phi}_{v}\right)$ utilizando a seguinte equação:

$$
\bar{\Phi}_{v}=\sum_{i=1}^{N} \frac{W_{i} T_{l i}}{V}
$$

Onde:

$$
\begin{aligned}
& N \quad=\text { número total de partículas; } \\
& W \quad=\text { peso atribuído a cada partícula; } \\
& T_{l} \quad=\text { track lenght }(\mathrm{cm}) ; \\
& V \quad=\text { volume da célula }\left(\mathrm{cm}^{3}\right) .
\end{aligned}
$$


A estimativa de fluxo utilizando os track length, permite bons resultados em consequência da grande amostragem, muito superior ao número de colisões. $\mathrm{O}$ resultado ainda pode ser subdivido em função da energia das partículas.

\subsection{Energia depositada por fótons (F6)}

A energia depositada por um fóton pode ser obtida pela equação:

$$
H_{t}=\frac{\rho_{a}}{m} \int d E \int d t \int d V \int d \Omega . \sigma_{t}(E) H(E) \psi(\vec{r}, \Omega, E, t)
$$

Onde:

$H_{f} \quad=\quad$ energia total depositada $(\mathrm{MeV} / \mathrm{g})$;

$\rho_{a}=$ densidade atômica (átomos/barn-cm);

$m \quad=$ massa da célula $(\mathrm{g})$;

$d E \quad=\quad$ energia $(\mathrm{MeV})$;

$d t \quad=\quad$ tempo (seg.);

$d \Omega=$ ângulo (sr);

$\sigma_{t}(E)=$ seção de choque microscópica total (barn);

$H(E)=$ energia transferida por colisão (MeV/colisão);

$\psi(\vec{r}, \Omega, E, t)=$ fluxo angular (partículas/sr.cm².MeV.seg).

O MCNP estima a energia depositada utilizando o calculo de fluxo por track length, a taxa de reação e uma função de transferência energética dependente da energia, pela equação:

$$
H_{t}=W T_{l} \sigma_{t}(E) H(E) \frac{\rho_{a}}{m}
$$

Desta forma o tally de deposição energética F6 que pode ser utilizado para nêutrons e fótons consiste basicamente, em um tally de fluxo (F4), multiplicado por uma função dependente da energia e pela seção de choque, considerando que toda energia transferida para os elétrons é depositada localmente.

\subsection{Energia depositada por fótons e elétrons ( $\left.{ }^{*} \mathrm{~F} 8\right)$}

A energia depositada é calculada pela intensidade dos pulsos produzidos pela interação da radiação, de forma similar aos detectores reais. O calculo é feito 
pela diferença da energia de uma partícula, ao entrar e sair da célula de interesse, armazenando os resultados em diferentes intervalos, de acordo com o valor da energia depositada.

No final de cada história a energia depositada em uma célula ( $\left.{ }^{*} \mathrm{~F} 8\right)$ é dividida pelo peso das partículas, a energia resultante determina em qual intervalo o resultado é armazenado. O número de partículas que deposita energia em uma determinada faixa energética corresponde ao peso coletivo das partículas (tally F8).

Adicionando um asterisco ao tally F8 a contagem de pulsos é convertida em deposição energética, pela equação:

$$
E=E_{d} x W_{c}
$$

Onde:

$E \quad=$ energia total depositada $(\mathrm{MeV}) ;$

$E_{d} \quad=$ energia depositada em um intervalo (MeV);

$W_{c}=$ peso coletivo de uma história.

Ao contrário dos outros tallies, a energia depositada depende do número de partículas que depositam energia em cada intervalo. O peso coletivo é um valor atribuído a um conjunto de partículas e não o peso de cada partícula.

Um caráter particular deste tally é que não é possível separar a energia depositada por fótons e por elétrons, uma vez que os cartões de saída *F8:e, ${ }^{*} F 8: p$, *F8:e,p produzem o mesmo resultado.

\subsubsection{Resposta}

O resultado $(Y)$ fornecido pelo MCNP, em um processo de amostragem aleatória é a média dos resultados obtidos na simulação de $N$ partículas e seu erro relativo, segundo a equação:

Onde:

$$
Y=\bar{x} \pm R
$$

$\bar{x}=$ valor médio dado por: 


$$
\bar{x}=\frac{1}{N} \sum_{i=1}^{N} x_{i}
$$

e

$R \quad=\quad$ erro relativo dado por:

$$
R \equiv \frac{S_{\bar{x}}}{\bar{x}}
$$

Onde:

$S_{\bar{x}}=$ desvio padrão da média, dado por:

$$
S_{\bar{x}}=\frac{\sqrt{\sum_{i=1}^{N}\left(x_{i}-\bar{x}\right)^{2}}}{\sqrt{N-1}}
$$

O manual do programa apresenta um pequeno guia para interpretação dos valores de erro relativo, para erros superiores a 0,5 os resultados não devem ser considerados e para erros acima de 0,1 os resultados são questionáveis.

Para obter valores confiáveis deve-se aumentar o número de partículas simuladas, reduzindo o desvio padrão da média, proporcional a $1 / \sqrt{N}$. Como o número de partículas é diretamente proporcional ao tempo, ao dividir o desvio padrão por um fator quatro, por exemplo, o tempo de simulação será dezesseis vezes maior.

\subsubsection{Técnicas de redução de variância}

O tempo de simulação para obter a precisão necessária ao tipo de aplicação, em muitos casos pode ser demasiadamente longo, já que a forma direta para reduzir o erro relativo dos resultados é aumentar o número de partículas, diretamente proporcional ao tempo de simulação.

O programa incorpora uma série de técnicas de redução de variância, que vão desde cortes energéticos, a modificações no processo de amostragem, aumentando a precisão dos resultados, sem necessariamente aumentar o número de partículas simuladas (BRIESMEISTER, 2000; BIELAJEW, 2001; SHULTIS et al., 2006). 
No entanto, como o próprio manual adverte, estas técnicas precisam ser cuidadosamente analisadas, pois podem introduzir erros que invalidem o resultado.

\subsubsection{Corte energético}

O corte energético (cartão CUT) estabelece o limite energético inferior, partículas com energia abaixo deste limite não são mais simuladas, desta forma o tempo de simulação de cada partícula é reduzido consideravelmente.

Ao atribuir a energia de corte é necessário considerar as futuras interações e a importância destas partículas no resultado final. O critério utilizado neste trabalho consiste em comparar o caminho médio percorrido por uma partícula com determinada energia, e selecionar o valor cujo comprimento da trajetória seja aproximadamente a metade do menor comprimento da célula de interesse.

\subsubsection{Divisão geométrica e roleta russa}

Esta é uma das técnicas de redução de variância mais antigas e mais utilizadas em todas as versões do código MCNP. A técnica consiste em aumentar o número de partículas à medida que estas migram para regiões de maior interesse, atribuindo diferentes importâncias para estas regiões.

Quando uma partícula passa de uma região com importância I para uma região com maior importância dada por $I^{\prime}$, esta é dividida em $n$ partículas idênticas e com peso reduzido, onde $n$ é a razão entre e $I^{\prime}$ e $I$. Ao migrar para regiões de menor importância as partículas são descartadas pelo método da roleta russa com a probabilidade de eliminação $(p)$, dada por:

$$
p=1-\left(\frac{I}{I}\right)
$$

Onde:

$I^{\prime}=$ importância da célula de destino;

$I$ = importância da célula inicial.

Regiões com maior importância são amostradas por um maior número de partículas, com menor peso, e regiões de menor importância amostradas com um menor número de partículas, com maior peso. 
A atribuição da importância de uma determinada região é feita pelo usuário, por exemplo, em uma simulação utilizando um objeto simulador de água, este pode ter maior importância que a camada de ar entre o acelerador e a superfície do objeto simulador. Esta atribuição pode ser feitas de diferentes formas e depende do conhecimento da simulação realizada.

Embora a divisão geométrica aumente o tempo de simulação de cada história, o número de partículas é ampliado apenas nas regiões de maior interesse, de forma que o tempo de simulação é muito inferior ao tempo necessário para simular estas partículas sendo geradas diretamente na fonte e atravessando regiões de menor interesse. 


\section{REVISÃO BIBLIOGRÁFICA}

Os linfomas cutâneos de Células-T compreendem um grupo de doenças relacionadas à ação linfoproliferativa dos Linfócitos- $T$, encarregados da defesa da pele que ao se tornarem malignos causam anormalidades, disseminando-se por todo o corpo do paciente.

Estudos recentes mostram que incidência destas doenças cresceu drasticamente desde 1973, chegando a corresponder a 3,4 \% dos linfomas não Hodgkin no ano de 2002. Os linfomas de células-T são classificados com base em sua histologia, aspectos clínicos e características moleculares, destes a micose fungóide é a mais comum, correspondendo a aproximadamente $44 \%$ de todos os linfomas cutâneos e entre 1 e 2 \% dos linfomas não Hodgkin (LANSIGAN et al., 2008; CRISCIONE et al., 2007).

A micose fungóide é uma doença crônica, lenta e progressiva. Seu nome deve-se a aparência de cogumelos ou fungos que os tumores apresentam em estágios avançados da doença (figura 10). Atinge pessoas, sobretudo, entre $45 \mathrm{e}$ 69 anos, embora também ocorra em crianças. Apresenta taxa de incidência anual de aproximadamente 0,29 a cada 100.000 habitantes e em casos avançados pode disseminar-se pelo corpo atingindo os nodos linfáticos, o sangue, a medula óssea, o fígado e outros órgãos internos (BECKER et al., 1995).

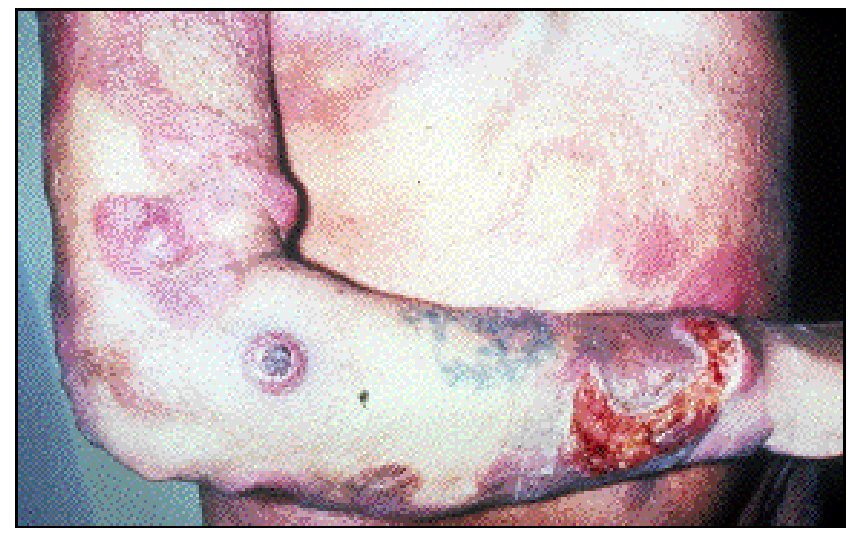

FIGURA 10: Paciente com micose fungóide. 
A síndrome de Sézary refere-se à forma mais agressiva dos linfomas cutâneos de células-T. Recebeu este nome por causa de Albert Sézary primeiro a caracterizar a doença, em 1938. Esta doença pode ocorrer independentemente ou como uma progressão da micose fungóide, a incidência desta doença corresponde a aproximadamente $3 \%$ dos linfomas cutâneos de células-T.

As causas destas doenças ainda são desconhecidas, sendo que, alguns estudos indicam uma correlação com o uso de pesticidas, no entanto, estes estudos não foram conclusivos. Existem também indícios de que a ocorrência da micose fungóide e da síndrome de Sézary não está relacionada à geografia nem a transmissão materna.

Entre as diversas técnicas de tratamento como a quimioterapia e a fototerapia, uma que se destaca como uma das mais eficazes é a técnica radioterápica conhecida como TSET, que consiste na irradiação do paciente com feixe de elétrons de energia entre 4 e $10 \mathrm{MeV}$ e campo de tratamento $200 \mathrm{~cm} \times 80 \mathrm{~cm}$. Na tabela 1 é apresentado um guia geral dos principais tipos de tratamento da micose fungóide nos principais estágios da doença (RAVI et al., 2001).

TABELA 1: Tratamentos mais utilizados nos diferentes estágios da doença.

\begin{tabular}{c|c}
\hline Estágio da Doença & Tratamentos mais Utilizados \\
\hline Lesões limitadas & PUVA \\
& Quimioterapia tópica \\
Radioterapia localizada & PUVA \\
Lesões generalizadas & TSET \\
& Quimioterapia tópica \\
Interferon \\
Antibióticos \\
Eritroderma & TSET \\
& Quimioterapia tópica ou sistêmi- \\
& ca \\
& Fotoforese \\
Doença Visceral & Quimioterapia sistêmica \\
& Estudos investigativos \\
\hline
\end{tabular}


A primeira tentativa de tratamento utilizando radiações ionizantes data de 1902 (SCHOLTZ, 1902), seguida por tentativas de tratamento com raios-X em 1939 (SOMMERVILLE, 1939), no entanto, os tratamentos com raios-X não obtiveram bons resultados em razão da supressão da medula óssea causada por este tipo de radiação. Somente em 1952 aproximadamente 50 anos após o início dos tratamentos com radiação ionizante, surgiram os primeiros tratamentos com feixes de elétrons de megavoltagem (TRUMP, 1953).

Desde então esta técnica de tratamento ganhou notoriedade e interesse da comunidade cientifica em geral e diversos estudos foram publicados sobre os resultados dos tratamentos.

Em 1971, a irradiação de corpo inteiro no tratamento da micose fungóide com altas doses, embora considerado um tratamento muito agressivo, era aconselhado especialmente em casos iniciais, já que o tempo livre da doença (período sem manifestação de sintomas) justificava este tipo de tratamento.

Em 1977 a Universidade de Stanford, pioneira na área, publicou os resultados de 18 anos de tratamento com 176 pacientes com micose fungóide, apresentando bons resultados de remissão e sobrevida nos tratamentos com altas doses, além do péssimo resultado obtido no tratamento com baixas doses (HOPPE et al., 1979).

Os resultados obtidos em Stanford foram comparados (VONDERHEID et al., 1979) com os resultados obtidos durante 10 anos, no tratamento de 243 pacientes portadores da micose fungóide, com quimioterapia tópica com mecloretamina. A comparação realizada, conclui que ambas as técnicas são eficazes, obtendo bons resultados, sobretudo em casos iniciais da doença, taxa de sobrevida média de 5 anos para casos com lesões limitadas, lesões generalizadas, tumores e eritemas de 85,75 , 42 e $50 \%$ respectivamente para o tratamento com mecloretamina contra $88,60,11$ e $54 \%$ obtidos pelo grupo de Stanford.

No entanto, estudos mais recentes mostram que a mecloretamina pode ser cancerígena e que até $40 \%$ dos pacientes tratados com essa droga desenvolveram hipersensibilidade ao contato, além do fato que o tempo livre da doença pode depender da continuidade do tratamento. 
A técnica radioterápica TSET continua sendo alvo de estudos (EL-KHATIB et al., 1995; CHEN et al., 2004), embora a grande maioria dos estudos publicados comprove a grande eficácia deste tipo de tratamento, esta ainda é uma técnica que apresenta inúmeras dificuldades de implementação, pois envolve adaptações nos aceleradores para que se possam obter grandes campos de tratamento.

Somente em dezembro de 1987, aproximadamente 35 anos após os primeiros tratamentos utilizando a irradiação de corpo inteiro com feixes de elétrons de mega-voltagem, a American Association of Physicists in Medicine (AAPM) lançou o protocolo $n^{\circ} 23$ (AAPM, 1987) que define os parâmetros relevantes ao tratamento, tais como:

\section{Homogeneidade e tamanho do campo}

O protocolo estabelece um campo de tratamento com $200 \mathrm{~cm} \mathrm{x}$ $80 \mathrm{~cm}$ com uma uniformidade na região central $(160 \mathrm{~cm} \times 60 \mathrm{~cm})$ de $8 \%$ na vertical e $4 \%$ na horizontal. Como a diferença na distribuição de dose no plano de tratamento e no corpo do paciente pode chegar a $15 \%$ ou mais dependendo da região do corpo, espera-se obter um campo de tratamento que seja o mais uniforme possível.

\section{Região de tratamento}

A micose fungóide é um linfoma cutâneo e seu tratamento deve ser restrito a região da pele, um dos motivos da prescrição de elétrons para este tipo de tratamento, uma vez que a deposição de energia por elétrons tem um alcance limitado. O TG23 estabelece a profundidade com dose relativa equivalente a $50 \%$ da dose máxima entre 5 e $15 \mathrm{~mm}$ de profundidade ou mais dependendo da gravidade da lesão.

Para realizar tratamentos em diferentes profundidades são utilizados feixes de elétrons com diferentes energias, placas degradadoras que atenuam a energia do feixe ou feixes inclinados. 


\section{Contaminação de raios-X}

Por se tratar de uma lesão superficial, a contaminação por raios- $X$ altamente energéticos, produzidos pela interação do feixe de elétrons com as placas espalhadoras e com o ar, é altamente indesejável, em consequência da grande penetração, que ocasiona danos aos tecidos sadios mais profundos.

A contaminação por raios-X é um fator relevante para esta técnica de tratamento em razão da necessidade de folhas espalhadoras e degradadoras de energia que produzem uma grande quantidade de raios- $X$ e da grande distância entre o acelerador e o paciente.

Segundo o protocolo, a contaminação de raios-X deve ser inferior a $1 \%$, em relação à dose máxima depositada por elétrons, em geral esta contaminação é da ordem de 0,4 a $4 \%$, sendo, que uma contaminação de $4 \%$ é considerada insatisfatória em muitas práticas clínicas (GUR et al., 1979; EL-KHATIB et al. 1991).

\section{Distância fonte superfície}

A distância entre 0 acelerador e o paciente varia entre 2 e $7 \mathrm{~m}$ dependendo da técnica a ser utilizada. Com base em outros estudos foi possível verificar que tratamentos com um único feixe, em geral são realizados a $7 \mathrm{~m}$ de distância, ao passo que irradiações com múltiplos campos ou translação do paciente podem ser realizadas a distâncias menores (CHEN, 2004).

\section{Taxa de dose}

A taxa de dose deve ser de $1 \mathrm{~Gy} / \mathrm{min}$ ou mais, para reduzir o tempo de tratamento e consequentemente à fadiga dos pacientes, em sua maioria idosos, debilitados e mantidos em posições desconfortáveis, necessárias para garantir uma melhor distribuição de dose durante o tratamento. 
O protocolo da AAPM também apresenta uma série de considerações a respeito do posicionamento dos pacientes e da necessidade de campos complementares.

Em virtude das características do corpo humano, a cabeça e as solas dos pés, assim como regiões de auto-blindagem como a região perineal, dos seios e partes sobrepostas, recebem uma sub-dosagem de radiação, necessitando de tratamentos auxiliares com raios- $X$ de orto-voltagem ou campos pequenos de elétrons.

Na figura 11 são ilustradas formas de posicionar o paciente para obter uma melhor distribuição de dose.

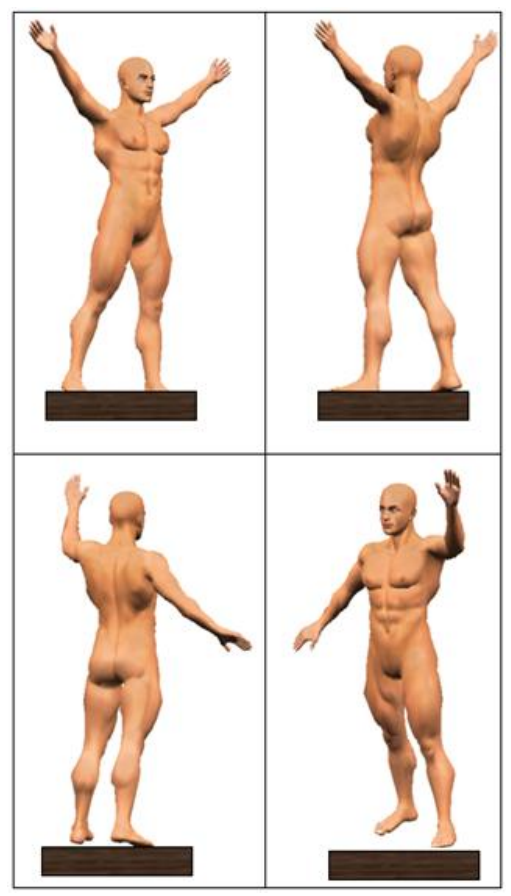

FIGURA 11: Posições de tratamento, baseadas no protocolo $n^{\circ} 23$ da AAPM.

O posicionamento do paciente e a análise das regiões de auto-blindagem são extremamente importantes em casos clínicos. O protocolo indica que uma variação de 7,5 \% no campo de tratamento pode ocasionar uma variação de até 15 \% no corpo do paciente, em razão das diferentes distâncias entre a pele e o acelerador. Em regiões de auto-blindagem esta variação pode chegar a $40 \%$ da dose. 
Outras regiões como o nariz, os olhos, a parte superior dos pés e as mãos podem necessitar de proteção, pelo menos em parte do tratamento por causa da sensibilidade ou da posição anatômica, que pode ocasionar uma maior exposição.

A blindagem dessas regiões pode ser feita com pequenas placas de chumbo ou cerrobend (liga eutética de bismuto, chumbo, estanho e cádmio), material de baixo ponto de fusão e características similares ao chumbo, amplamente utilizado em hospitais.

A implementação desta modalidade de tratamento apresenta inúmeras dificuldades práticas, seja pela dificuldade de obter um grande campo de radiação, seja pela contaminação de raios- $X$, agravada pela necessidade de placas espaIhadoras, pela grande distância entre o acelerador e o paciente ou até mesmo pela limitação do espaço físico da maioria das salas de tratamento.

Muitas técnicas foram desenvolvidas para realizar este tratamento, em geral envolvendo a rotação ou translação da fonte ou do paciente, entre as principais podemos citar a técnica desenvolvida pela Universidade de Stanford.

Esta técnica consiste na irradiação do paciente com um ou múltiplos campos de radiação, utilizando folhas espalhadoras e degradadoras de energia para obter grandes campos, utilizando também uma grande distância entre a fonte e o paciente. Na figura 12 é ilustrado um tratamento com um único feixe espalhado, utilizando uma base rotativa.

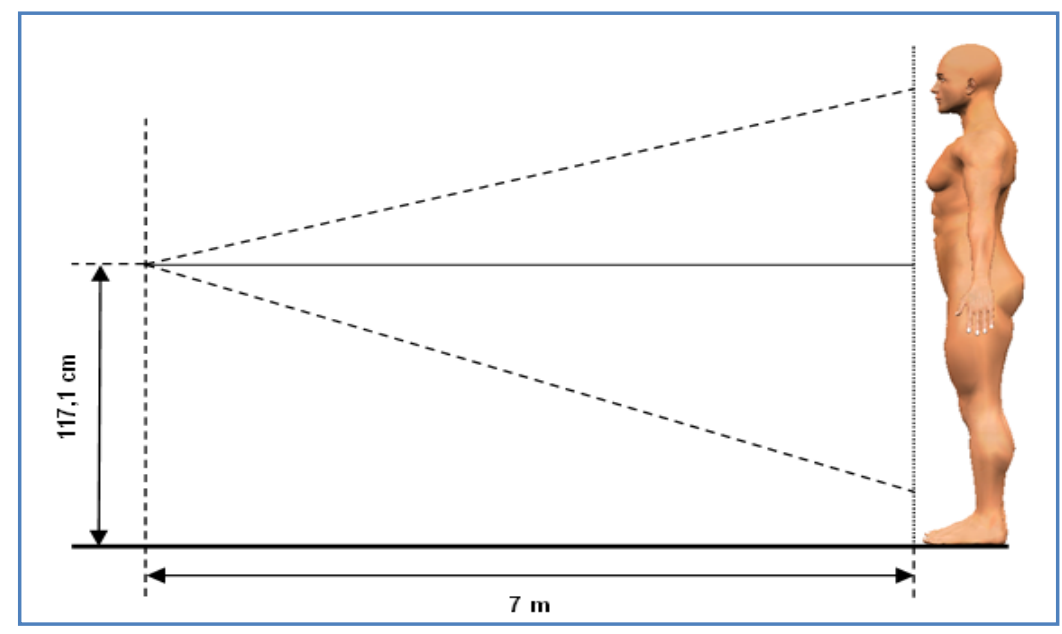

FIGURA 12: Tratamento com um único feixe espalhado (CHEN et al., 2004). 
Esta técnica apresenta bons resultados, sendo também a de mais fácil implementação e planejamento de tratamento.

O trabalho realizado por Chen em 2004 comparou a técnica de Stanford com feixe único e com feixe duplo (figura 13), o resultado obtido é similar, embora cada técnica apresente uma determinada vantagem.

Ao utilizar dois feixes de radiação foi possível reduzir em 3,2 $\mathrm{m}$ a distância de tratamento, no entanto houve uma grande redução da taxa de dose, de 750 cGy/min com um único feixe para $140 \mathrm{cGy} / \mathrm{min}$ com dois feixes, em virtude das duas folhas espalhadoras utilizadas no tratamento com dois feixes, aumentando significativamente o tempo de irradiação, pois além da atenuação do feixe é necessário movimentar o acelerador durante a irradiação.

A técnica com dois campos também apresenta contaminação por raios- $X$ de $0,52 \%$, ao passo que a irradiação com um único campo apresenta contaminação de $0,4 \%$. Na figura 13 é possível observar que o centro dos feixes no tratamento com dois campos é direcionado para fora do paciente, em virtude da maior intensidade dos raios- $X$ nessa região. Dessa forma a contaminação por raios-X cai de $0,52 \%$ para $0,43 \%$, similar ao tratamento com um feixe único.



FIGURA 13: Tratamento com dois feixes espalhados (CHEN et al., 2004).

A distribuição de dose relativa (figura 14) para um único feixe apresenta grande simetria, no entanto, a distribuição utilizando dois campos apresenta uni- 
formidade muito superior, como pode ser observado, sobretudo nos extremos do campo.

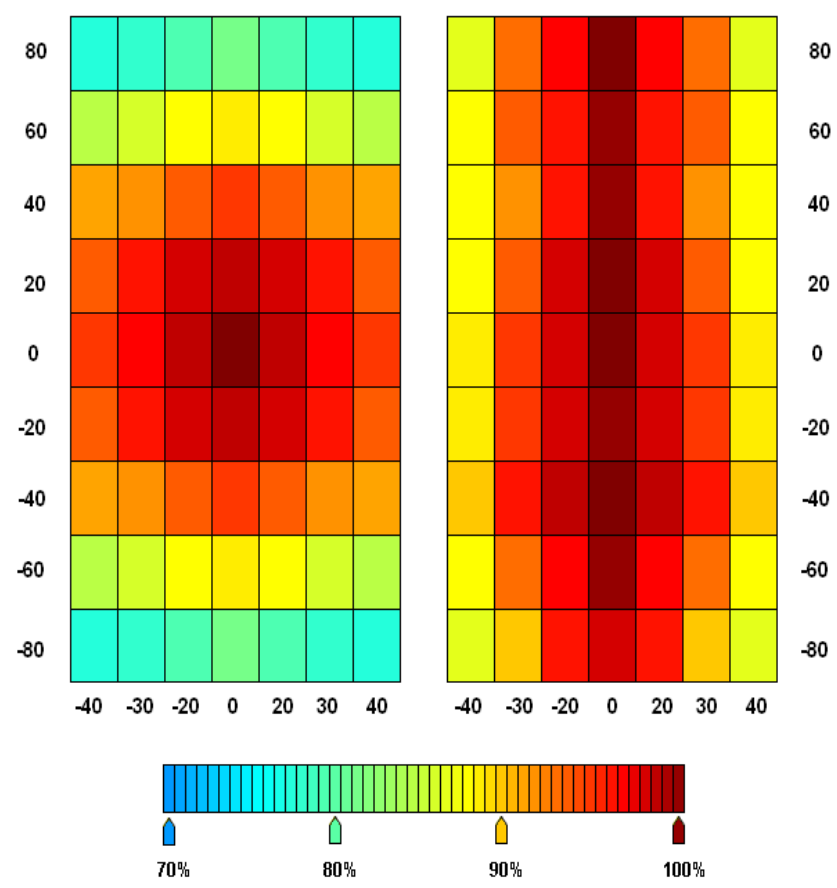

FIGURA 14: Distribuição de dose para um feixe (esquerda) e dois feixes (direita) (CHEN et al., 2004).

Existem diversas variações na forma de tratamento, em determinados casos podem ser utilizados até 12 campos de radiação (BECKER et al., 1995), que necessitam de um menor espalhamento. A profundidade de deposição energética pode ser modificada com a variação da inclinação do feixe reduzindo a necessidade de degradar a energia do feixe.

Tratamentos utilizando TSET podem levar até duas horas, considerando o tempo de preparação e posicionamento do paciente e os múltiplos campos utilizados. Em alguns casos, a dose necessária também é alta, variando de acordo com a gravidade da doença.

Para reduzir o tempo de tratamento, muitos trabalhos utilizaram alta-taxa de dose, embora observando um aumento das morbidades da radiação, como os eritemas. No entanto, estas morbidades na maioria dos casos são desconsideradas, em razão do benefício de um menor tempo de tratamento, que pode ser reduzido para até $15 \mathrm{mim}$, reduzindo a fadiga e melhorando a distribuição de dose, 
pois os pacientes se movimentam menos em tempos de irradiação reduzido (PARIDA et al. 2005).

A técnica turca desenvolvida entre 1995 e 2001, também apresentou bons resultados. A técnica envolve a translação do paciente em relação ao feixe, permitindo o tratamento a distâncias de aproximadamente $2 \mathrm{~m}$, no entanto, esta técnica apresenta um alto custo tanto de desenvolvimento quanto de manutenção, custo não justificado em consequência da baixa incidência da doença (ULUTIN et al. 2002).

As medidas dosimétricas destes campos de tratamento, normalmente são feitas em objetos simuladores de água, no entanto, no caso da irradiação de corpo inteiro, medidas na água são complicadas, pois necessitariam de um objeto simulador com grandes dimensões e um enorme volume de água. Assim a maioria das medidas é realizada com placas de água sólida, que apresentam propriedades similares à água, tornando mais fácil o procedimento experimental e o posicionamento dos dosímetros.

Uma importante ferramenta que permite simular as alterações no acelerador, a dosimetria do campo e até mesmo o tratamento dos pacientes é o método de Monte Carlo, que cada vez mais vem sendo utilizado. Graças ao avanço computacional, o tempo de simulação foi reduzido e o método já faz parte de diversos programas clínicos, utilizados para planejar tratamentos de pacientes (WIESLANDER, 2007).

Programas como o MCNP, o PENELOPE e o GEANT podem ser utilizados para simular aceleradores lineares particulares, por meio da modelagem geométrica dos componentes do acelerador ou pela reconstrução empírica do espectro do feixe.

É possível realizar diversos tipos de simulação como perfis radiais e axiais de dose, análise de blindagens, espalhamento e degradação energética do feixe e até mesmo a distribuição da dose em pacientes utilizando modelos geométricos ou até mesmo imagens médicas como ilustrado pela figura 15 que representa a distribuição da dose depositada por fótons na pele de um paciente posicionado lateralmente (ANTUNES et al., 2009). 


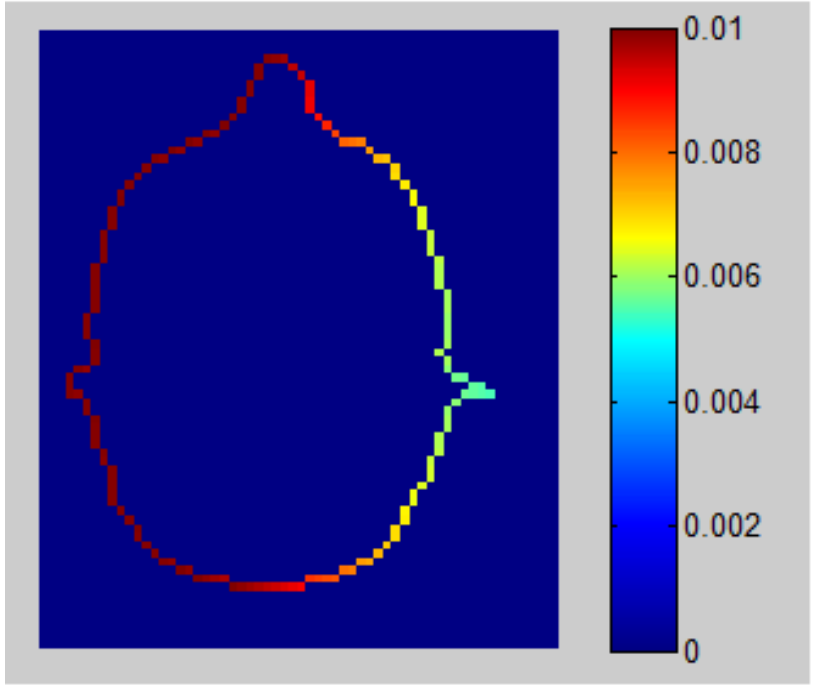

FIGURA 15: Distribuição de dose na pele, obtida simulando um feixe de fótons.

$\mathrm{Na}$ técnica TSET, estes programas podem ser aplicados tanto na construção das placas, quanto na dosimetria do campo e da pele do paciente, esta última de difícil realização experimental. 


\section{OBJETIVOS}

O presente estudo pretende auxiliar na implementação da técnica radioterápica conhecida como Total Skin Electron Therapy no Serviço de Radioterapia do Hospital das Clínicas da Universidade de São Paulo. Para isso, pretende-se utilizar o código computacional MCNP4C baseado no método de Monte Carlo para caracterizar o acelerador Varian Clinac $2100 \mathrm{C}$ e construir placas degradadoras e espalhadoras de energia que possibilitem a produção de um grande campo de radiação atendendo as especificações do relatório $n^{\circ} .23$ da AAPM.

O objetivo do trabalho pode ser divido em cinco objetivos específicos, sendo:

- Caracterizar o espectro de elétrons de $6 \mathrm{MeV}$ do acelerador Varian Clinac $2100 \mathrm{C}$, utilizando a abertura máxima de campo e alta taxa de dose, condições necessárias ao tratamento de TSET;

- Selecionar os materiais mais adequados para produção das folhas espaIhadoras e degradadoras de energia. Para isto, simularam-se folhas de diferentes materiais posicionadas na saída do acelerador, o que possibilitou a análise de parâmetros clínicos como $\circ R_{50}$, nas simulações de perfil radial, região de build-up e contaminação por raios- $X$, nas simulações de perfil de dose em profundidade (PDP);

- Simular a geometria das folhas espalhadoras para obter um campo de tratamento com $60 \mathrm{~cm} \times 60 \mathrm{~cm}$, e uniformidade superior a $10 \%$, à distância fonte superfície (DFS) de 1,3 m, determinada pelo sistema de posicionamento do acelerador;

- Simular a geometria das folhas espalhadoras de diferentes materiais, para obter um campo de tratamento com $200 \mathrm{~cm} \times 80 \mathrm{~cm}$, com uniformidade de $8 \%$ e $4 \%$ na vertical e na horizontal, respectivamente e que atenda todas as especificações do relatório $n^{\circ}$. 23 da AAPM; 
- Confecção das placas espalhadoras e degradadoras de energia e realização de medidas experimentais para validação dos resultados das simulações com o programa MCNP4C. 


\section{MATERIAIS E MÉTODOS}

A metodologia utilizada neste trabalho consiste em:

- Medidas experimentais com o feixe de elétrons de $6 \mathrm{MeV}$ do acelerador linear do Hospital das Clínicas, com abertura máxima dos colimadores e alta taxa de dose, tais como:

- Perfis radiais e axiais de dose a DFS 0,7 e $1 \mathrm{~m}$ sem folha espalhadora, realizadas em um objeto simulador de água automatizado com uma câmara de ionização de placas paralelas. Estas medidas experimentais foram utilizadas para caracterizar e validar a fonte utilizada nas simulações.

- Perfis radiais e axiais de dose a DFS $1 \mathrm{~m}$ com folhas espalhadoras de cobre e alumínio, realizadas em um objeto simulador de água automatizado com uma câmara de ionização de placas paralelas. Estas medidas experimentais foram utilizadas para validar as simulações realizadas com placas espalhadoras de diferentes materiais.

- Perfil radial e axial de dose a DFS 1,3 m com uma folha espalhadora de cobre, utilizando uma câmara de ionização de placas paralelas entre placas de água de sólida para caracterização do perfil radial e um filme radiocrômico entre placas de água sólida para caracterização do perfil axial. Estas medidas experimentais foram utilizadas para validar a simulação do campo de tratamento de lesões com extensão de até $60 \mathrm{~cm}$.

- Perfil radial de dose a DFS 2,95 m com uma folha espalhadoras de cobre, utilizando TLD's e filmes radiocrômicos. Esta medida experimental foi utilizada para validar a simulação do campo de tratamento para irradiação de corpo inteiro. 
- Simulações numéricas pelo método de Monte Carlo, realizadas para analisar feixes com diferentes energias, caracterizar a fonte de elétrons, selecionar os materiais mais adequados a produção das placas espalhadoras e para simular a geometria das placas.

\subsection{Dosímetros utilizados}

As medidas experimentais foram realizadas com três tipos de dosímetros, sendo eles: a) uma câmara de ionização de placas paralelas; b) dosímetros termoluminescentes do tipo LiF 100; c) filmes radiocrômicos.

\subsubsection{Câmara de ionização}

Foi utilizada uma câmara de ionização de placas paralelas, modelo Markus da PTW (Physikalisch-Technische Werkstätten), com parede de $0,9 \mathrm{~mm}$ de espessura, constituída por uma folha de polietileno grafitado e um eletrodo coletor, também de poliestireno grafitado. Com espaçamento de $2 \mathrm{~mm}$ entre os eletrodos e anel de guarda com 0,2 mm de comprimento (RODRIGUES et al., 2006).

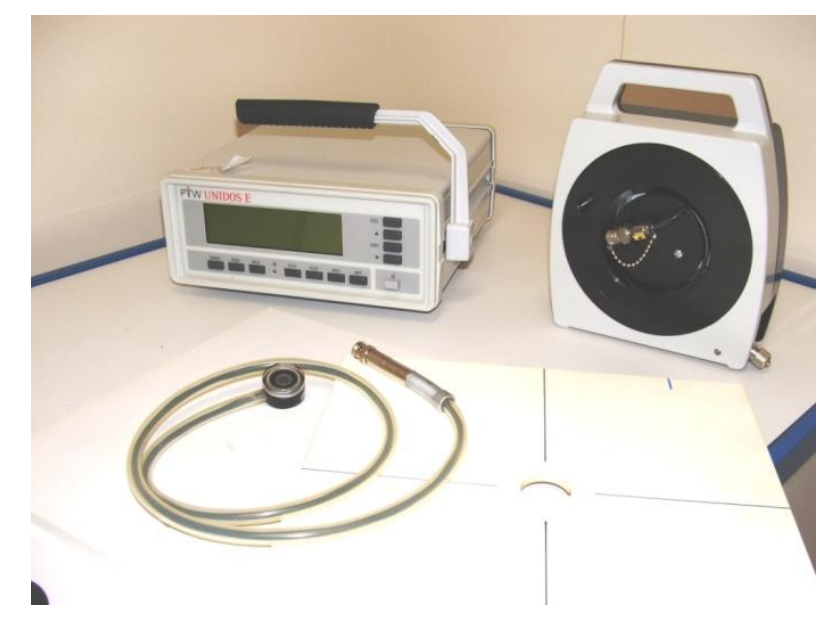

FIGURA 16: Eletrômetro, câmara de ionização e cabo.

Observa-se na figura 16 o eletrômetro, a câmara de ionização e o cabo, utilizados nas medidas experimentais.

A aquisição dos dados, obtidos mediante medidas experimentais com a câmara de ionização, foi realizada por meio de um eletrômetro, modelo UNIDOS E da PTW. 


\subsubsection{Filme radiocrômico}

Foi utilizado o filme radiocrômico GAFCHROMIC (figura 17) da ISP (International Specialty Products), com $20 \mathrm{~cm} \times 25 \mathrm{~cm}$. A aquisição dos dados da PDP a DFS 1,3 m, foi realizada por meio do scanner Epson $10000 \mathrm{XL}$ e a análise dos resultados por meio do programa OmniPro Accept 7.

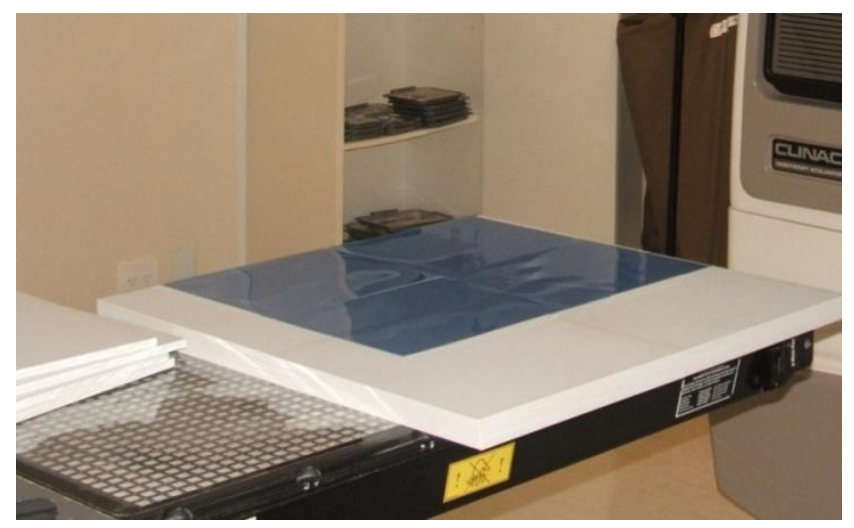

FIGURA 17: Filme Gafchromic da ISP, posicionado sobre placas de água sólida.

O densitômetro Densi X da PTW foi utilizado na leitura dos filmes utilizados na medida de perfil radial a 2,95 m, onde não são necessários intervalos de medição tão pequenos, quanto os utilizados na medida de PDP.

\subsubsection{Dosímetro termoluminescente (TLD 100)}

Os dosímetros utilizados (figura 18) são de fluoreto de lítio (LiF) conhecidos comercialmente como TLD100, produzidos pela Harshaw, dopados com titânio e magnésio (LiF:Mg:Ti), apresentando sensibilidade a fótons e elétrons, dimensões de $3 \mathrm{~mm} \times 3 \mathrm{~mm}$ e espessura de $1 \mathrm{~mm}$.

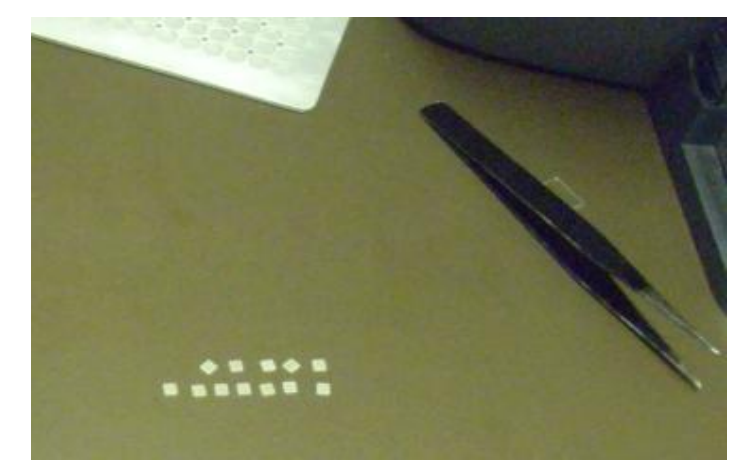

FIGURA 18: Dosímetros termoluminescentes do tipo LiF 100. 
Em consequência da grande variação da resposta, os dosímetros foram calibrados mediante oito irradiações. O processo experimental utilizado para calibrar os dosímetros consiste em três etapas descritas a seguir.

\subsubsection{Tratamento térmico}

O tratamento térmico é realizado antes de cada irradiação com o objetivo de eliminar todos os resquícios de irradiações anteriores. O procedimento recomendado pelo fabricante consiste em submeter às pastilhas a uma temperatura de $400{ }^{\circ} \mathrm{C}$ por uma hora, e em seguida tratar os dosímetros por duas horas a uma temperatura de $100^{\circ} \mathrm{C}$.

A estufa (figura 19) Fisher Scientific, modelo 650-58, controlada eletronicamente, foi utilizada para realizar o tratamento térmico.



FIGURA 19: Estufa Fisher Scientific, utilizada no tratamento térmico dos dosímetros.

\subsubsection{Irradiação}

Os dosímetros foram irradiados no acelerador linear Varian Clinac $2100 \mathrm{C}$ do Hospital das Clinicas com um feixe de elétrons com energia de $9 \mathrm{MeV}$ em um campo de $15 \mathrm{~cm} \times 15 \mathrm{~cm}$, a DFS de $98,1 \mathrm{~cm}$.

Os dosímetros foram posicionados (figura 20) no isocentro do acelerador (1 $\mathrm{m}$ de distância da fonte) entre duas placas de água sólida $\left(\mathrm{C}_{8} \mathrm{H}_{8}+2,1 \% \mathrm{TiO}_{2}\right.$, densidade $\rho=1,045 \mathrm{~g} / \mathrm{cm}^{3}$ ) com $30 \mathrm{~cm} \times 30 \mathrm{~cm}$, a placa inferior com $3 \mathrm{~cm}$ de es- 
pessura, para evitar o efeito de retroespalhamento, e a superior com 1,9 cm de espessura, para posicionar os dosímetros próximos a região de build-up, onde a energia depositada é conhecida.

O material utilizado constitui um objeto simulador de boa reprodutibilidade, apresentando características muito úteis para a dosimetria clínica, com boa similaridade com a água e número atômico efetivo próximo ao do tecido mole, além de não apresentar efeito significante de carga, causado pelo feixe de elétrons (ICRU 44, 1989).

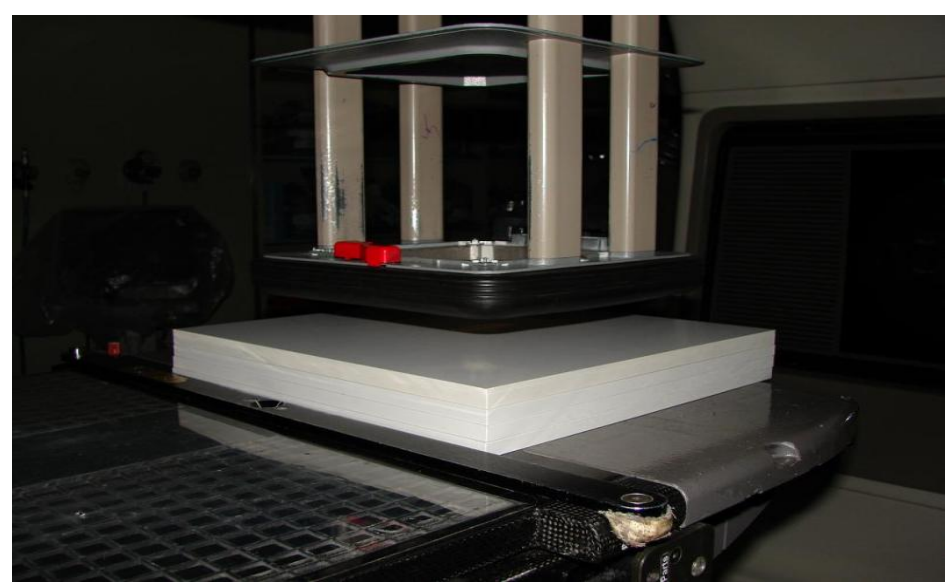

FIGURA 20: TLDs entre placas de água sólida.

\subsubsection{Resposta termoluminescente}

A resposta termoluminescente foi aquisitada pela leitora Harshaw modelo 3500 (figura 21), por meio de uma fotomultiplicadora multi-canais. Os dados obtidos foram processados e analisados pelo programa WinREMS PL-26732.8.1.0.0.

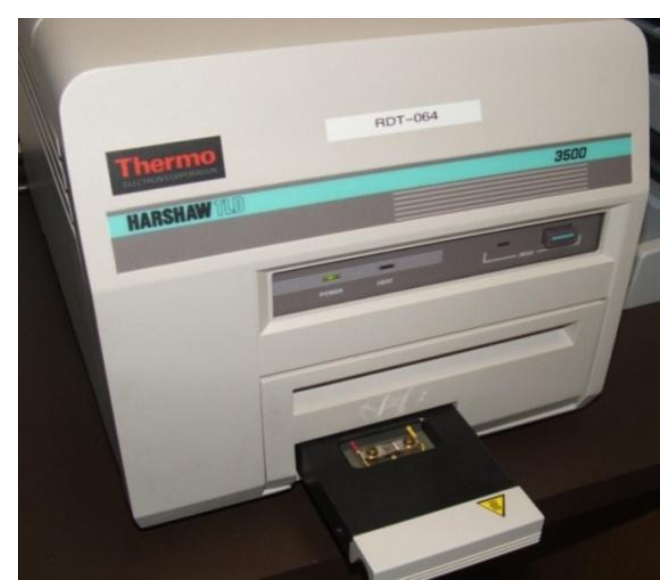

FIGURA 21: Leitora Harshaw 3500. 
A taxa de aquecimento utilizada $\left(10^{\circ} \mathrm{C} / \mathrm{s}\right)$ foi estabelecida a partir de estudos bibliográficos (MCKEEVER, 2005) e inúmeras irradiações. As contagens foram realizadas entre $50 \stackrel{\circ}{\circ}$ e $300^{\circ} \mathrm{C}$, uma vez que nesta faixa estão compreendidos os picos de emissão mais estáveis, reduzindo assim a interferência da temperatura ambiente, e do tempo entre a irradiação e a leitura.

\subsection{Medidas experimentais "Acelerador Linear Varian Clinac 2100C"}

As medidas experimentais dos perfis axiais e radias de dose foram realizadas a DFS 0,7 e $1 \mathrm{~m}$, para caracterizar o acelerador e validar as simulações realizadas.

\subsubsection{Caracterização do feixe de elétrons}

O feixe de elétrons de $6 \mathrm{MeV}$ do acelerador Varian Clinac $2100 \mathrm{C}$ do Serviço de Radioterapia do Hospital das Clínicas foi caracterizado a partir de medidas experimentais de PDP e perfis radiais em 12,8, 13,2, 18,4 e $23 \mathrm{~mm}$ de profundidade, sendo as duas primeiras próximas a profundidade de dose máxima, a terceira e a quarta nas profundidades do $R_{80}$ e do $R_{50}$, respectivamente. As medidas foram realizadas a DFS $0,7 \mathrm{~m}$, com abertura máxima de campo e alta taxa de dose (888 UM/min), condições utilizadas em TSET.

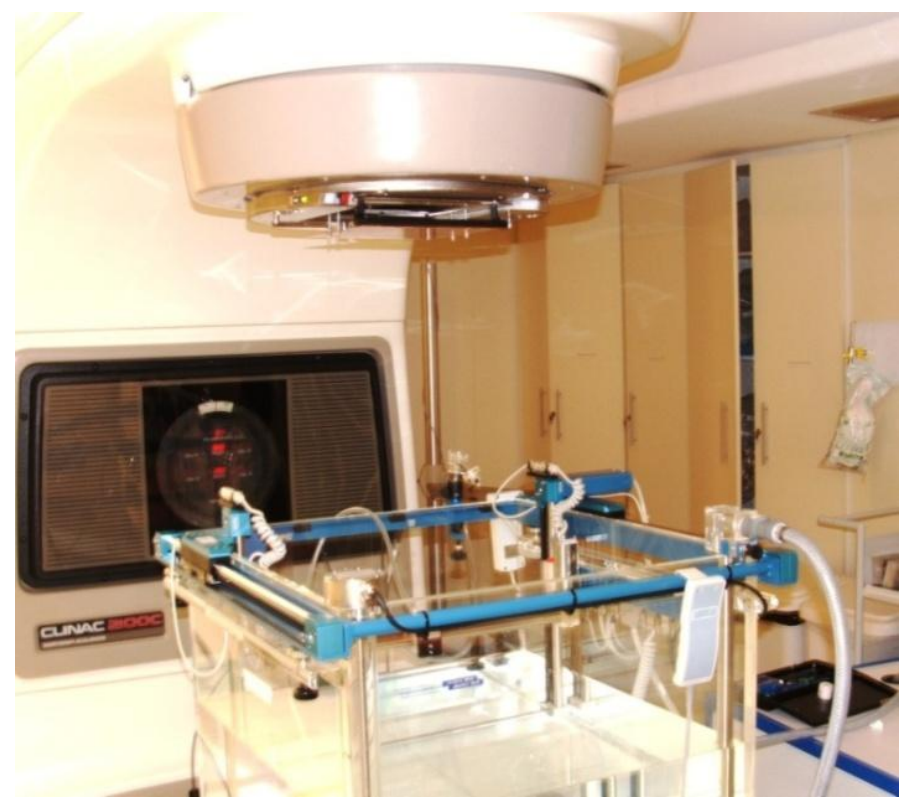

FIGURA 22: Acelerador linear Varian Clinac 2100C e objeto simulador de água automatizado utilizados nas medidas experimentais. 
Conforme apresentado na figura 22 as medidas experimentais foram realizadas em um objeto simulador de água automatizado da marca Wellhofer, de formato cúbico, com $50 \mathrm{~cm}$ de lado e paredes de acrílico. O sistema apresenta um suporte de posicionamento remoto com possibilidade de movimentação nos eixos $X Y Z$, no qual foi fixada uma câmara de ionização de placas paralelas modelo Markus da PTW, o sistema foi preenchido com água e posicionado a DFS 0,7 m.

Para liberar a abertura máxima de campo e alta taxa de dose é necessário introduzir no acelerador uma bandeja específica (figura 23) fornecida junto ao aparelho.

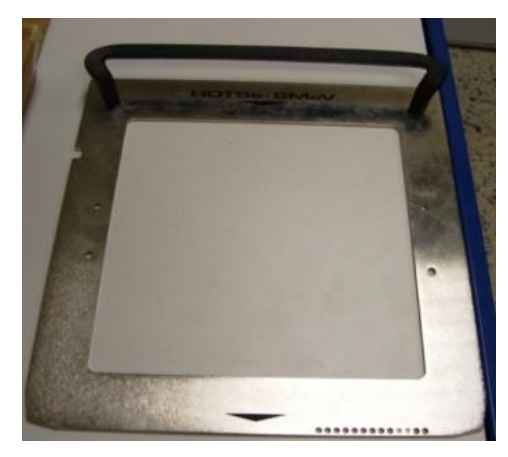

FIGURA 23: Bandeja de suporte para placas espalhadoras e degradadoras de energia.

Este acessório consiste basicamente em um suporte com abertura central quadrada de $20 \mathrm{~cm} \times 20 \mathrm{~cm}$, que ao ser inserido no acelerador habilita as configurações necessárias a TSET e é utilizado para fixar as folhas espalhadoras (para caracterizar o feixe de elétrons do acelerador a bandeja de TSET foi utilizada sem nenhum material).

\subsubsection{Validação do espectro}

Utilizando o mesmo procedimento experimental da caracterização do espectro a DFS $0,7 \mathrm{~cm}$, foram realizadas medidas de PDP e perfis radiais a DFS 1 $\mathrm{m}$, alterando apenas a distância fonte superfície e a profundidade dos perfis radiais, que foram realizados em quatro profundidades dentro da região de tratamento $(3,7,11$ e $15 \mathrm{~mm})$. 
Alterando em $30 \mathrm{~cm}$ à distância fonte superfície a PDP sofre uma pequena alteração em consequência da maior camada de ar e o perfil radial apresenta diferenças significativas em consequência da maior camada de ar e da abertura do feixe, que provoca grandes alterações no tamanho de campo em razão da DFS.

Os resultados obtidos nas medidas experimentais a DFS $1 \mathrm{~m}$ foram utilizados para validar o espectro reconstruído pelo programa MCNP4C, verificando a conformidade entre os resultados simulados e experimentais em uma condição diferente da utilizada para ajustar o espectro.

\subsubsection{Validação das simulações com materiais}

No processo de seleção de materiais foram realizadas simulações de perfis radiais e axiais de dose. Os resultados obtidos nestas simulações foram validados experimentalmente com uma combinação de placas quadradas $(20 \mathrm{~cm} \times 20 \mathrm{~cm}$ ) de alumínio e cobre com espessura de 1 e 0,2 mm, respectivamente. Estes materiais foram selecionados em razão dos bons resultados observados nas simulações, além do baixo custo e da disponibilidade comercial.

As placas foram posicionadas na janela de saída do acelerador, sendo que as medidas experimentais foram realizadas em um objeto simulador a DFS $1 \mathrm{~m}$, com a mesma configuração utilizada na caracterização e validação do espectro. Foram realizadas medidas de perfis radiais (7 e $11 \mathrm{~mm}$ de profundidade) e PDP, para placas com espessura total de 1, 3, e $5 \mathrm{~mm}$ de alumínio e 0,8 $\mathrm{mm}$ de cobre.

\subsubsection{Dosimetria dos campos de tratamento}

Os campos de tratamento simulados foram validados em duas situações distintas: a) feixe único espalhado a DFS 1,3 $\mathrm{m}$, para o tratamento de lesões com comprimento máximo de $60 \mathrm{~cm}$; b) feixe único espalhado a DFS 2,3 m, para irradiações de corpo inteiro.

\subsubsection{Feixe único a DFS $1,3 \mathrm{~m}$}

O campo de tratamento foi espalhado utilizando duas placas quadradas de cobre sendo a primeira de lado $20 \mathrm{~cm}$ e $1 \mathrm{~mm}$ de espessura e a segunda de lado $24 \mathrm{~cm}$ e $0,5 \mathrm{~mm}$ de espessura, posicionadas $11 \mathrm{~cm}$ abaixo da janela do acelerador. 




FIGURA 24: Câmara de ionização entre placas de água sólida.

O perfil radial foi caracterizado com uma câmara de ionização de placas paralelas, posicionada entre placas de água sólida como mostra a figura 24.

A câmara foi posicionada a $3 \mathrm{~mm}$ de profundidade e o perfil obtido movimentando a mesa de tratamento em intervalos de $5 \mathrm{~cm}$.

A deposição de dose em profundidade foi caracterizada utilizando um filme radiocrômico, posicionado verticalmente, entre placas de água sólida.

O espalhamento do feixe faz com que a energia depositada na região de penumbra apresente menor gradiente de dose, o que causa a deposição de doses significativas em regiões não afetadas pelo tumor.

Para reduzir o efeito nos tecidos sadios adjacentes a lesão pode ser utilizado um colete de chumbo. Para verificar a atenuação da dose em razão da blindagem, as medidas experimentais realizadas com a câmara de ionização entre placas de água sólida foram repetidas utilizando um colete de chumbo com $1 \mathrm{~mm}$ de espessura, posicionado na superfície das placas de água sólida.

\subsubsection{Feixe único a DFS 2,95 m}

O feixe de elétrons de $6 \mathrm{MeV}$, foi espalhado com as mesmas placas de cobre utilizadas para obter o campo de tratamento a DFS $1,3 \mathrm{~m}$, posicionada a 9,5 cm de distância da bandeja de TSET. 


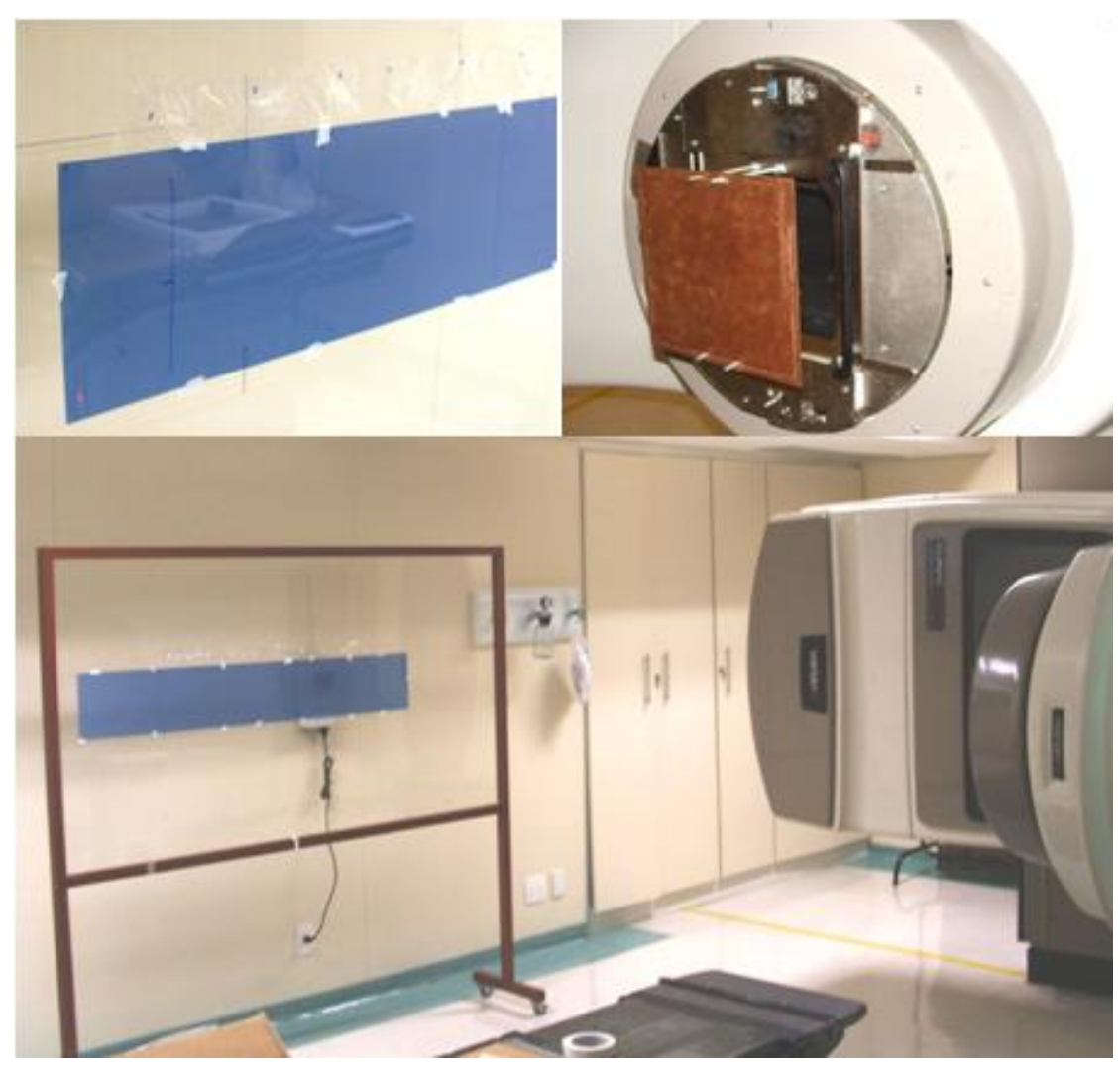

FIGURA 25: Acelerador linear Varian Clinac 2100C, filmes radiocrômicos e dosímetros termoluminescentes (LiF 100), utilizados na medida de perfil radial a DFS $2,95 \mathrm{~m}$.

O perfil radial de dose a DFS 2,95 m, foi caracterizado em um dos lados do eixo central, utilizando filmes radiocrômicos e dosímetros termoluminescentes (figura 25), posicionados sobre uma placa de acrílico com $1 \mathrm{~cm}$ de espessura.

Os dosímetros termoluminescentes foram posicionados em intervalos de $10 \mathrm{~cm}$ até $80 \mathrm{~cm}$ de distância do eixo central, e em intervalos de $5 \mathrm{~cm}$ na região entre 80 e $95 \mathrm{~cm}$, utilizando 9 dosímetros, posicionados lado a lado em uma região quadrada de $9 \mathrm{~mm} \times 9 \mathrm{~mm}$, para caracterizar cada ponto.

Os filmes radiocrômicos, em um total de cinco, foram posicionados de forma continua, caracterizando o campo de tratamento até $1,2 \mathrm{~m}$ de distância do eixo central.

\subsection{Simulações pelo código MCNP4C}

O programa MCNP4C foi utilizado para: a) simular feixes de tratamentos monoenergéticos; b) simular o feixe de $6 \mathrm{MeV}$ do acelerador do Hospital das Clí- 
nicas; c) analisar diferentes materiais; d) simular a composição e a geometria das folhas espalhadoras e degradadoras de energia.

\subsubsection{Comparação entre feixes monoenergéticos de 4, 6, 9 e $12 \mathrm{MeV}$}

Os aceleradores clínicos atuais possuem diferentes energias, o que possibilita grandes variações nas condições de tratamento. Para analisar qual energia é mais adequada a TSET, foram simulados feixe de elétrons monoenergéticos de 4, 6, 9 e $12 \mathrm{MeV}$.

Os parâmetros clínicos como a profundidade da região de tratamento, 0 tamanho do campo e a contaminação por raios- $X$ foram comparados, mediante simulações de perfis radias e axiais de dose em um objeto simulador de água, posicionado a DFS $2,5 \mathrm{~m}$.

Como alguns tratamentos são realizados com múltiplos campos, apresentando bons resultados, a inclinação do feixe também foi considerada, uma vez que altera significativamente as características da distribuição de dose em profundidade. As características da PDP foram simuladas com ângulos de incidência do feixe em relação à superfície do objeto simulador entre 0 e $75^{\circ}$, para as diferentes energias.

\subsubsection{Fonte de elétrons}

O feixe de um acelerador linear pode ser obtido simulando todos os componentes do acelerador, ou reconstruído por meio de medidas experimentais. Como não foi possível obter as especificações do acelerador com o fabricante, optou-se por construir o espectro com base em medidas experimentais de perfis axiais e radiais, realizadas a DFS $0,7 \mathrm{~m}$.

Este é um processo empírico, que consiste em criar uma fonte inicial no código MCNP4C (YORIYAZ et al., 2007) com parâmetros estabelecidos com base em trabalhos anteriores, estudos bibliográficos e experiência. A fonte de elétrons utilizada inicialmente apresentava uma distribuição energética em torno de $6 \mathrm{MeV}$ e distribuição espacial plana. 
Foram realizadas simulações de perfis e PDP nas mesmas condições das medidas experimentais realizadas para caracterizar o acelerador, introduzindo no código os materiais e a geometria da sala de tratamento. Na figura 26 é representada a geometria utilizada na simulação.

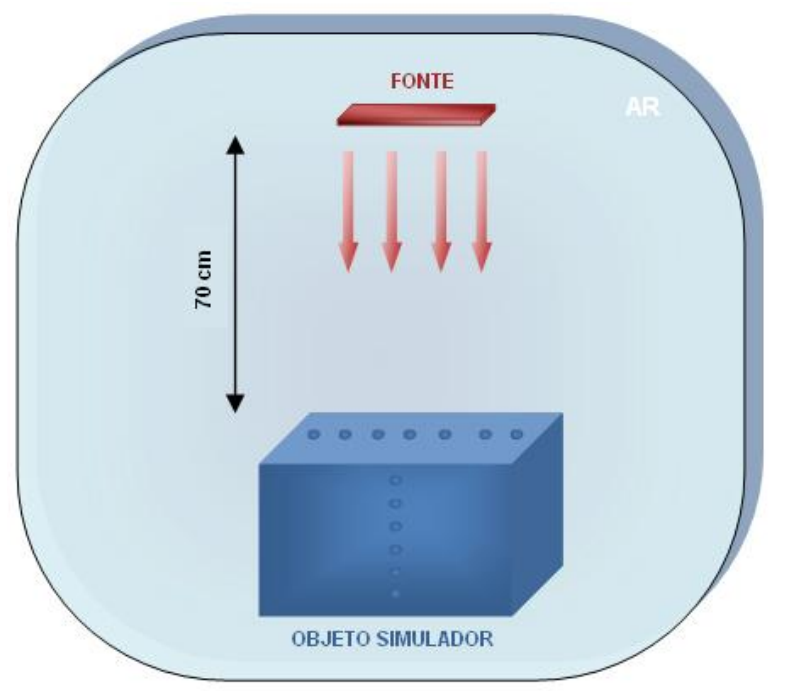

FIGURA 26: Geometria utilizada na simulação da fonte a DFS 0,7 m.

O objeto simulador constituído de água, com formato cúbico de aresta $30 \mathrm{~cm}$, foi simulado contendo em seu interior pequenas elipsóides que definem a região de interesse para cálculo da dose. Foi utilizado o tally *F8 do MCNP4C que calcula a energia depositada por fótons e elétrons, fornecendo uma resposta em MeV e o tally F6 que calcula a energia depositada somente por fótons, fornecendo uma resposta em $\mathrm{MeV} / \mathrm{g}$.

A caracterização do acelerador foi separada em duas etapas, sendo a primeira de caracterização energética do feixe, realizada com base em medidas de dose em profundidade, e a segunda na caracterização da distribuição espacial e angular do feixe, determinada por meio de medidas experimentais de perfis radiais de dose.

Utilizando-se a fonte estabelecida inicialmente, foram simuladas medidas de dose em profundidade, comparando o resultado simulado com o experimental. Como esperado, a PDP inicial apresentou grandes variações, fazendo-se necessárias alterações empíricas tanto na intensidade, quanto nas subdivisões do espectro energético. 
A cada alteração uma nova simulação foi realizada comparando novamente os resultados até que se obtivesse uma PDP simulada o mais próximo possível a experimental.

A distribuição espacial foi obtida de forma semelhante à distribuição energética, onde foi determinada uma região quadrada de lado $20 \mathrm{~cm}$, representando a distribuição geométrica do feixe na janela de saída do acelerador. Esta região foi subdividida em diversas regiões menores (figura 27) com intensidades distintas.

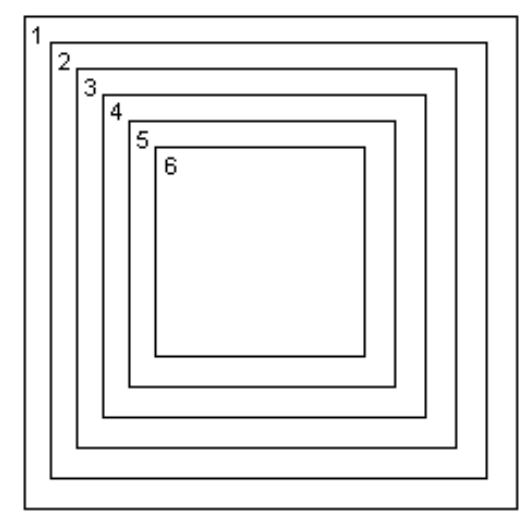

FIGURA 27: Representação da subdivisão da fonte no código MCNP4C.

Inicialmente utilizou-se uma distribuição homogênea em todas as regiões, posteriormente as subdivisões, assim como suas intensidades, foram sendo alteradas até que se obtivesse um resultado simulado próximo ao experimental.

Neste tipo de aplicação em particular os colimadores são posicionados com abertura máxima e os aplicadores não são utilizados, desta forma, o campo de tratamento aumenta significativamente com a distância. Para obter resultados compatíveis com os experimentais em diferentes distâncias fonte superfície, foi introduzida uma distribuição angular nos parâmetros de especificação da fonte, para que os elétrons emitidos apresentem uma inclinação em relação à reta normal a superfície fonte.

Outra possibilidade abordada neste trabalho consiste em utilizar uma fonte pontual com uma distribuição angular dividida em regiões de diferentes intensidades, obtendo um campo circular conforme ilustrado na figura 28. 
Como o campo de tratamento clínico é quadrado, ao utilizar uma fonte pontual é necessário criar um campo maior que o experimental, e delimitá-lo introduzindo superfícies que representam a janela do acelerador.

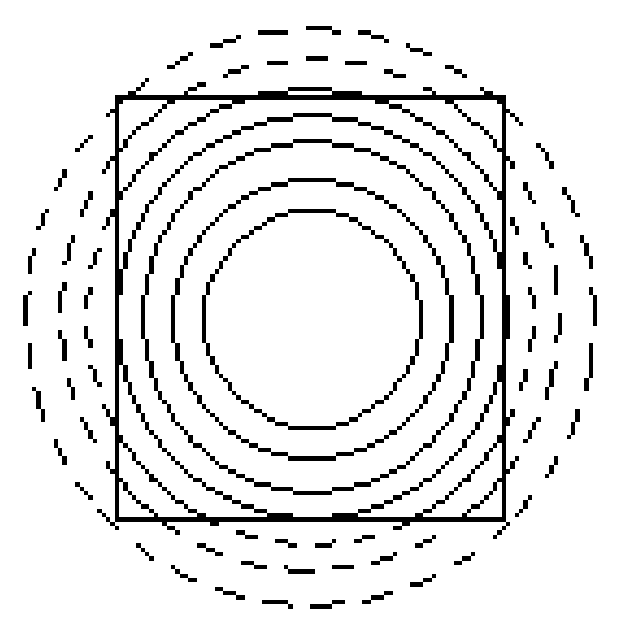

FIGURA 28: Ilustração de um campo circular delimitado, obtido com uma fonte pontual.

Outro fator relevante para este tipo de fonte é a comparação de perfis radiais em posições fora do eixo central, em razão da distribuição angular do feixe. A distribuição angular foi ajustada de forma empírica até que os perfis simulados no eixo central e fora deste apresentassem uma grande aproximação em relação aos resultados experimentais.

A última etapa do processo de caracterização do acelerador consiste na validação da fonte em outra condição, além da utilizada para ajustar o espectro, garantindo que o espectro simulado represente o feixe de tratamento em outras condições.

\subsubsection{Seleção de materiais}

Para selecionar os materiais mais adequados para a construção das folhas espalhadoras e degradadoras de energia, foram analisados diversos materiais, sendo eles: cobre, zinco, alumínio, titânio, chumbo, berílio, prata, ouro, estanho, cádmio e acrílico. 
Uma placa plana com $20 \mathrm{~cm} \times 20 \mathrm{~cm}$ de lado e $1 \mathrm{~mm}$ de espessura, foi posicionada $49,1 \mathrm{~cm}$ abaixo da fonte e $1 \mathrm{~mm}$ abaixo da janela simulada do acelerador, em seguida, utilizando-se o espectro obtido, foram realizadas simulações de PDP e perfis radiais ( $5 \mathrm{~mm}$ de profundidade) a DFS $1 \mathrm{~m}$, para cada material. $\mathrm{Na}$ figura 29 é representada a geometria utilizada nas simulações.

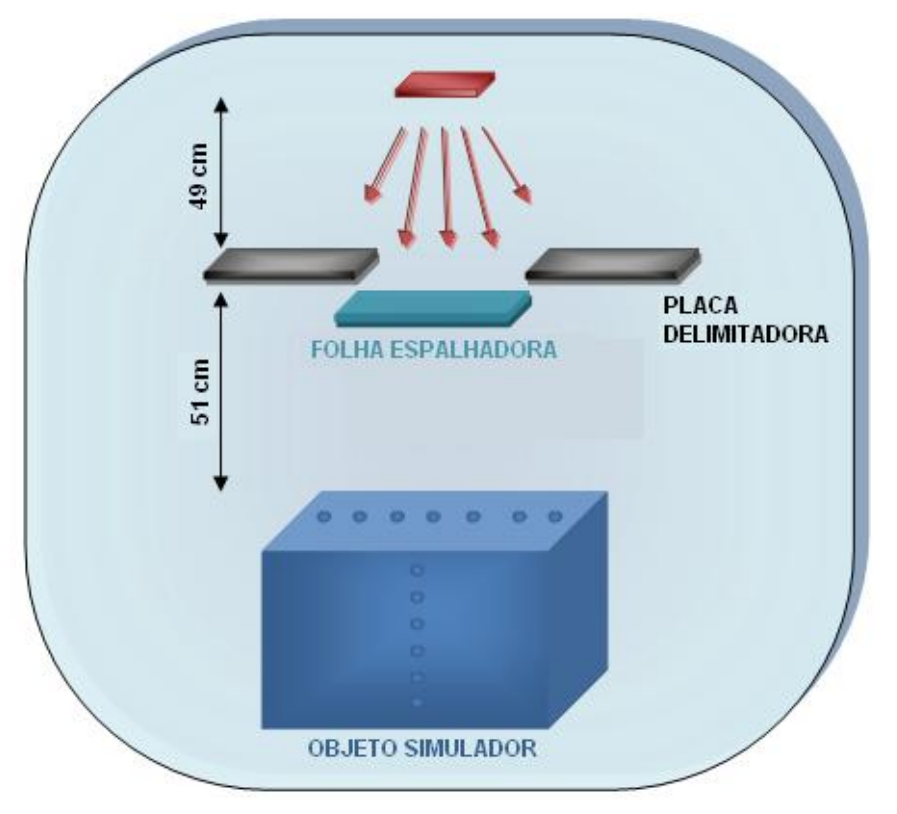

FIGURA 29: Representação da geometria utilizada nas simulações de materiais.

Esta análise permitiu a seleção dos materiais mais adequados a esta técnica de tratamento, considerando os parâmetros da PDP e dos perfis obtidos, como a superficialização e atenuação da dose, a produção de raios- $X$, o espalhamento eletrônico, e o fluxo de partículas.

\subsubsection{Placas espalhadoras e degradadoras de energia}

As placas espalhadoras foram simuladas com geometria similar à utilizada na seleção de materiais, alterando os seguintes parâmetros:

- Geometria da placa (circular, retangular e elipsoidal);

- Espessura e camadas das placas;

- Materiais (cobre, alumínio, zinco e acrílico);

- Distância da placa ao acelerador;

- Distância fonte superfície. 
O resultado obtido para cada combinação de parâmetros foi analisado com base na PDP e no perfil radial simulado, utilizando a menor espessura possível de cada material e buscando atender duas técnicas de tratamento:

- Feixe único de tratamento para lesões de até $60 \mathrm{~cm}$ (DFS 1,3 m);

- TSET com feixe único $(2,95 \mathrm{~m})$. 


\section{RESULTADOS E DISCUSSÕES}

Este capítulo apresenta todos os resultados experimentais e simulados, sendo eles:

- Calibração dos dosímetros termoluminescentes utilizados na medida do perfil radial do campo de tratamento a DFS 2,95 m.

- Comparação entre os feixes monoenergéticos de 4, 6, 9 e $12 \mathrm{MeV}$, mediante simulações de perfis radiais e axiais de dose.

- Medidas experimentais para caracterização da fonte de elétrons a DFS $0,7 \mathrm{~m}$.

- Reconstrução da fonte no MCNP4C. Comparação entre os resultados simulados e experimentais a DFS $0,7 \mathrm{~m}$.

- Validação da fonte simulada. Comparação entre os resultados simulados e experimentais a DFS $1 \mathrm{~m}$.

- Análise de diferentes materiais mediante simulações de perfis axiais e radiais de dose.

- Validação das simulações com diferentes materiais. Comparação entre os resultados simulados e experimentais com placas espalhadoras de cobre e alumínio.

- Validação da simulação do campo de tratamento de lesões com extensão de até $60 \mathrm{~cm}$. Comparação entre os resultados simulados e experimentais.

- Validação da simulação do campo de tratamento para irradiação de corpo inteiro. Comparação entre os resultados simulados e experimentais.

Os resultados obtidos com a câmara de ionização apresentam incerteza de $1 \%$, os demais resultados apresentam a incerteza descrita no texto, uma vez que na maior parte dos resultados a incerteza não poderia ser observada no gráfico, em consequência dos valores pouco expressivos (da ordem de $1 \%$ ) e do tamanho do pontos utilizados. 


\subsection{Avaliação dos dosímetros termoluminescentes LiF-100}

Dosímetros termoluminescentes apresentam uma grande dispersão na resposta, seja em virtude da diferença de massa ou por características intrínsecas, como a dopagem do material. Em razão das variações na resposta, faz-se necessário um processo de calibração e seleção individual (FILL et al., 1999; ROSA et al., 1999).

Com o intuito de utilizar o maior número possível de TLDs, foi adotado um processo de calibração individual que permite a correção da resposta de cada TLD com relação à média do grupo, reduzindo assim, a dispersão dos resultados, o que torna desnecessário a seleção de dosímetros de acordo com a faixa de resposta.



FIGURA 30: Número de dosímetros em função da faixa da resposta, em cada uma das 8 irradiações realizadas.

As respostas termoluminescentes foram analisadas, por meio de 8 irradiações com 1,04 Gy, nas quais os dosímetros foram posicionados de forma aleatória, garantindo que a variação da resposta em relação à média não fosse causada pela posição de irradiação. Os dosímetros foram agrupados em função da resposta, como pode ser observado na figura 30 que apresenta o número de dosímetros 
no eixo das ordenadas e a intensidade da emissão termoluminescente (nC) no eixo das abscissas.

A leitura normalizada de cada dosímetro foi obtida, dividindo sua respectiva resposta pela média do grupo, em cada uma das irradiações realizadas. Os dosímetros foram agrupados em função da resposta normalizada, como pode ser observado na figura 31 .

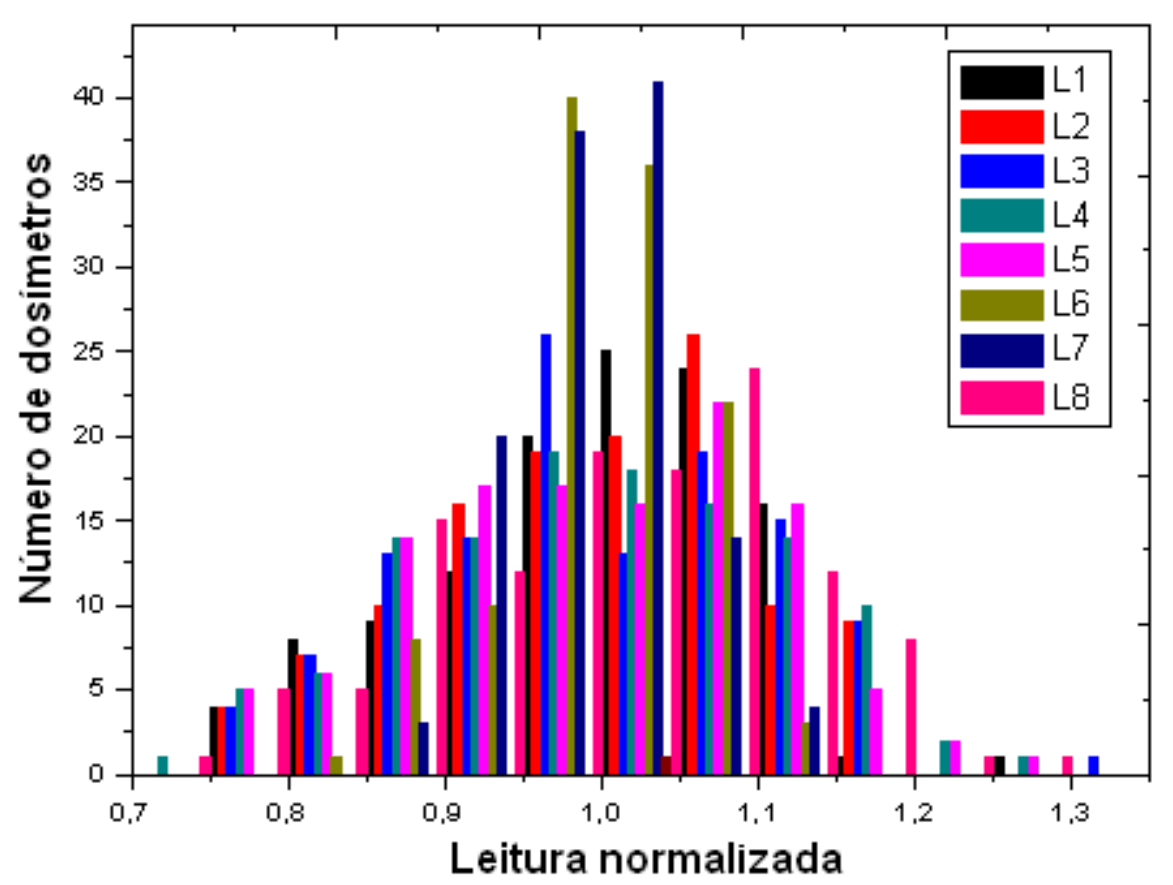

FIGURA 31: Número de dosímetros em função da faixa da resposta normalizada, em cada uma das 8 irradiações realizadas.

Mediante os resultados obtidos verificou-se que a resposta normalizada da maioria dos dosímetros apresenta comportamento similar em todas as medidas experimentais, exceto nas leituras 6 e 8 . Em virtude dos resultados observados estas medidas foram descartadas, pois indicam uma possível variação no processo experimental.

A resposta normalizada dos dosímetros foi analisada nas demais leituras. Do total de 124 dosímetros, 110 apresentaram comportamento regular, ou seja, a resposta estava sempre acima ou sempre abaixo da média dependendo da sensibilidade de cada dosímetro. 
Para os dosímetros selecionados foram calculados fatores de correção individuais, que consistem na leitura de cada dosímetro normalizada pela média do lote em cada irradiação. O fator de correção final consiste na média aritmética dos fatores obtidos em cada uma das seis irradiações, correspondendo à sensibilidade média de cada dosímetro, em relação à média do lote.


FIGURA 32: a) dispersão da resposta termoluminescente normalizada pela média; b) dispersão da resposta termoluminescente corrigida e normalizada pela média.

A resposta de cada dosímetro foi dividida pelo respectivo fator de correção, aproximando a resposta individual da média do lote e reduzindo a dispersão dos dados, como pode ser observado na figura 32.

A dispersão entre as leituras individuais que ultrapassava $20 \%$ foi reduzida para menos de $10 \%$, após a aplicação dos fatores de correção, homogeneizando as respostas.

Mediante a dispersão dos resultados corrigidos é possível observar a inversão da resposta, entre a segunda e a terceira leitura, em relação à média para diversos dosímetros. Quando a inversão da resposta de um determinado dosímetro ocorreu em uma ou duas leituras, estas foram descartadas e o fator de correção foi calculado considerando as demais irradiações.

Na tabela 2 são apresentados os fatores de correção (F.C) para cada dosímetro e o desvio padrão da média dos fatores de correção, obtido mediante seis irradiações. 
TABELA 2: Fatores de correção (F.C) e desvio padrão (\%) dos fatores de correção de cada dosímetro, obtidos pela resposta normalizada em cada uma das seis irradiações.

\begin{tabular}{|c|c|c|c|c|c|c|c|c|}
\hline TLD & F.C & Desv. (\%) & TLD & F.C & Desv. (\%) & $\overline{T L D}$ & F.C & Desv. (\%) \\
\hline 1 & 1,09 & 3,9 & 45 & 0,79 & 3,9 & 86 & 0,82 & 3,6 \\
\hline 2 & 1,10 & 1,9 & 46 & 0,77 & 1,1 & 87 & 0,92 & 4,6 \\
\hline 3 & 1,25 & 3,8 & 47 & 0,76 & 1,1 & 88 & 1,06 & 1,3 \\
\hline 5 & 1,08 & 3,6 & 48 & 1,00 & 1,8 & 89 & 0,89 & 1,4 \\
\hline 6 & 1,09 & 3,3 & 49 & 0,90 & 3,3 & 90 & 0,82 & 2,9 \\
\hline 7 & 1,03 & 2,7 & 50 & 1,00 & 3,4 & 91 & 0,95 & 2,0 \\
\hline 8 & 1,15 & 0,7 & 51 & 1,05 & 3,8 & 92 & 1,03 & 1,5 \\
\hline 10 & 0,83 & 1,6 & 52 & 1,13 & 2,0 & 93 & 0,82 & 1,4 \\
\hline 11 & 1,12 & 1,3 & 53 & 1,15 & 1,9 & 94 & 1,01 & 3,2 \\
\hline 12 & 1,12 & 2,6 & 54 & 0,98 & 3,6 & 95 & 0,92 & 4,5 \\
\hline 13 & 0,97 & 0,7 & 55 & 0,83 & 0,4 & 96 & 1,05 & 2,6 \\
\hline 14 & 1,10 & 1,9 & 56 & 1,08 & 3,4 & 97 & 0,90 & 2,9 \\
\hline 15 & 1,05 & 2,5 & 57 & 0,94 & 1,7 & 98 & 1,08 & 3,2 \\
\hline 16 & 1,00 & 0,8 & 58 & 0,95 & 1,5 & 99 & 1,00 & 4,5 \\
\hline 17 & 1,07 & 1,6 & 59 & 0,92 & 1,4 & 100 & 0,99 & 2,5 \\
\hline 18 & 1,04 & 2,6 & 60 & 0,97 & 2,2 & 101 & 1,07 & 2,0 \\
\hline 19 & 1,03 & 2,0 & 61 & 0,92 & 3,0 & 102 & 1,19 & 3,0 \\
\hline 20 & 0,84 & 3,7 & 62 & 1,12 & 2,3 & 103 & 1,11 & 3,5 \\
\hline 21 & 1,07 & 2,2 & 63 & 0,89 & 1,1 & 104 & 0,91 & 0,9 \\
\hline 22 & 1,09 & 1,3 & 64 & 0,91 & 4,9 & 105 & 0,94 & 2,4 \\
\hline 23 & 1,01 & 2,7 & 65 & 0,92 & 1,3 & 106 & 1,10 & 3,2 \\
\hline 24 & 1,09 & 2,7 & 66 & 0,90 & 3,2 & 107 & 1,09 & 1,8 \\
\hline 25 & 1,00 & 2,8 & 67 & 0,95 & 3,3 & 108 & 1,06 & 2,7 \\
\hline 26 & 0,88 & 2,4 & 68 & 0,87 & 1,4 & 109 & 1,08 & 2,6 \\
\hline 27 & 1,10 & 2,0 & 69 & 0,83 & 0,5 & 110 & 0,99 & 3,2 \\
\hline 29 & 1,05 & 0,8 & 70 & 1,07 & 1,8 & 111 & 0,87 & 2,4 \\
\hline 30 & 1,04 & 3,0 & 71 & 1,08 & 1,9 & 112 & 1,03 & 2,8 \\
\hline 31 & 1,17 & 0,5 & 72 & 1,03 & 2,3 & 113 & 1,16 & 4,5 \\
\hline 32 & 1,00 & 1,7 & 73 & 0,90 & 1,9 & 114 & 1,15 & 2,6 \\
\hline 33 & 1,09 & 0,7 & 74 & 0,90 & 2,6 & 115 & 1,15 & 1,3 \\
\hline 34 & 1,00 & 2,9 & 75 & 0,92 & 4,8 & 116 & 1,13 & 1,8 \\
\hline 35 & 1,03 & 3,8 & 76 & 0,97 & 3,7 & 117 & 1,18 & 3,1 \\
\hline 36 & 1,12 & 0,7 & 77 & 0,81 & 4,3 & 118 & 1,11 & 3,1 \\
\hline 37 & 1,04 & 1,2 & 78 & 1,17 & 0,7 & 119 & 1,00 & 4,3 \\
\hline 38 & 1,00 & 0,8 & 79 & 0,94 & 3,1 & 120 & 1,10 & 3,3 \\
\hline 39 & 0,92 & 2,6 & 80 & 0,87 & 1,1 & 121 & 1,03 & 7,2 \\
\hline 40 & 0,75 & 1,8 & 81 & 0,96 & 2,7 & 122 & 1,12 & 3,5 \\
\hline 41 & 1,00 & 2,0 & 82 & 0,99 & 0,8 & 123 & 1,17 & 1,6 \\
\hline 42 & 1,02 & 3,2 & 83 & 0,88 & 2,0 & 124 & 1,07 & 3,1 \\
\hline 43 & 0,98 & 3,1 & 84 & 0,92 & 3,5 & & & \\
\hline 44 & 0,94 & 1,1 & 85 & 0,98 & 0,9 & & & \\
\hline
\end{tabular}

Utilizando os fatores de correção o desvio padrão do lote (tabela 3) foi reduzido para menos da metade, em todas as leituras utilizadas na calibração. O desvio padrão máximo obtido ao utilizar os fatores de correção é $4,1 \%$, este re- 
sultado possibilita medidas relativas confiáveis e com grande precisão, em se tratando de dosímetros termoluminescentes.

TABELA 3: Desvio padrão da média em porcentagem, para 110 dosímetros sem fator de correção em comparação ao desvio padrão dos dados corrigidos.

\begin{tabular}{|c|c|c|c|c|c|c|}
\hline \multirow[b]{3}{*}{$\begin{array}{l}\text { Resposta } \\
\text { s/ correção }\end{array}$} & \multicolumn{6}{|c|}{ Desvio Padrão da Média (\%) } \\
\hline & $\begin{array}{c}\text { Leitura } \\
1\end{array}$ & $\begin{array}{l}\text { Leitura } \\
2\end{array}$ & $\begin{array}{c}\text { Leitura } \\
3\end{array}$ & $\begin{array}{c}\text { Leitura } \\
\quad 4\end{array}$ & $\begin{array}{c}\text { Leitura } \\
5\end{array}$ & $\begin{array}{l}\text { Leitura } \\
6\end{array}$ \\
\hline & 9,8 & 10,1 & 10,9 & 11,6 & 10,9 & 11,1 \\
\hline $\begin{array}{l}\text { Resposta } \\
\text { Corrigida }\end{array}$ & 4,1 & 3,3 & 2,9 & 2,9 & 2,7 & 3,2 \\
\hline
\end{tabular}

\subsection{Comparação entre feixes monoenergéticos de 4, 6, 9 e $12 \mathrm{MeV}$}

O acelerador linear Varian Clinac $2100 \mathrm{C}$ do Hospital das Clínicas apresenta apenas a energia $6 \mathrm{MeV}$, disponível nas configurações necessárias a TSET. Para verificar se está energia é adequada a técnica proposta neste trabalho foram realizada simulações de perfis radiais e axiais de dose com feixes monoenergéticos de 4, 6, 9 e $12 \mathrm{MeV}$.

Os resultados obtidos foram comparados considerando o espalhamento eletrônico, a distribuição de dose em profundidade, a produção de raios-X e alguns parâmetros clínicos. Embora os feixes simulados não representem feixes de aceleradores reais, que apresentam uma distribuição energética, os resultados possibilitam a comparação entre as diferentes energias analisadas.

\subsubsection{Perfis radiais e axiais de dose}

Os elétrons podem ser considerados basicamente monoenergéticos na saída do tubo acelerador. No entanto, o feixe interage com folhas espalhadoras, colimadores, câmaras de ionização e outros componentes do acelerador, além de interagir com o ar, modificando sua distribuição energética e sua direção.

A distribuição energética do feixe é uma característica de cada acelerador. Em tratamentos reais, a obtenção de feixes monoenergéticos é impossível. No 
entanto, a simulação destes feixes fornece parâmetros aproximados e permite a comparação entre diferentes energias.

Os feixes monoenergéticos simulados de 4, 6, 9 e 12 MeV foram comparados mediante simulações de perfis radiais e axiais de dose, simulados a DFS 2,5 $\mathrm{m}$, com erro relativo inferior a $1 \%$ em regiões com dose relativa acima de $40 \% \mathrm{e}$ erro relativo inferior a $3 \%$ nos extremos do campo.

A energia do feixe mais adequada a uma técnica clínica depende do tipo de tratamento e das características de cada lesão. Feixes com menor energia apresentam menor alcance, sendo indicados no tratamento de lesões mais superficiais, ao passo que, feixes de maior energia são indicados no tratamento de lesões mais profundas.

Na figura 33 é apresentada a comparação entre as PDPs obtidas numericamente, para as energias analisadas.

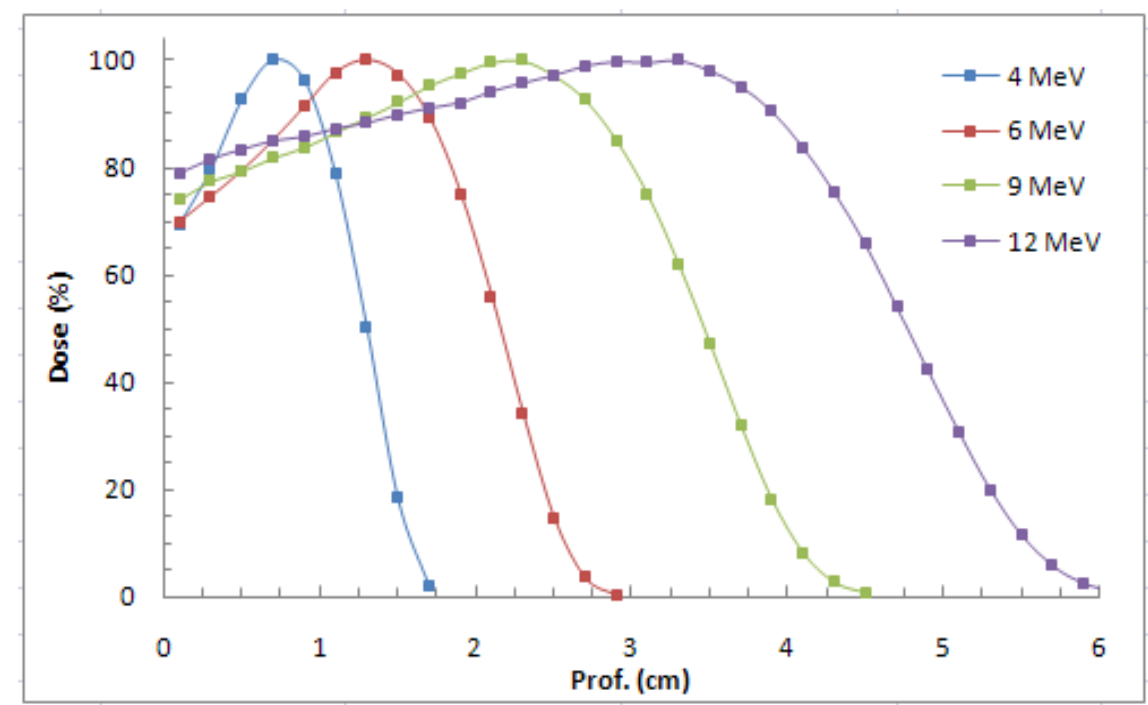

FIGURA 33: Comparação entre as PDPs obtidas pelo método de Monte Carlo, para as energias de 4, 6, 9 e $12 \mathrm{MeV}$, em um objeto simulador de água a DFS 2,5 m.

Mediante os resultados obtidos é possível observar que os feixes de menor energia apresentam uma queda mais acentuada na energia depositada, após a região de tratamento, visto que elétrons de menor energia são espalhados em grandes ângulos em relação à direção inicial. Este efeito causa uma queda abrupta na energia depositada, e reduz a dose nos tecidos sadios adjacentes. 
$\mathrm{Na}$ tabela 4 são apresentados alguns parâmetros clínicos (item 2.2.3), como a profundidade de dose máxima $\left(R_{100}\right)$, a energia mais provável $\left(\overline{\boldsymbol{\epsilon}}_{\boldsymbol{p}, \mathbf{0}}\right)$ e a energia média $\left(\overline{\boldsymbol{\epsilon}}_{\mathbf{0}}\right)$ na superfície do objeto simulador, calculadas pelas equações 2 e 3, respectivamente. Todos os resultados apresentados na tabela foram obtidos mediante simulações de PDP, para as diferentes energias analisadas.

A região de tratamento $\left(R_{80}\right)$, para um feixe com $4 \mathrm{MeV}$, corresponde a $1,1 \mathrm{~cm}$, aproximadamente três e quatro vezes inferior ao resultado obtido com os feixes de 9 e $12 \mathrm{MeV}$, respectivamente.

Mesmo sem folhas espalhadoras que atenuem a energia do feixe, a região de tratamento obtida com um feixe de $4 \mathrm{MeV}$, não é suficiente para tratar parte dos casos clínicos. A profundidade do $R_{50}$ obtida é $1,3 \mathrm{~cm}$ e não abrange toda a região especificada pelo TG23.

TABELA 4: Parâmetros clínicos simulados para feixes de elétrons monoenergéticos com energias de 4, 6, 9 e $12 \mathrm{MeV}$.

\begin{tabular}{|c|c|c|c|c|}
\hline \multirow{2}{*}{ Parâmetros } & \multicolumn{4}{|c|}{ Energia (MeV) } \\
\hline & 4 & 6 & 9 & 12 \\
\hline$R_{100}(\mathrm{~cm})$ & 0,7 & 1,3 & 2,3 & 3,3 \\
\hline$R_{90}(\mathrm{~cm})$ & 1,0 & 1,7 & 2,8 & 3,9 \\
\hline$R_{80}(\mathrm{~cm})$ & 1,1 & 1,8 & 3,0 & 4,2 \\
\hline$R_{50}(\mathrm{~cm})$ & 1,3 & 2,2 & 3,5 & 4,8 \\
\hline$R_{p} \quad(\mathrm{~cm})$ & 1,6 & 2,6 & 4,1 & 5,6 \\
\hline $\begin{array}{ll}R_{q} & (\mathrm{~cm})\end{array}$ & 1,3 & 2,1 & 3,4 & 4,6 \\
\hline $\bar{\epsilon}_{0} \quad(\mathrm{MeV})$ & 3,0 & 5,0 & 8,1 & 11,1 \\
\hline $\bar{\epsilon}_{p, 0}(\mathrm{MeV})$ & 3,4 & 5,4 & 8,4 & 11,4 \\
\hline Raios-X (\%) & 0,13 & 0,23 & 0,46 & 0,75 \\
\hline
\end{tabular}

A profundidade da região de tratamento dever ser suficiente para tratar a maior parte dos casos clínicos, conciliando a deposição de dose em profundidade de feixes de maior energia, aos parâmetros limitantes como a produção de raios$\mathrm{X}$.

Feixes de menor energia apresentam menor contaminação por raios-X, esta contaminação determinada pela razão entre a dose máxima depositada por raios-X e a energia máxima depositada, com incerteza de aproximadamente $0,01 \%$ da dose máxima depositada. 
O resultado obtido numericamente pode subestimar a contaminação por raios- $X$, uma vez que, a fonte utilizada é uma fonte apenas de elétrons, com contaminação proveniente da interação do feixe com o ar. Em aceleradores reais 0 feixe apresenta uma componente de fótons produzidos pelas interações dos elétrons com os componentes do acelerador, os quais não foram simulados.

A diferença entre a contaminação por raios- $x$ obtida numérica e experimentalmente é de aproximadamente $0,17 \%$ para energia de $6 \mathrm{MeV}$, conforme descrito no item 6.5.1, e pode aumentar para feixes de elétrons com energias mais altas.

A contaminação obtida com o feixe de $12 \mathrm{MeV}$ é próxima a $1 \%$, que é o valor máximo indicado pelo protocolo da AAPM em tratamentos de TSET, e 6,8 vezes superior a contaminação obtida com um feixe de $4 \mathrm{MeV}$.

Outro parâmetro de fundamental importância a esta técnica de tratamento é o espalhamento do feixe, caracterizado mediante simulações de perfis radiais.

Os perfis radiais (figura 34 ) foram simulados em um objeto simulador de água com $80 \mathrm{~cm}$ de comprimento em intervalos de $5 \mathrm{~cm}$. Como a distribuição espacial e angular (descrita no item 6.4.2) do feixe utilizado é simétrica, os perfis foram simulados em apenas um dos lados do eixo central, a $5 \mathrm{~mm}$ de profundidade.

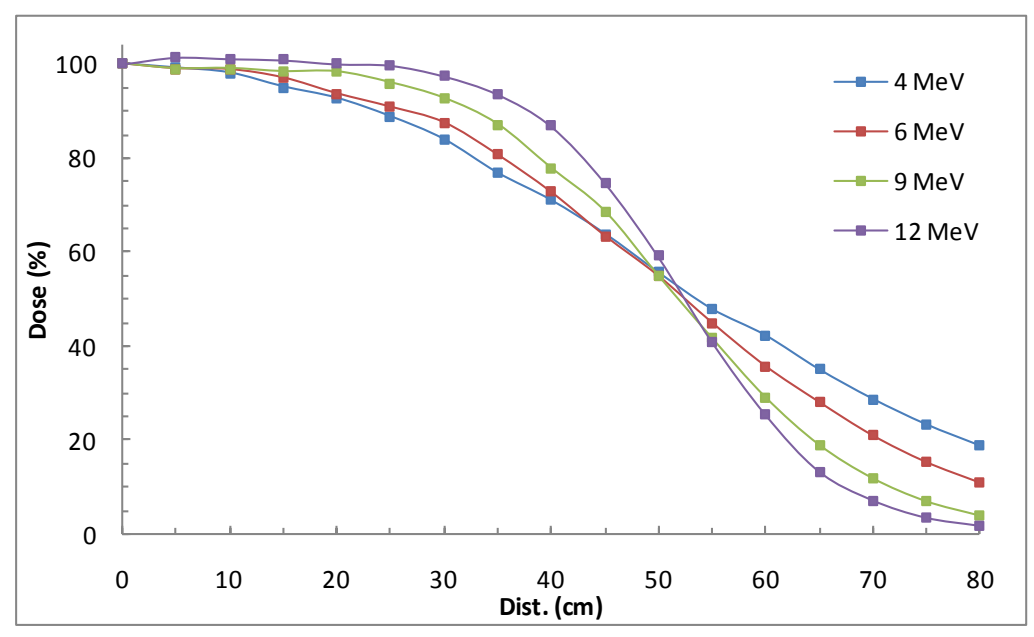

FIGURA 34: Comparação entre os perfis radiais obtidos pelo método de Monte Carlo, para as energias de 4, 6, 9 e $12 \mathrm{MeV}$ em um dos lados do campo de tratamento. 
Feixes de menor energia apresentam um maior espalhamento, mesmo interagindo apenas com o ar. A $0,7 \mathrm{~m}$ de distância do eixo central a dose relativa obtida com o feixe de $4 \mathrm{MeV}$ é superior em 8,17 e $25 \%$ a dose relativa obtida com feixes de 6, 9 e $12 \mathrm{MeV}$, respectivamente. $O$ resultado condiz com o esperado, uma vez que o caminho livre médio é menor para energias mais baixas.

Como o espalhamento eletrônico é inversamente proporcional a energia, que por sua vez é diretamente proporcional a produção de raios- $X$, feixes com energias mais altas como $12 \mathrm{MeV}$, não são indicados a esta modalidade terapêutica.

Para produzir um campo de tratamento de $200 \mathrm{~cm} \times 80 \mathrm{~cm}$, com deposição superficial de dose, em uma distância fonte superfície restrita, utilizando um feixe com energia próxima a $12 \mathrm{MeV}$, seriam necessárias folhas espalhadoras com alto número atômico (proporcional ao espalhamento eletrônico), ou com grande espessura. Em ambos os casos a contaminação por raios- $X$ seria inaceitável.

Considerando os resultados obtidos feixes com baixa energia como $4 \mathrm{MeV}$ seriam os mais indicados à modalidade terapêutica TSET, no entanto a deposição superficial de energia pode não ser suficiente para o tratamento de lesões mais profundas e restringir sua aplicação.

À medida que, feixes com energia de $6 \mathrm{MeV}$ não apresentam tal restrição, produzem maior espalhamento e menor contaminação por raios- $\mathrm{X}$, quando comparado às energias superiores. Sendo o feixe, dentre os analisados, com energia mais adequada ao desenvolvimento da técnica proposta.

\subsection{2 Ângulo de incidência}

Muitos tratamentos são realizados com múltiplos campos, devido tanto as dimensões restritas de algumas salas de tratamento, quanto à maior homogeneidade obtida em muitos casos.

Estes tratamentos não utilizam folhas espalhadoras que causem grande atenuação na energia do feixe, podendo atingir regiões mais profundas que o tumor, no caso de lesões superficiais ou quando utilizados feixes de maior energia. 
O efeito produzido pela inclinação do feixe nos perfis axiais de dose foi analisado mediante simulações de PDP, utilizando diferentes ângulos de incidência, em relação à reta normal a superfície do objeto simulador (eixo onde foi simulada a PDP), como pode ser observado na figura 35.

As simulações foram realizadas com uma fonte pontual, monoenergética, com abertura de $5^{\circ}$. Todos os resultados foram obtidos a DFS $1 \mathrm{~m}$, com erro relativo inferior a $2 \%$.

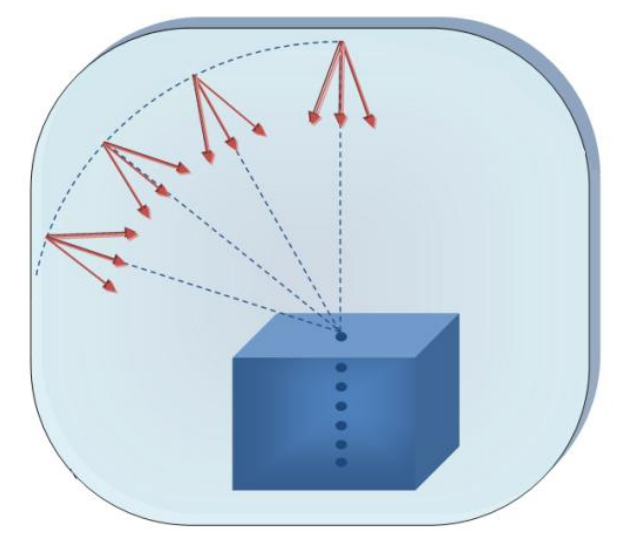

FIGURA 35: Representação das simulações realizadas com feixes inclinados, em relação à reta normal a superfície do objeto simulador.

Todas as energias apresentaram superficialização na deposição de dose, em virtude da inclinação do feixe. Variações mais significativas podem ser observadas em ângulos de incidência superiores a $15^{\circ}$, sendo que, para inclinações superiores a $60^{\circ}$ a PDP perde a maior parte das suas características, apresentando dose máxima na superfície, seguida de um grande gradiente de dose.
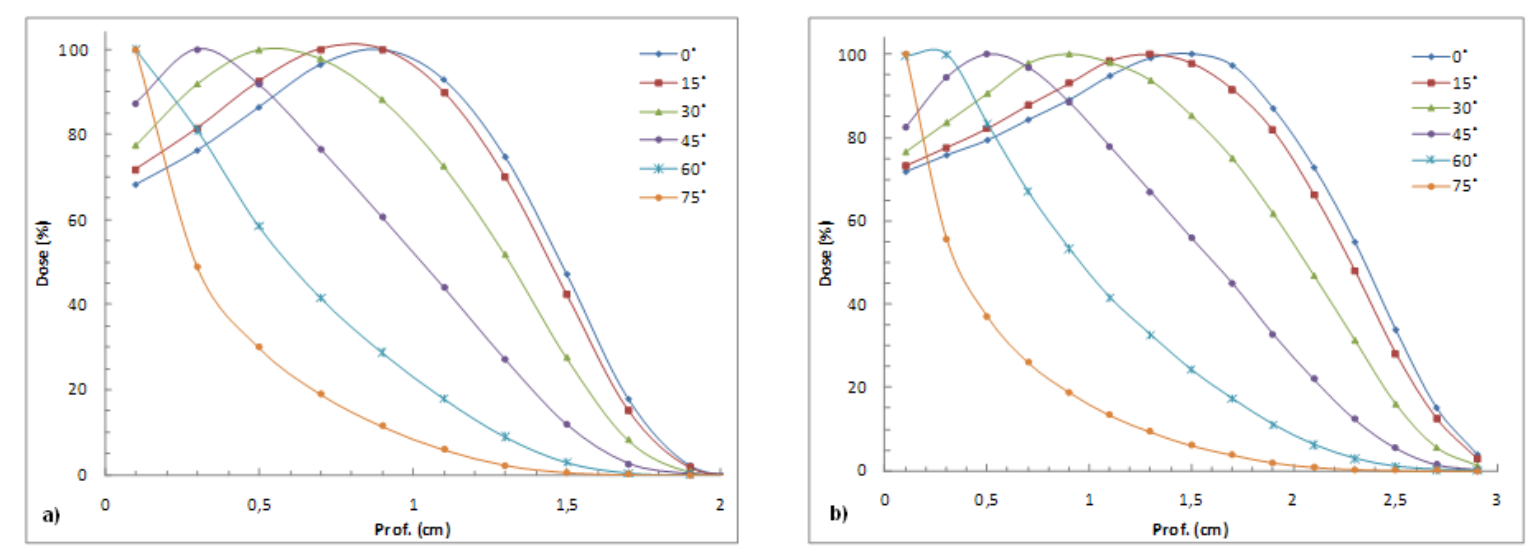

FIGURA 36: PDP em um objeto simulador de água, com ângulos de incidência do feixe entre 0 e $75^{\circ}$, para feixes de elétrons com energia: a) $4 \mathrm{MeV}$; b) $6 \mathrm{MeV}$. 

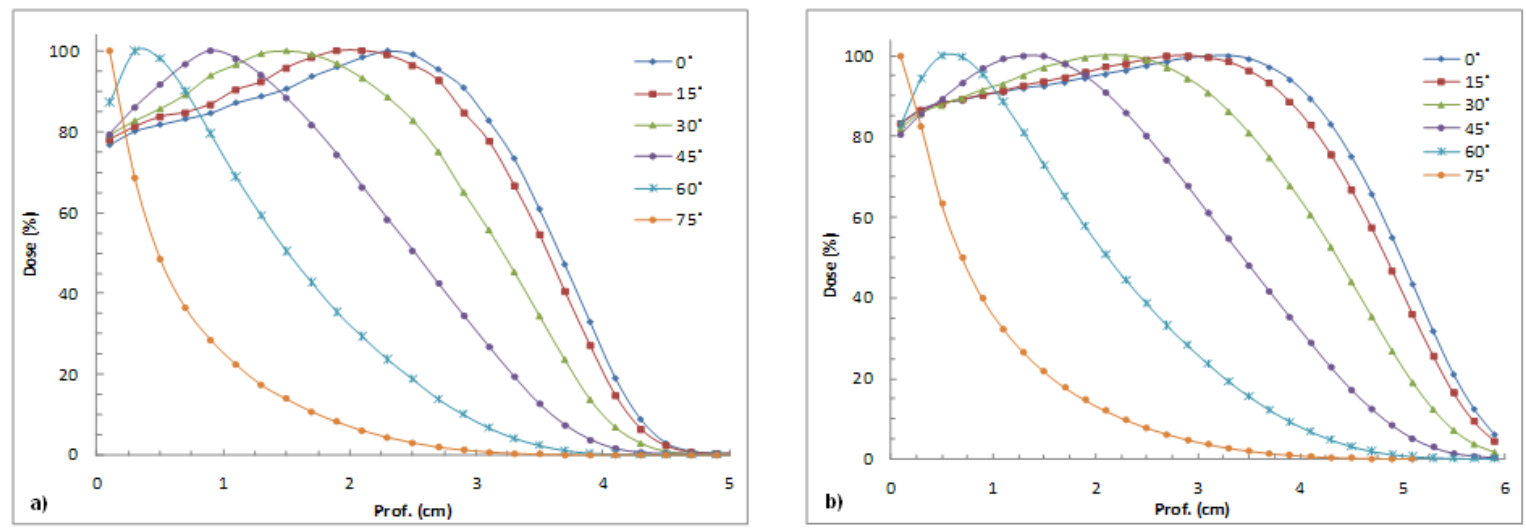

FIGURA 37: PDP em um objeto simulador de água, com ângulos de incidência do feixe entre 0 e $75^{\circ}$, para feixes de elétrons com energia: a) $9 \mathrm{MeV}$; b) $12 \mathrm{MeV}$.

As figuras 36 e 37 apresentam o comportamento da PDP para as energias de 4, 6, 9 e $12 \mathrm{MeV}$, em função do ângulo de incidência do feixe.

Na tabela 5 é apresentada a profundidade da região de tratamento determinada pela posição do $R_{80}$, para as energias e os ângulos de incidência analisados.

A inclinação do feixe, além de utilizada na composição de tratamentos com múltiplos campos, também pode ser utilizada em casos onde a região de tratamento ultrapasse a profundidade do tumor.

TABELA 5: Profundidade da região de tratamento para feixes monoenergéticos de 4, 6, 9 e $12 \mathrm{MeV}$, em função do ângulo de inclinação do feixe.

\begin{tabular}{c|cccc}
\hline $\begin{array}{c}\text { Ângulo de } \\
\text { Incidência ( }\end{array}$ & \multicolumn{4}{|c}{ Região de Tratamento (cm) } \\
\hline $\mathbf{0}$ & $\mathbf{4 ~ M e V}$ & $\mathbf{6 ~ M e V}$ & $\mathbf{9 ~ M e V}$ & $\mathbf{1 2} \mathbf{~ M e V}$ \\
$\mathbf{1 5}$ & 1,1 & 2,0 & 3,2 & 4,4 \\
$\mathbf{3 0}$ & 1,1 & 1,9 & 3,0 & 4,2 \\
$\mathbf{4 5}$ & 1,0 & 1,6 & 2,6 & 3,5 \\
$\mathbf{6 0}$ & 0,7 & 1,1 & 1,7 & 2,5 \\
$\mathbf{7 5}$ & 0,5 & 0,6 & 0,9 & 1,3 \\
\hline
\end{tabular}

A região de tratamento para o feixe de $12 \mathrm{MeV}$ com inclinação de $30^{\circ}$ é $0,9 \mathrm{~cm}$ inferior a região de tratamento com o feixe paralelo. Em tratamentos com feixes inclinados, esta energia pode ser utilizada para o tratamento de lesões superficiais. 


\subsection{Características do feixe de elétrons}

A distribuição energética e espacial do feixe de elétrons de $6 \mathrm{MeV}$ do acelerador linear do Hospital das Clínicas, foi caracterizada por meio de medidas de perfis radiais e axiais de dose, realizadas com DFS 0,7 m em um objeto simulador automatizado de água com uma câmara de ionização de placas paralelas, utilizando a placa de TSET sem folha espalhadora, abertura máxima de campo e alta taxa de dose.

\subsubsection{Percentual de dose em profundidade}

A PDP experimental (figura 38) foi obtida com uma câmara de ionização de placas paralelas com precisão de $1 \%$, em intervalos de $0,3 \mathrm{~mm}$, até $4 \mathrm{~cm}$ de profundidade (perpendicularmente a superfície), em um objeto simulador de água.

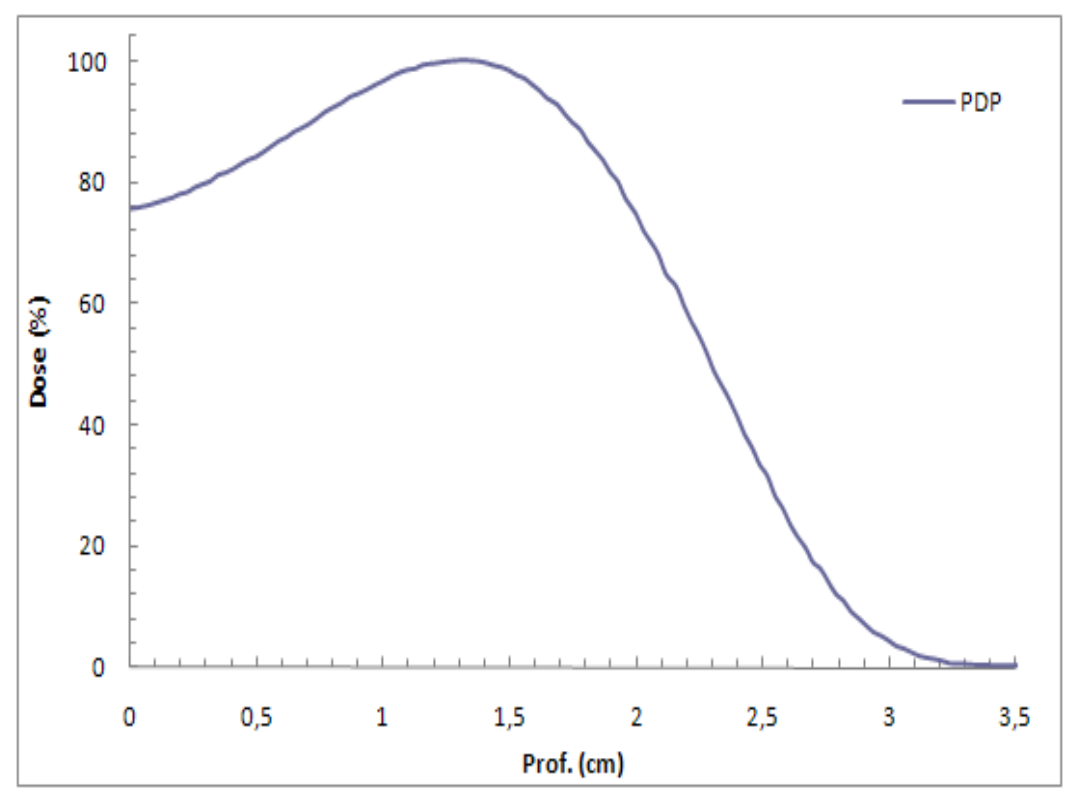

FIGURA 38: PDP experimental a DFS 0,7 $\mathrm{m}$.

A partir do resultado da distribuição de dose em profundidade é possível verificar alguns parâmetros clínicos (tabela 6 ), como o gradiente de dose $(G)$, a energia mais provável $\left(\overline{\boldsymbol{\epsilon}}_{p, \mathbf{0}}\right)$ e a energia média $\left(\overline{\boldsymbol{\epsilon}}_{\mathbf{0}}\right)$ na superfície do objeto simulador, obtidos pelas equações 4,2 e 3 e utilizados na caracterização do feixe e no planejamento dos tratamentos. 
O alcance terapêutico do feixe pode ser definido pela posição do $R_{90}$, após a posição da dose máxima, embora em muitos casos seja utilizada a posição $R_{80}$ ou até mesmo a posição do $R_{85}$ para definir a região de alcance terapêutico.

Este feixe em particular possui um alcance terapêutico de aproximadamente $1,9 \mathrm{~cm}\left(R_{80}\right)$, próximo ao resultado estimado $(2,0 \mathrm{~cm})$ pela fórmula empírica:

$$
R_{80}=\frac{E}{3}
$$

Onde:

$E \quad=$ energia nominal do feixe.

Sem a utilização de placas degradadoras de energia este feixe depositaria altas doses em regiões sadias, além da profundidade do tumor na maioria dos tratamentos superficiais.

Ao passo que, em grandes distâncias a interação com ar e a utilização de folhas espalhadoras e degradadoras reduzem a região de tratamento e o alcance dos elétrons, em consequência da atenuação da energia do feixe.

TABELA 6: Parâmetros clínicos obtidos mediante PDP experimental, realizada com a bandeja de TSET, sem nenhuma folha espalhadora, a DFS 0,7 $\mathrm{m}$.

\begin{tabular}{|c|c|}
\hline Parâmetros & $\begin{array}{c}P D P \\
\text { Experimental }\end{array}$ \\
\hline$R_{100}(\mathrm{~cm})$ & 1,3 \\
\hline$R_{90}(\mathrm{~cm})$ & 1,7 \\
\hline$R_{80}(\mathrm{~cm})$ & 1,9 \\
\hline$R_{50}(\mathrm{~cm})$ & 2,3 \\
\hline$R_{\mathrm{p}} \quad(\mathrm{cm})$ & 2,9 \\
\hline$R_{\mathrm{q}} \quad(\mathrm{cm})$ & 2,2 \\
\hline$G$ & 4,1 \\
\hline $\bar{\epsilon}_{\mathbf{0}} \quad(\mathrm{MeV})$ & 5,4 \\
\hline $\bar{\epsilon}_{p, 0}(\mathrm{MeV})$ & 6,0 \\
\hline
\end{tabular}




\subsubsection{Perfis radiais de dose}

Os perfis radiais foram caracterizados em quatro profundidades distintas $(12,8,13,2,18,4$ e $23 \mathrm{~mm})$ sem apresentar variações significativas, como pode ser observado na figura 39 .

Os perfis radiais obtidos foram analisados considerando as especificações da IAEA (International Atomic Energy Agency) e da IEC (International Electrotechical Comission) (PODGORSAK, 2005), considerando os seguintes parâmetros:



FIGURA 39: Perfis radiais em um objeto simulador de água a DFS 0,7 m.

\section{Tamanho de campo}

O tamanho de campo é estabelecido pela distância entre os pontos com dose relativa $50 \%$, neste caso o tamanho de campo obtido com a abertura máxima dos colimadores, a DFS $0,7 \mathrm{~m}$ é de aproximadamente $28,3 \mathrm{~cm}$.

\section{Região de Penumbra}

A região de penumbra apresenta grande gradiente de dose, sendo delimitada pela região com dose relativa entre $80 \%$ e $20 \%$. A IEC estabelece a profundidade para a medição da região de penumbra, como a metade do valor da profundidade onde a dose relativa é $80 \%$. Usualmente a penumbra pode ser caracterizada em diversas profundidades. 
A $12,8 \mathrm{~mm}$ de profundidade, próxima a profundidade do $R_{100}$, a extensão da região de penumbra é de 3,2 cm (entre $\pm 15,8$ e $\pm 12,6 \mathrm{~cm}$ ) em cada lado do campo, não apresentando diferenças significativas nas demais profundidades analisadas.

A variação da região de penumbra em função da profundidade, para esta energia é mais relevante em profundidades onde a dose é menor que $20 \%$ da dose máxima no eixo central, pois o perfil do feixe de elétrons sofre um abaulamento nestas profundidades.

\section{Uniformidade e Simetria}

A uniformidade e simetria do feixe foram analisadas mediante medidas de perfis radiais em diferentes profundidades, nos dois eixos. O resultado obtido a $12,8 \mathrm{~mm}$ de profundidade pode ser observado na figura 40 . Os demais resultados apresentaram o mesmo comportamento.

Segundo especificação da IEC nenhum ponto dentro da região de $90 \%$ de isodose deve apresentar valor 1,05 vezes maior que a dose no eixo central em uma mesma profundidade. Em todas as profundidades verificadas experimentalmente os perfis não apresentaram pontos com dose superior a $3 \%$ da dose no eixo central.

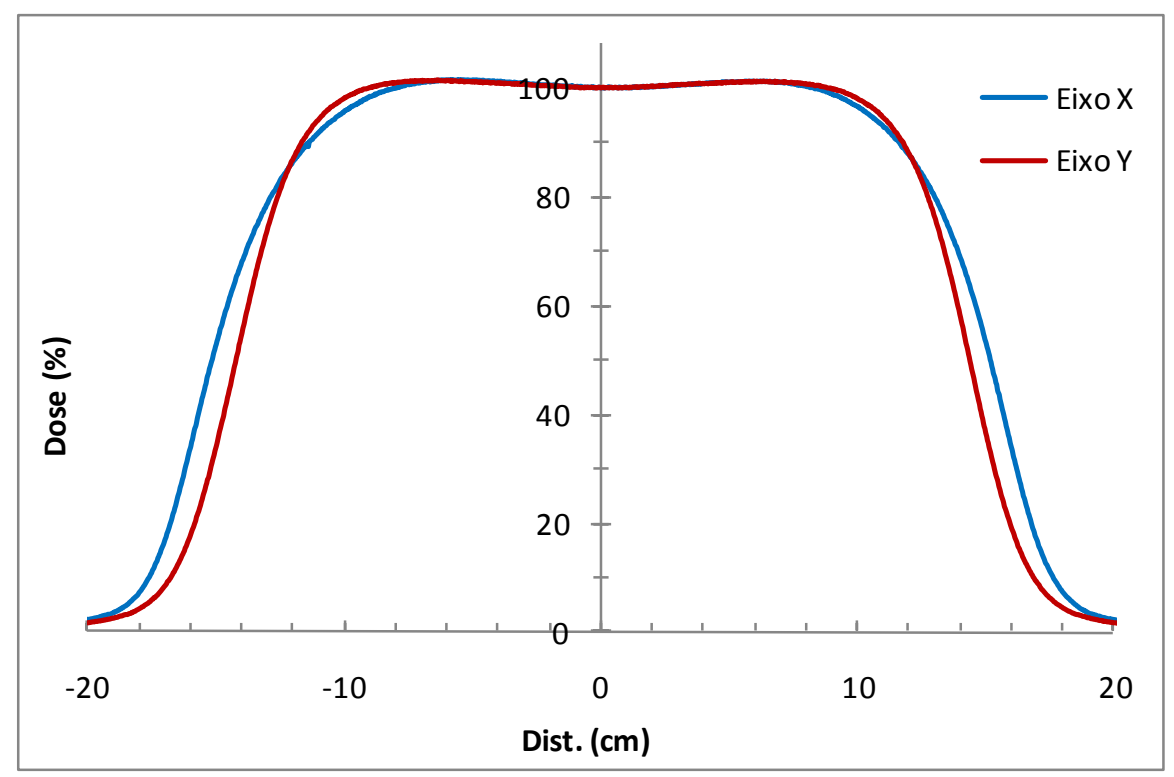

FIGURA 40: Comparação entre os perfis radiais de dose nos eixos $x$ e y a 12,8 $\mathrm{mm}$ profundidade, obtidos a DFS $0,7 \mathrm{~m}$. 
A IEC também especifica uma uniformidade superior a $3 \%$ para quaisquer pontos simétricos em relação ao eixo central. Por meio dos resultados apresentados é possível verificar que o acelerador atende as especificações da IEC, com diferença máxima entre os pontos próxima a 2,7 \%, na região entre 10 e $15 \mathrm{~cm}$ de distância do eixo central.

\subsection{Simulação da fonte de elétrons}

A reconstrução da fonte de elétrons foi realizada com base nas medidas experimentais de perfis axiais e radiais de dose, realizadas para caracterizar o feixe de elétrons do acelerador. Os perfis axiais relacionados à distribuição energética do feixe e os perfis radiais ao tamanho da fonte e sua distribuição angular.

\subsubsection{Percentual de dose em profundidade}

O espectro energético do feixe de elétrons, utilizado nas simulações foi obtido empiricamente por meio de simulações de PDP em um objeto simulador de água, com elipsóides posicionadas axialmente em intervalos de $2 \mathrm{~mm}$.

A deposição energética foi calculada numericamente até $2,9 \mathrm{~cm}$ de profundidade, com erro relativo inferior a $0,7 \%$ até $2,5 \mathrm{~cm}$ e erro relativo de $1,5 \%$ na profundidade máxima.

Os resultados obtidos por meio das simulações foram comparados com as medidas experimentais, realizadas com a câmara de placas paralelas em intervalos de 0,3 mm, consideradas referência.

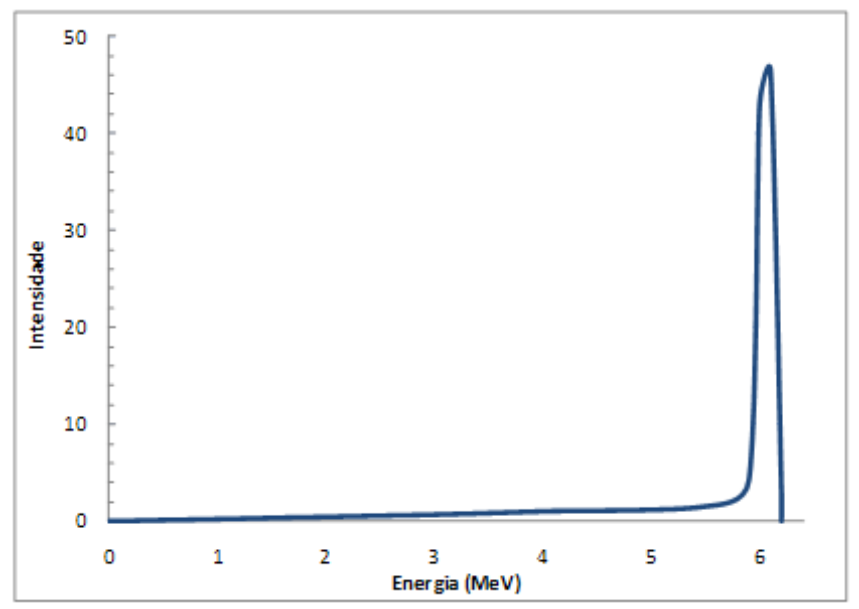

FIGURA 41: Distribuição energética utilizada nas simulações pelo MCNP4C. 
Dentre as diferentes distribuições energéticas simuladas, o espectro apresentado na figura 41, com distribuição energética entre 0 e 6,2 MeV, apresentou os resultados numéricos mais próximos aos resultados experimentais.

A PDP simulada pelo MCNP4C comparada ao resultado experimental pode ser observada na figura 42.

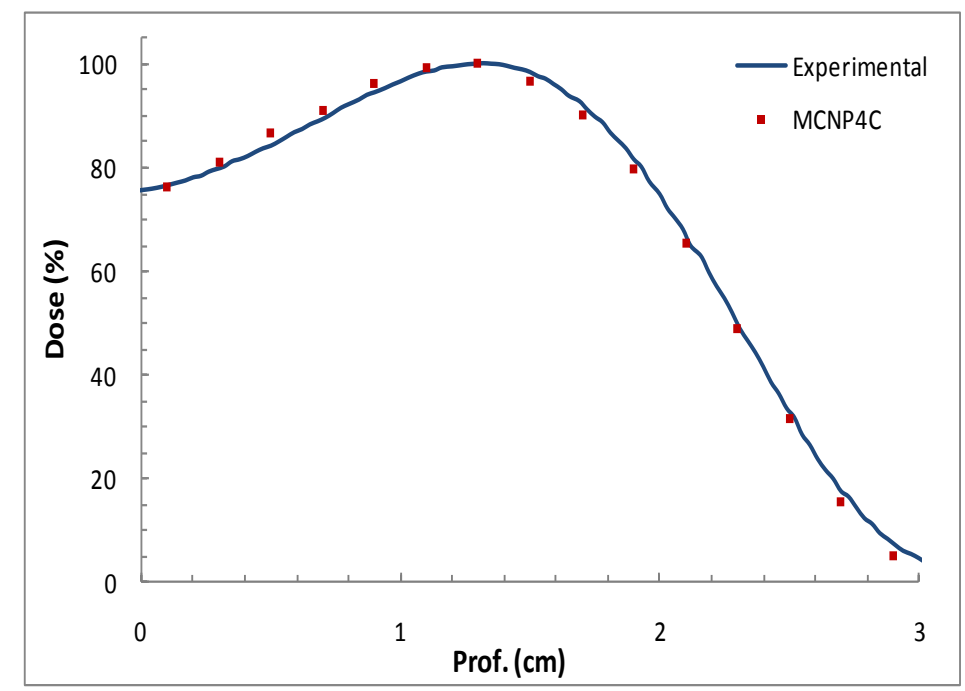

FIGURA 42: Comparação entre a PDP obtida pelo método de Monte Carlo e o resultado obtido experimentalmente a DFS $0,7 \mathrm{~m}$, para o feixe de $6 \mathrm{MeV}$.

Em todas as profundidades analisadas a diferença entre o resultado simulado e o resultado experimental é inferior a 2,3\%, exceto a 2,7 cm onde a diferença é $4,9 \%$ e a $2,9 \mathrm{~cm}$ de profundidade, onde a diferença percentual equivale a $35 \%$.

A 2,9 cm, único ponto com diferença significativa, a energia é depositada principalmente por fótons e corresponde a menos de $5 \%$ da energia máxima depositada.

Prolongando a PDP experimental após o alcance prático dos elétrons é possível estimar a contaminação por raios-X em $0,4 \%$ da energia máxima depositada (EL-KHATIB ET AL. 1991).

A dose devido à contaminação por raios-X obtida mediante simulações numéricas equivale a $0,23 \%$ da energia máxima depositada. Este resultado subestima em $0,17 \%$ a contaminação real, uma vez que, a fonte utilizada emite so- 
mente elétrons, sendo a contaminação por raios-X proveniente da interação destes elétrons com o ar, ao passo que, o feixe de elétrons do acelerador apresenta uma componente de fótons proveniente da interação dos elétrons com os componentes do acelerador, os quais não foram simulados.

A distribuição de dose em profundidade foi utilizada para determinar parâmetros de tratamento. Na tabela 7 é apresentada a comparação entre os parâmetros obtidos mediante simulações numéricas pelo método de Monte Carlo e os resultados experimentais.

TABELA 7: Comparação entre os parâmetros obtidos, mediante PDP experimental (referência) e simulada, em um objeto simulador de água a DFS 0,7 m.

\begin{tabular}{|c|c|c|c|}
\hline \multicolumn{4}{|c|}{ Parâmetros Clínicos } \\
\hline & Experimental & MCNP & Diferença (\%) \\
\hline$R_{100}(\mathrm{~cm})$ & $1,30 \pm 0,05$ & $1,3 \pm 0,1$ & 0 \\
\hline$R_{90}(\mathrm{~cm})$ & $1,74 \pm 0,07$ & $1,70 \pm 0,05$ & 2,3 \\
\hline$R_{80}(\mathrm{~cm})$ & $1,93 \pm 0,05$ & $1,90 \pm 0,05$ & 1,6 \\
\hline$R_{50}(\mathrm{~cm})$ & $2,30 \pm 0,05$ & $2,29 \pm 0,05$ & 0,4 \\
\hline$R_{p} \quad(\mathrm{~cm})$ & $2,89 \pm 0,05$ & $2,87 \pm 0,05$ & 0,7 \\
\hline$R_{q}(\mathrm{~cm})$ & $2,19 \pm 0,05$ & $2,15 \pm 0,05$ & 1,8 \\
\hline$G$ & $4,1 \pm 0,4$ & $4,0 \pm 0,3$ & 2,4 \\
\hline $\bar{\epsilon}_{0} \quad(\mathrm{MeV})$ & $5,4 \pm 0,1$ & $5,3 \pm 0,1$ & 1,9 \\
\hline $\bar{\epsilon}_{p, 0}(\mathrm{MeV})$ & $6,0 \pm 0,1$ & $5,9 \pm 0,1$ & 1,7 \\
\hline
\end{tabular}

Os parâmetros clínicos apresentados foram obtidos graficamente assim como as incertezas das suas profundidades. A incerteza foi obtida traçando duas PDPs, considerando o desvio máximo e mínimo dos resultados.

Os parâmetros obtidos indiretamente como o gradiente de dose $(G)$, a energia mais provável $\left(\overline{\boldsymbol{\epsilon}}_{\boldsymbol{p}, \mathbf{0}}\right)$ e a energia média $\left(\overline{\boldsymbol{\epsilon}}_{\mathbf{0}}\right)$ na superfície do objeto simulador, foram obtidos pelas equações 4,2 e 3 , respectivamente. Os resultados obtidos apresentam valores dentro das incertezas, obtidas pela propagação dos erros dos parâmetros utilizados nos cálculos. 
A diferença máxima entre a profundidade dos parâmetros clínicos simulados e experimentais é $0,4 \mathrm{~mm}$ na posição do $R_{90}$, um dos parâmetros de maior importância nos sistemas de planejamento. No entanto, esta diferença é inferior à incerteza da simulação, além de não ser significativa em um tratamento de pele, com parâmetros de maior influência como a posição do paciente e a profundidade do tumor.

\subsubsection{Perfis radiais de dose}

A simulação de um feixe de tratamento com abertura similar a real foi um dos maiores obstáculos enfrentados na caracterização do acelerador. Em tratamentos convencionais com feixes de elétrons utilizando aplicadores, a abertura do feixe não é tão significativa, quando comparada a aplicações sem aplicadores e com os colimadores posicionados na abertura máxima.

A definição precisa da distribuição espacial e angular da fonte utilizada é o parâmetro de maior importância no desenvolvimento das folhas espalhadoras e degradadoras de energia, uma vez que pequenas variações na fonte podem ocasionar grandes variações nas simulações a longas distâncias.

Para obter um feixe de elétrons similar ao real, foi utilizada uma fonte quadrada com dimensões reduzidas $(0,1 \mathrm{~mm} \times 0,1 \mathrm{~mm})$, considerada pontual. Outras distribuições geométricas foram utilizadas, no entanto os resultados obtidos apresentaram menor aproximação aos resultados experimentais.

O feixe de elétrons simulado apresenta formato cônico, em razão do formato pontual da fonte, e não representa o feixe de tratamento do acelerador. Para conformá-lo a uma região quadrada foram introduzidas placas delimitadoras com abertura central de 20,6 cm x 20,6 cm, posicionadas $49 \mathrm{~cm}$ abaixo da fonte, representando a janela do acelerador.

A região externa a abertura apresenta importância "zero", desta forma todas as partículas que atingem esta região são descartadas pelo método da roleta russa. Na figura 43 é representada a geometria utilizada para simular o feixe de elétrons. 


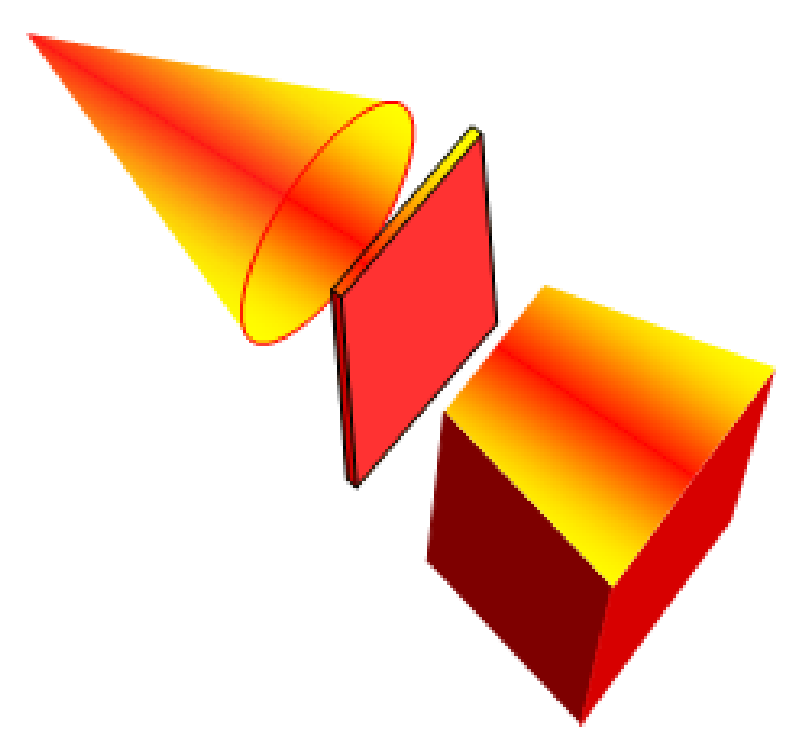

FIGURA 43: Representação geométrica da fonte, da janela simulada e do feixe de elétrons.

A distribuição angular do feixe (figura 44) foi estabelecida empiricamente entre 0 e $16,6^{\circ}$, entre a direção de emissão e a reta normal a fonte, por meio de simulações de perfis radiais comparadas aos resultados experimentais.

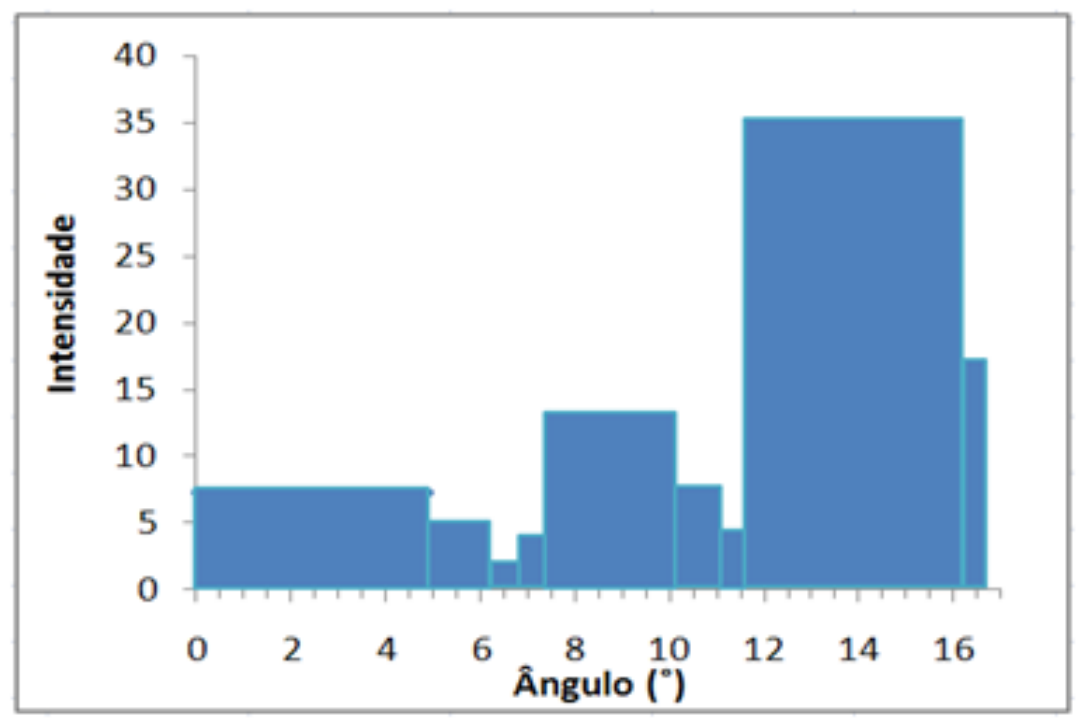

FIGURA 44: Distribuição angular dos elétrons emitidos pela fonte utilizada nas simulações pelo código MCNP4C.

O campo de tratamento do acelerador apresenta simetria superior a 2,7 \%, entre lados opostos ao eixo central. Em consequência da simetria observada nos perfis radiais experimentais e da distribuição angular uniforme da fonte simulada, o perfil radial foi caracterizado pelo método de Monte Carlo em apenas um dos 
lados do eixo central, em intervalos de $1 \mathrm{~cm}$ com erro relativo inferior a 1,2\%, até a distância de $14 \mathrm{~cm}$, e erro relativo de $4 \%$ no extremo do campo.

A caracterização dos perfis radiais foi realizada em diferentes profundidades, três destas $(12,8 \mathrm{~mm}, 13,2 \mathrm{~mm}$ e $18,4 \mathrm{~mm}$ ) dentro da região de tratamento, determinada pela PDP experimental, e a $23 \mathrm{~mm}$ de profundidade.

As medidas de referência foram realizadas com uma câmara de ionização em intervalos de 0,3 mm. As figuras 45 a 48 apresentam a comparação entre o perfil radial experimental no eixo central e os perfis radiais simulados no eixo central e deslocados em 5 e $10 \mathrm{~cm}$ do eixo.

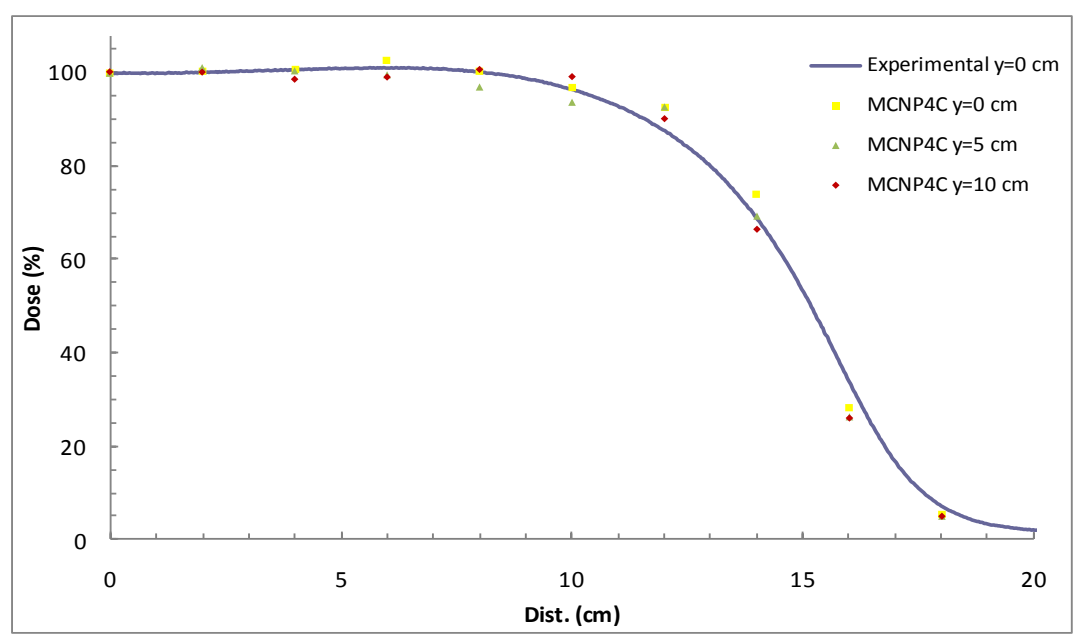

FIGURA 45: Comparação do perfil radial experimental e simulado, no eixo central e fora do eixo, a 12,8 $\mathrm{mm}$ profundidade (DFS 0,7 m).

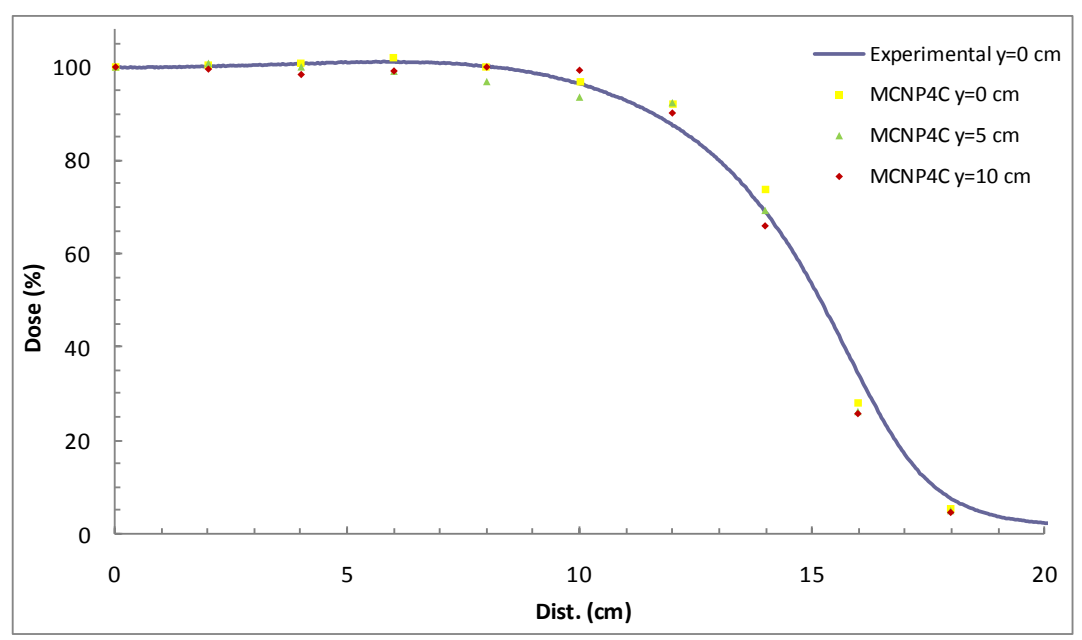

FIGURA 46: Comparação do perfil radial experimental e simulado, no eixo central e fora do eixo, a 13,2 $\mathrm{mm}$ profundidade (DFS 0,7 $\mathrm{m}$ ). 


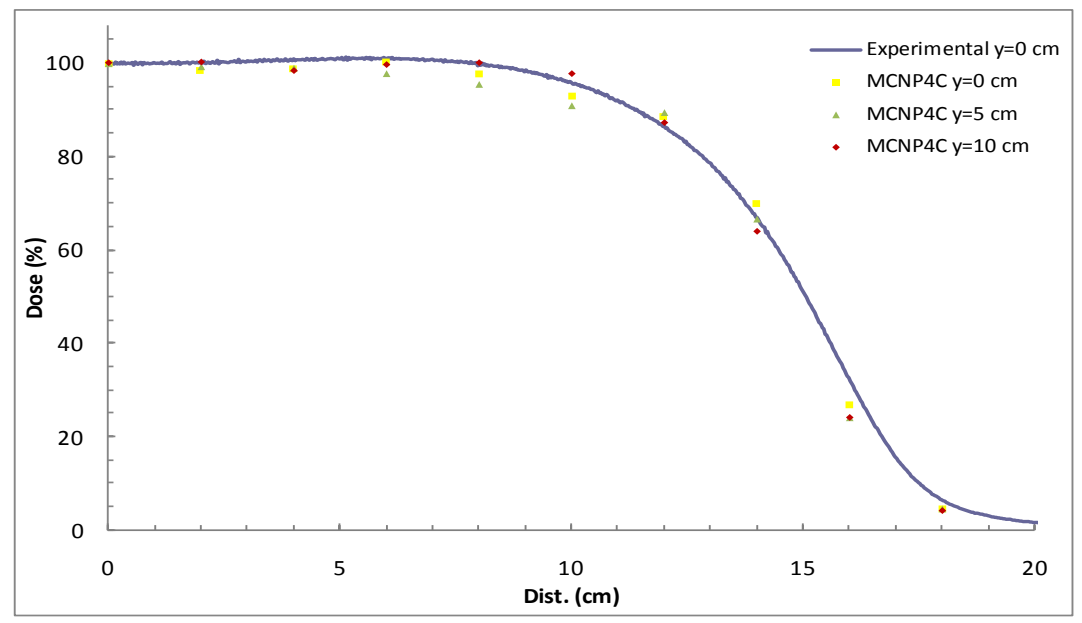

FIGURA 47: Comparação do perfil radial experimental e simulado, no eixo central e fora do eixo, a 18,4 $\mathrm{mm}$ profundidade (DFS 0,7 m).

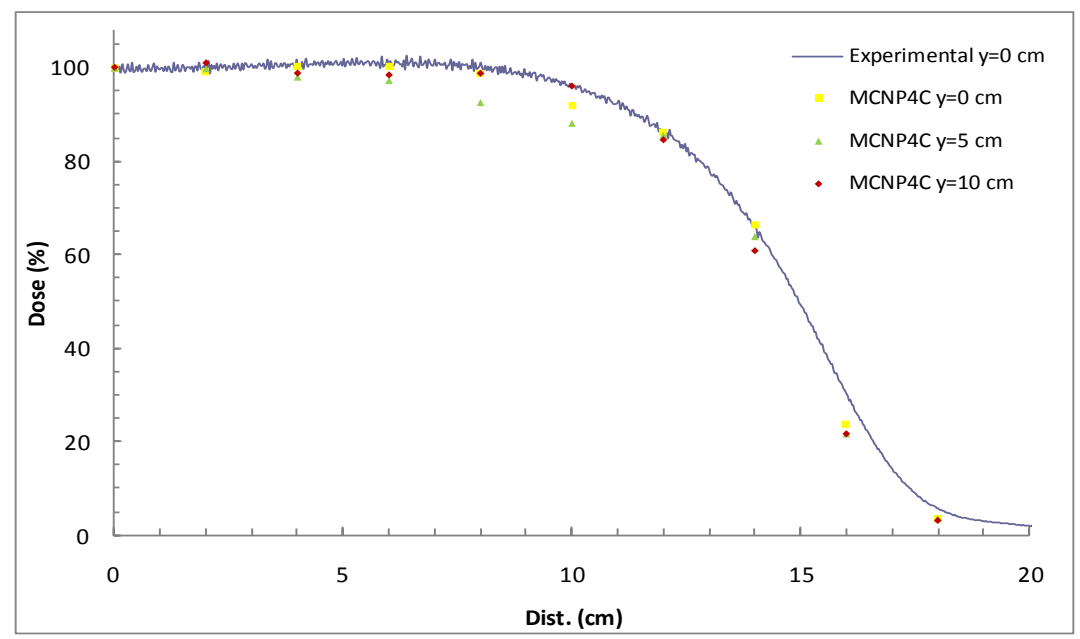

FIGURA 48: Comparação do perfil radial experimental e simulado, no eixo central e fora do eixo, a $23 \mathrm{~mm}$ profundidade (DFS 0,7 m).

Os perfis radiais simulados apresentam grande concordância em relação aos resultados experimentais, à distribuição radial de dose apresenta diferença inferior a $5 \%$, em profundidades com dose relativa superior a $70 \%$, exceto em dois pontos simulados a $23 \mathrm{~mm}$ de profundidade, que apresentam diferenças próximas a $10 \%$.

Nos extremos do campo, em regiões com dose relativa inferiores a $30 \%$, os resultados apresentam diferenças percentuais de até $35 \%$.

Em consequência da utilização de uma fonte com distribuição angular subdividida em regiões com diferentes intensidades, o campo de tratamento apresenta distribuição circular, que poderia levar a grandes diferenças na energia depositada nos extremos do campo. No entanto, a distribuição angular utilizada minimiza 
este efeito, de maneira que é possível considerar o campo uniforme em toda região de tratamento, em todas as profundidades analisadas, sem introduzir erros superiores a $5 \%$.

\subsection{Validação da fonte de elétrons}

A fonte utilizada nas simulações foi obtida com base nas medidas realizadas a DFS 0,7 m. Para verificar se o espectro construído é válido em outras situações, foram realizadas medidas experimentais de perfis radiais e axiais de dose a DFS $1 \mathrm{~m}$ em um objeto simulador automatizado de água com uma câmara de ionização de placas paralelas, utilizando a placa de TSET sem folha espalhadora, abertura máxima de campo e alta taxa de dose.

\subsubsection{Percentual de dose em profundidade}

A distribuição de dose em profundidade não apresenta grandes variações, em consequência da maior distância entre a fonte e a superfície do objeto simulador. Conforme esperado, verificou-se uma pequena superficialização da dose, ocasionada pela atenuação da energia do feixe em contato com ar.

A PDP foi simulada a DFS $1 \mathrm{~m}$, com precisão equivalente à utilizada na reconstrução do espectro. A comparação entre os resultados simulados e experimentais pode ser observada na figura 49.

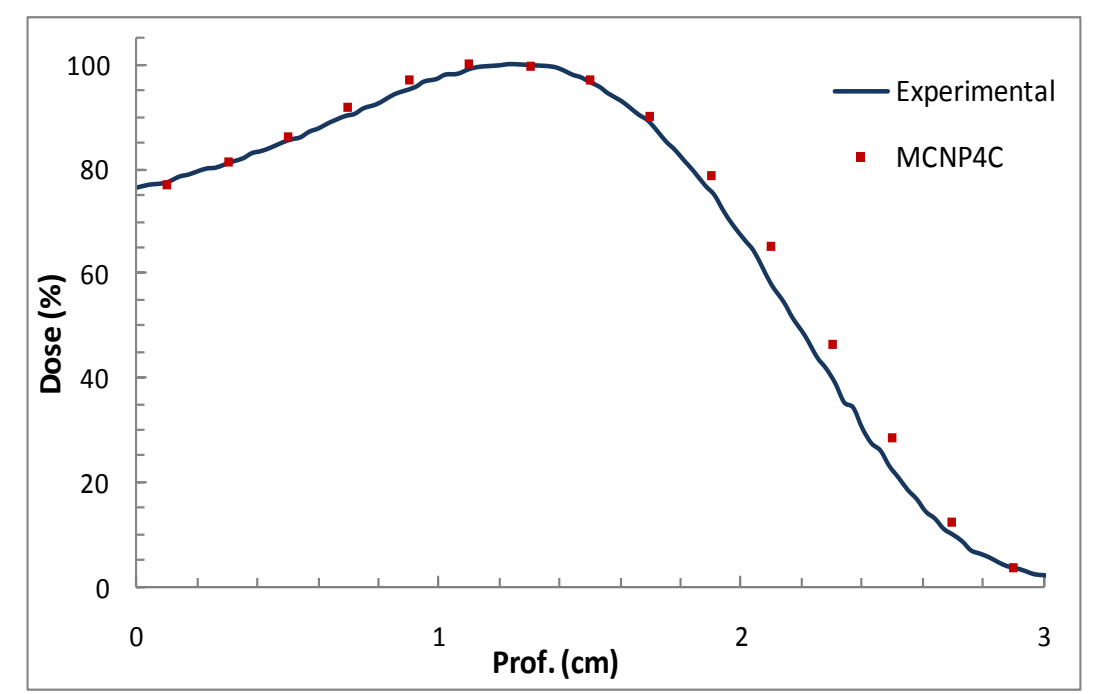

FIGURA 49: Comparação entre a PDP obtida pelo método de Monte Carlo e o resultado obtido experimentalmente a DFS $1 \mathrm{~m}$, para o feixe de $6 \mathrm{MeV}$ 
A diferença entre os resultados é inferior a $2 \%$ dentro da região de tratamento, estabelecida pela profundidade do $R_{80}$. Em profundidades acima de $2 \mathrm{~cm}$, a diferença percentual varia entre 5 e $25 \%$.

Por meio da comparação dos parâmetros clínicos (tabela 8), é possível verificar que todos os resultados simulados apresentam diferenças percentuais, em relação aos resultados experimentais, próximas as diferenças observadas a DFS $0,7 \mathrm{~m}$.

A posição do $R_{100}$ apresenta a maior diferença percentual (3,2 \%), em consequência do espectro energético utilizado nas simulações, que corresponde a uma diferença de 0,4 $\mathrm{mm}$ na profundidade de dose máxima, dentro da incerteza dos resultados simulados.

O gradiente de dose $(G)$ é o único parâmetro que apresenta diferença superior a incerteza, em virtude da maior diferença entre os resultados simulados e experimentais em profundidade superiores a $2 \mathrm{~cm}$.

TABELA 8: Comparação entre os parâmetros obtidos, mediante PDP experimental e simulada, em um objeto simulador de água a DFS $1 \mathrm{~m}$.

\begin{tabular}{|c|c|c|c|}
\hline \multicolumn{4}{|c|}{ Parâmetros Clínicos } \\
\hline & Experimental & MCNP & Diferença (\%) \\
\hline$R_{100}(\mathrm{~cm})$ & $1,26 \pm 0,05$ & $1,3 \pm 0,1$ & 3,2 \\
\hline$R_{90}(\mathrm{~cm})$ & $1,67 \pm 0,06$ & $1,68 \pm 0,05$ & 0,6 \\
\hline$R_{80}(\mathrm{~cm})$ & $1,84 \pm 0,05$ & $1,88 \pm 0,05$ & 2,2 \\
\hline$R_{50}(\mathrm{~cm})$ & $2,19 \pm 0,05$ & $2,15 \pm 0,05$ & 1,8 \\
\hline$R_{p} \quad(\mathbf{c m})$ & $2,74 \pm 0,05$ & $2,77 \pm 0,05$ & 1,1 \\
\hline$R_{q} \quad(\mathrm{~cm})$ & $2,01 \pm 0,05$ & $1,95 \pm 0,05$ & 3,0 \\
\hline $\boldsymbol{G}$ & $3,8 \pm 0,4$ & $3,4 \pm 0,3$ & 10,5 \\
\hline $\bar{\epsilon}_{0} \quad(\mathrm{MeV})$ & $5,1 \pm 0,1$ & $5,0 \pm 0,1$ & 2,0 \\
\hline $\bar{\epsilon}_{p, 0}(\mathrm{MeV})$ & $5,7 \pm 0,1$ & $5,8 \pm 0,1$ & 1,8 \\
\hline
\end{tabular}




\subsubsection{Perfis radiais de dose}

A distribuição angular do feixe foi validada por meio de perfis radiais realizados a 3, 7, 11 e $15 \mathrm{~mm}$ de profundidade, comparados com as simulações realizadas no eixo e deslocadas em 10 e $16 \mathrm{~cm}$ do eixo central. Os resultados obtidos podem ser observados nas figuras 50 a 53.

A diferença percentual entre os resultados simulados e experimentais é inferior $2,5 \%$, na região com dose relativa superior a $80 \%$, a aproximadamente 16 cm de distância do eixo central.

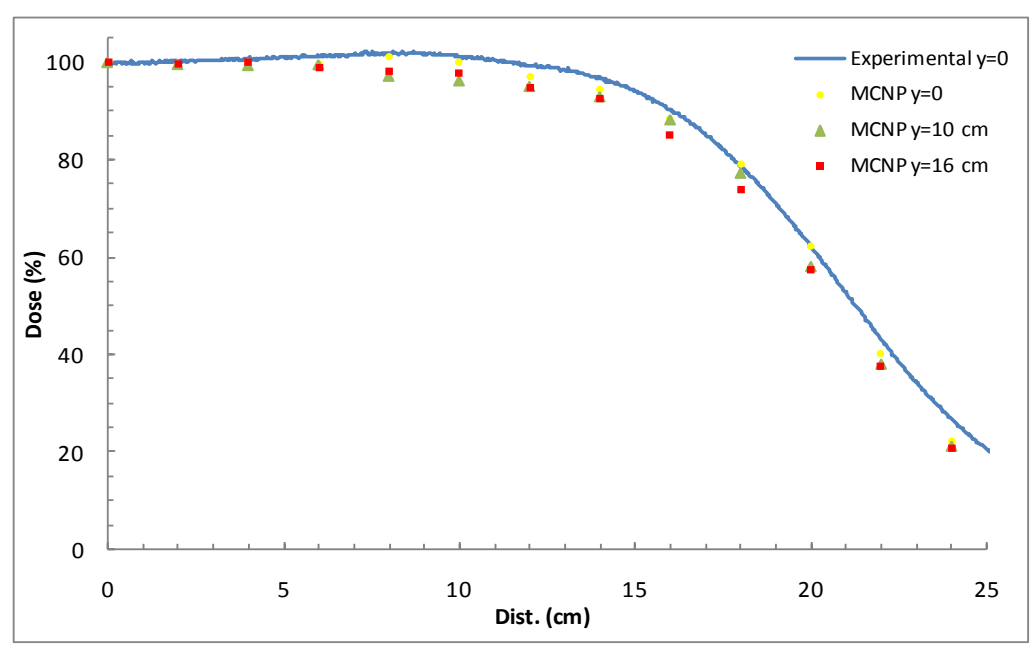

FIGURA 50: Comparação do perfil radial experimental e simulado, no eixo central e fora do eixo, a $3 \mathrm{~mm}$ de profundidade (DFS $1 \mathrm{~m}$ ).

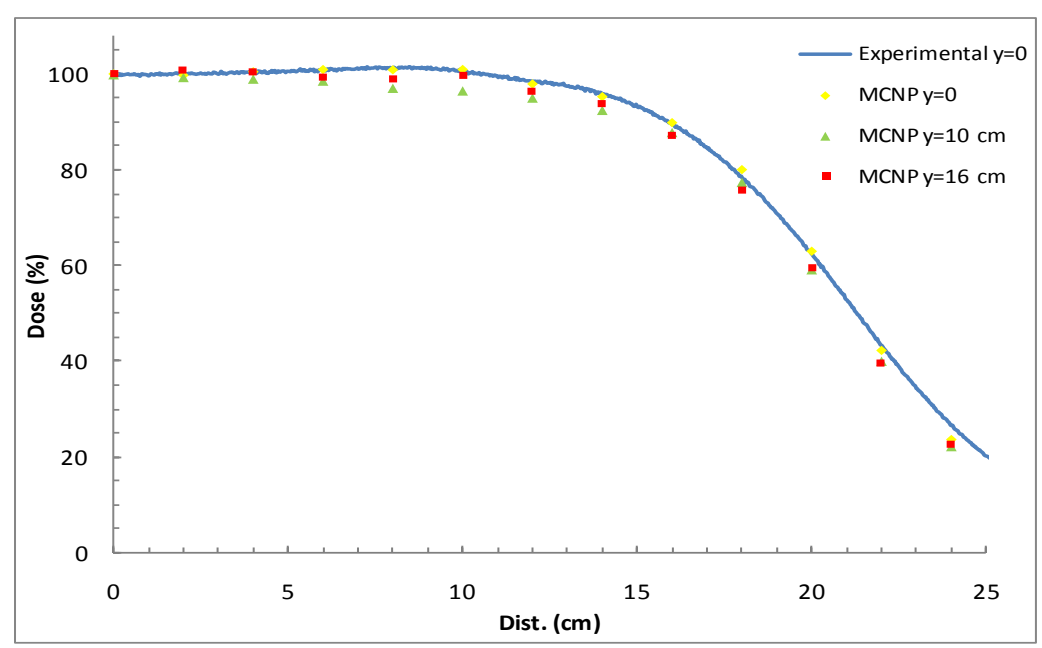

FIGURA 51: Comparação do perfil radial experimental e simulado, no eixo central e fora do eixo, a $7 \mathrm{~mm}$ de profundidade (DFS $1 \mathrm{~m}$ ). 


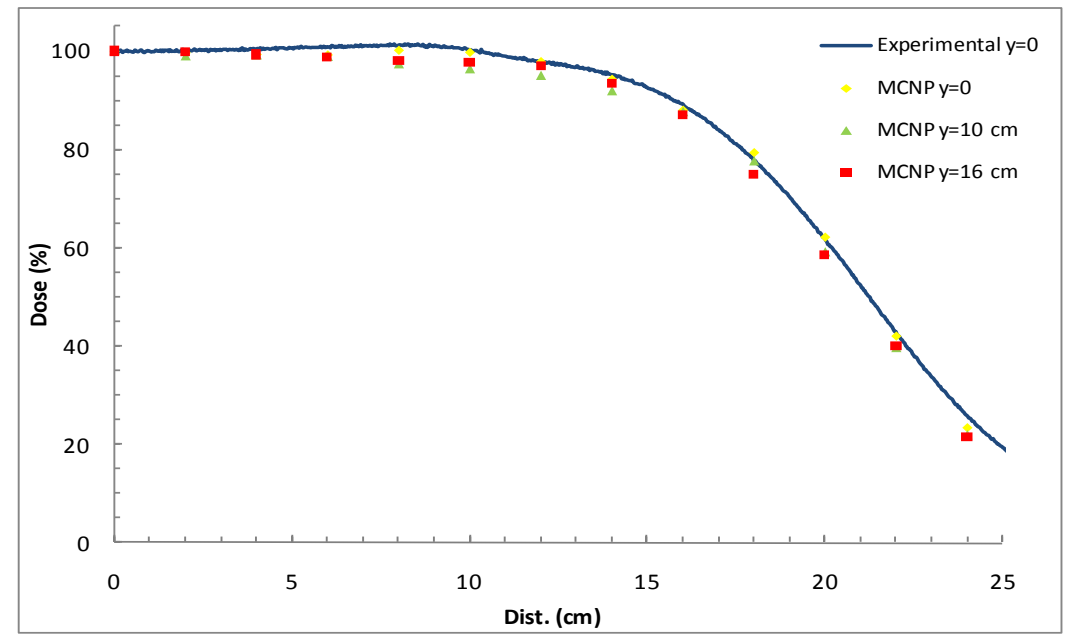

FIGURA 52: Comparação do perfil radial experimental e simulado, no eixo central e fora do eixo, a $11 \mathrm{~mm}$ de profundidade (DFS $1 \mathrm{~m}$ ).

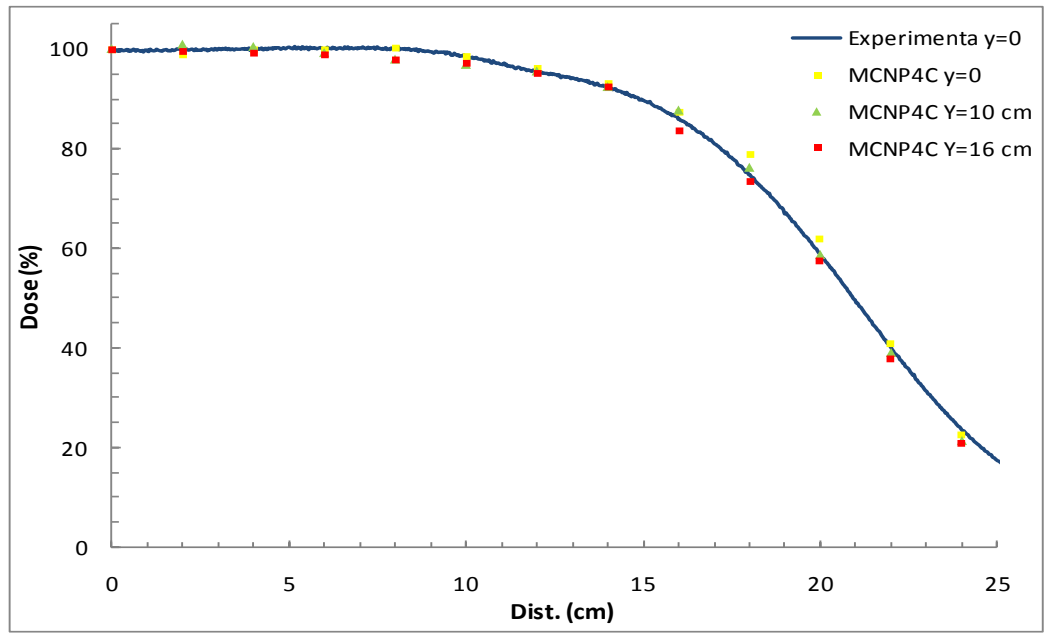

FIGURA 53: Comparação do perfil radial experimental e simulado no eixo central e fora do eixo a $15 \mathrm{~mm}$ de profundidade (DFS $1 \mathrm{~m}$ ).

Os resultados obtidos a DFS $1 \mathrm{~m}$, para validação do espectro, apresentam diferenças percentuais similares às obtidas a DFS $0,7 \mathrm{~m}$, com resultados superiores nos extremos do campo, onde a diferença percentual máxima entre os resultados é inferior a $16 \%$.

Em tratamentos com abertura máxima do feixe e sem aplicadores o tamanho do campo de tratamento apresenta grande variação, chegando a $5 \mathrm{~cm}$ de diferença entre a posição do $R_{50}$ a DFS $0,7 \mathrm{~m}$ e a DFS $1 \mathrm{~m}$.

A distribuição angular utilizada possibilita não só a homogeneidade do campo, como representa com grande similaridade a abertura do feixe, conforme os resultados obtidos em duas posições distintas. 


\subsection{Análise de materiais}

Diversos materiais foram simulados buscando conciliar o espalhamento eletrônico aos fatores limitantes, como a produção de raios-X e a atenuação energética do feixe.

Na Tabela 9 são apresentados os parâmetros obtidos por meio de simulações com o programa MCNP4C, para placas de diferentes materiais, ordenados pelo número atômico.

TABELA 9: Comparação de parâmetros entre placas espalhadoras e degradadoras de energia quadradas com $20 \mathrm{~cm}$ de lado e $1 \mathrm{~mm}$ de espessura para diferentes materiais, simulados na saída do acelerador a DFS $1 \mathrm{~m}$.

\begin{tabular}{|c|c|c|c|c|c|c|c|}
\hline \multirow{2}{*}{ Materiais } & \multirow{2}{*}{$\begin{array}{c}\begin{array}{c}\text { Perfil } \\
\text { Radial }\end{array} \\
\begin{array}{c}R_{50} \\
(\mathrm{~cm})\end{array}\end{array}$} & \multicolumn{4}{|c|}{ PDP } & \multirow{2}{*}{$\begin{array}{l}\text { Raios X } \\
\text { (\% de } \\
\text { dose) }\end{array}$} & \multirow{2}{*}{$\begin{array}{c}\text { Atenuação } \\
(\%)\end{array}$} \\
\hline & & $\begin{array}{c}R_{100} \\
(\mathrm{~mm})\end{array}$ & $\begin{array}{c}R_{80} \\
(\mathrm{~mm})\end{array}$ & $\begin{array}{c}\bar{\epsilon}_{\mathbf{0}} \\
(\mathrm{MeV})\end{array}$ & $\begin{array}{c}R_{\mathbf{p}} \\
(\mathbf{m m})\end{array}$ & & \\
\hline $\mathrm{Ar}$ & 21,0 & 13,0 & 18,7 & 5,02 & 28,0 & 0,24 & 0,0 \\
\hline Acrílico & 21,0 & 11,0 & 17,8 & 4,80 & 27,2 & 0,24 & 2,0 \\
\hline Berílio & 21,0 & 11,0 & 17,6 & 4,75 & 26,9 & 0,24 & 1,7 \\
\hline Alumínio & 21,9 & 11,0 & 17,1 & 4,60 & 26,3 & 0,25 & 16,1 \\
\hline Titânio & 25,8 & 11,0 & 16,2 & 4,36 & 24,9 & 0,34 & 45,1 \\
\hline Cobre & 32,4 & 8,0 & 13,6 & 3,76 & 21,9 & 0,65 & 71,4 \\
\hline Zinco & 31,6 & 9,0 & 14,6 & 4,01 & 23,4 & 0,55 & 66,9 \\
\hline Prata & 33,7 & 5,0 & 11,8 & 3,40 & 20,5 & 1,12 & 81,5 \\
\hline Cádmio & 34,9 & 7,0 & 13,2 & 3,71 & 22,2 & 0,92 & 78,0 \\
\hline Estanho & 34,1 & 8,0 & 14,3 & 3,97 & 23,3 & 0,80 & 74,8 \\
\hline Ouro & 29,8 & 3,0 & 6,4 & 2,13 & 14,9 & 8,70 & 97,5 \\
\hline Chumbo & 34,0 & 5,0 & 10,5 & 3,17 & 20,1 & 2,00 & 88,9 \\
\hline
\end{tabular}

A posição do $R_{50}$ nas simulações de perfil radial define o tamanho do campo de tratamento e foi utilizada como parâmetro de espalhamento do feixe. Os materiais com maior número atômico, como a prata, o cádmio, o estanho e o chumbo apresentam um aumento significativo no tamanho do campo, a diferença chega a $66 \%$, quando comparado ao resultado sem folha espalhadora. 
Embora apresentem grande espalhamento, estes materiais, exceto o estanho, não são indicados a esta prática em consequência de uma combinação de parâmetros, tais como:

\section{Contaminação por raios-X}

A contaminação apresentada corresponde à energia máxima depositada pelos raios- $X$ comparada à energia máxima depositada.

O resultado obtido para os materiais com maior espalhamento, inviabiliza sua utilização, uma vez que, a contaminação por raios-X é superior a especificada pelo TG23, mesmo utilizando placas com apenas $1 \mathrm{~mm}$ de espessura.

\section{Profundidade da região de tratamento}

A profundidade da região definida pela posição do $R_{80}$ é reduzida em virtude da atenuação da energia do feixe, efeito acentuado em materiais com maior número atômico e maior densidade. Em tratamentos reais com placas destes materiais, a deposição energética pode ser tão superficial, que não trate todas as regiões atingidas.

\section{Intensidade do feixe}

A intensidade do feixe (comparada à intensidade do feixe no ar) repercute diretamente no tempo de tratamento, a atenuação do feixe, pode tornar o tempo de tratamento tão longo, que seja inviável manter o posicionamento do paciente.

O ouro, dentre todos os materiais analisados, apresentou os piores resultados, embora tenha número atômico inferior ao chumbo, sua densidade (19,3 $\mathrm{g} / \mathrm{cm}^{3}$ ) é muito superior aos demais materiais analisados, ocasionando uma grande atenuação na energia e na intensidade do feixe, além de produzir uma deposição de energia por raios- $X$ de $8,7 \%$.

Com base nos resultados obtidos foram selecionados os seguintes materiais: 
- Acrílico;

- Alumínio;

- Titânio;

- Cobre;

- Zinco;

- Estanho.

O acrílico e o alumínio devem ser utilizados para alterar a distribuição de dose em profundidade, sem alterar significativamente a uniformidade do campo. Desta forma será possível realizar o tratamento de lesões mais superficiais, inserindo placas destes materiais para superficializar a distribuição de dose.

O berílio pode ser utilizado com o mesmo propósito, no entanto, apresentou resultados similares ao acrílico, material amplamente utilizado em hospitais, e por isso foi descartado.

O titânio apresenta propriedades intermediárias, entre os materiais de menor e maior espalhamento, e pode ser utilizado para produzir as placas espalhadoras, no entanto sua utilização pode ser limitada em virtude das dimensões reduzidas da sala de tratamento.

O cobre, o zinco e o estanho possuem características similares, ambos aumentam significativamente o tamanho do campo e apresentam contaminação por raios-X inferior aos materiais que produzem um espalhamento eletrônico similar, como o chumbo e a prata.

A contaminação por raios- $X$ observada, limita a espessura das placas de cobre, zinco e estanho a valores próximos de $1 \mathrm{~mm}$ de espessura, considerando que em condições reais a maior distância de tratamento produz um maior número de fótons.

\subsection{Validação das simulações de materiais}

Os resultados obtidos pelo método de Monte Carlo foram validados por meio de medidas experimentais de PDP e perfis axiais a DFS $0,7 \mathrm{~m}$, com placas 
de 1, 3 e $5 \mathrm{~mm}$ de espessura de alumínio e uma placa de cobre com 0,8 $\mathrm{mm}$ de espessura.

\subsubsection{Percentual de dose em profundidade}

A distribuição de dose em profundidade para as placas de alumínio (figuras 54 a 56) e cobre, foram simuladas em intervalos de $2 \mathrm{~mm}$ com erro relativo inferior a $1 \%$ na região de tratamento e erro relativo de $2,5 \%$ nas maiores profundidades.

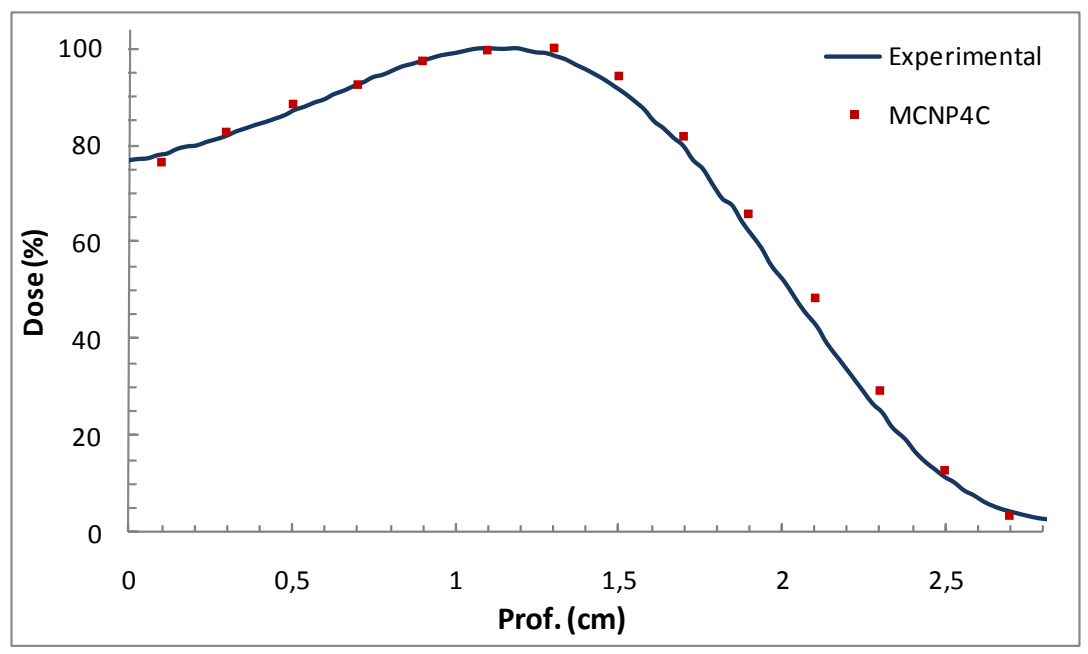

FIGURA 54: PDP (DFS $1 \mathrm{~m}$ ) com uma placa de alumínio com $1 \mathrm{~mm}$ de espessura posicionada na janela do acelerador.

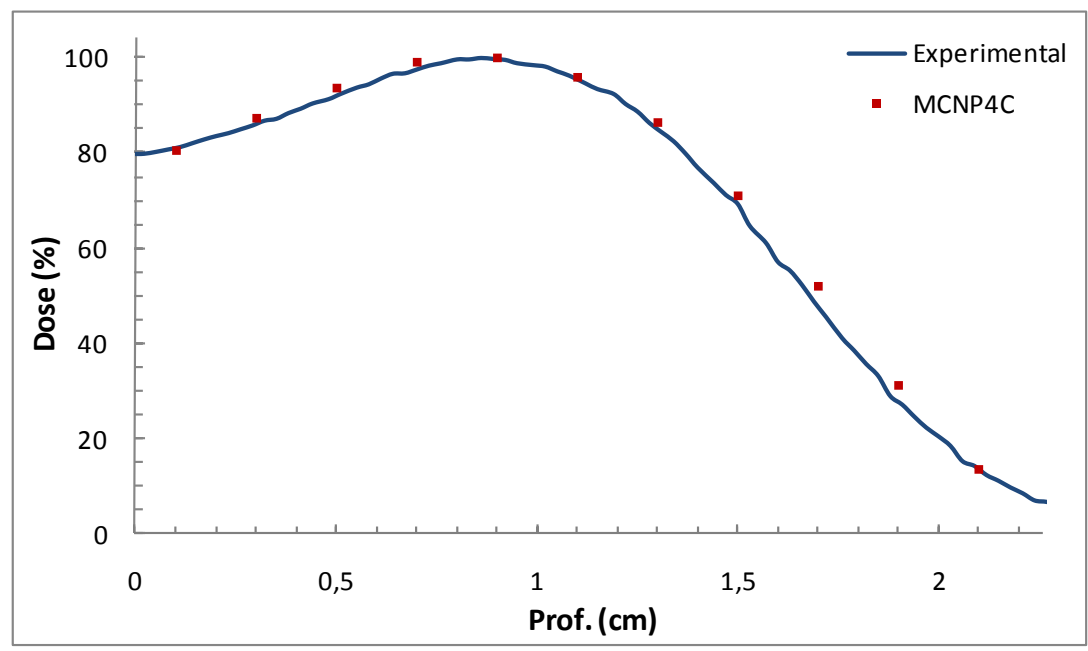

FIGURA 55: PDP (DFS $1 \mathrm{~m}$ ) com uma placa de alumínio com $3 \mathrm{~mm}$ de espessura posicionada na janela do acelerador. 


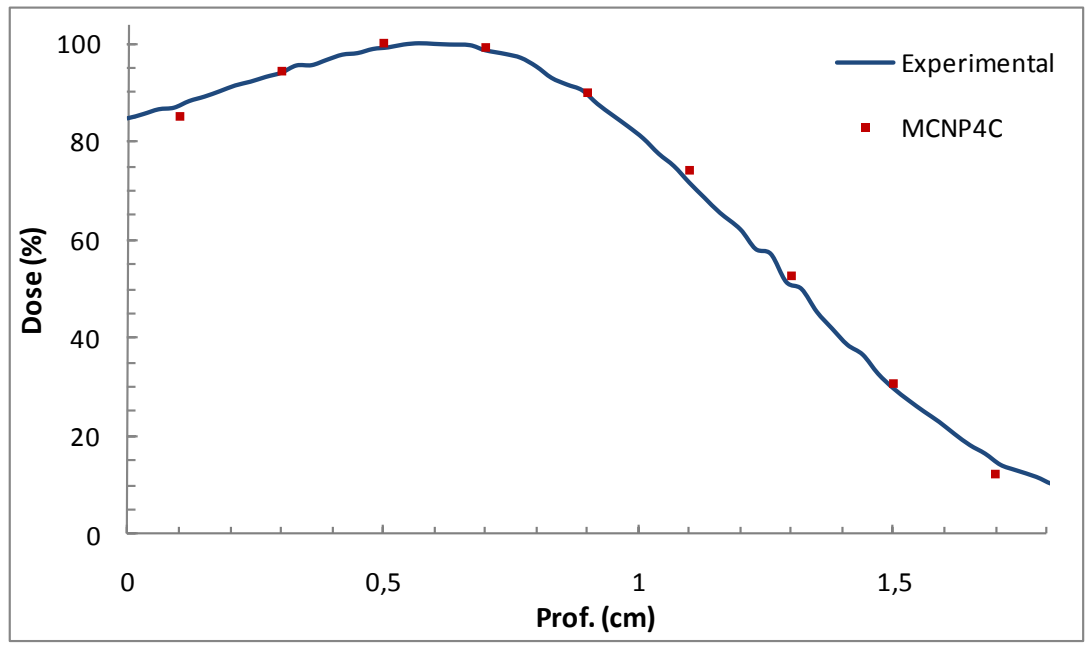

FIGURA 56: PDP (DFS $1 \mathrm{~m}$ ) com uma placa de alumínio com $5 \mathrm{~mm}$ de espessura posicionada na janela do acelerador.

Os resultados simulados com as placas de alumínio não apresentam diferenças percentuais superiores a 2 \% na região de tratamento. Na profundidade máxima esta diferença não é superior a $12 \%$, mesmo utilizando uma placa com 5 $\mathrm{mm}$ de alumínio, que atenua significativamente a energia do feixe, reduzindo a profundidade do $R_{100}$ de $1,2 \mathrm{~cm}$ (com $1 \mathrm{~mm}$ de alumínio) para 0,6 cm.

O resultado simulado com uma placa de cobre (figura 57 ) de 0,8 $\mathrm{mm}$ de espessura apresenta um aspecto deslocado, em relação ao resultado experimental. Em virtude do deslocamento, a diferença percentual entre os resultados simulados e experimentais é superior a $10 \%$, em profundidades superiores a 1,5 cm, chegando a $38 \%$ na maior profundidade simulada.

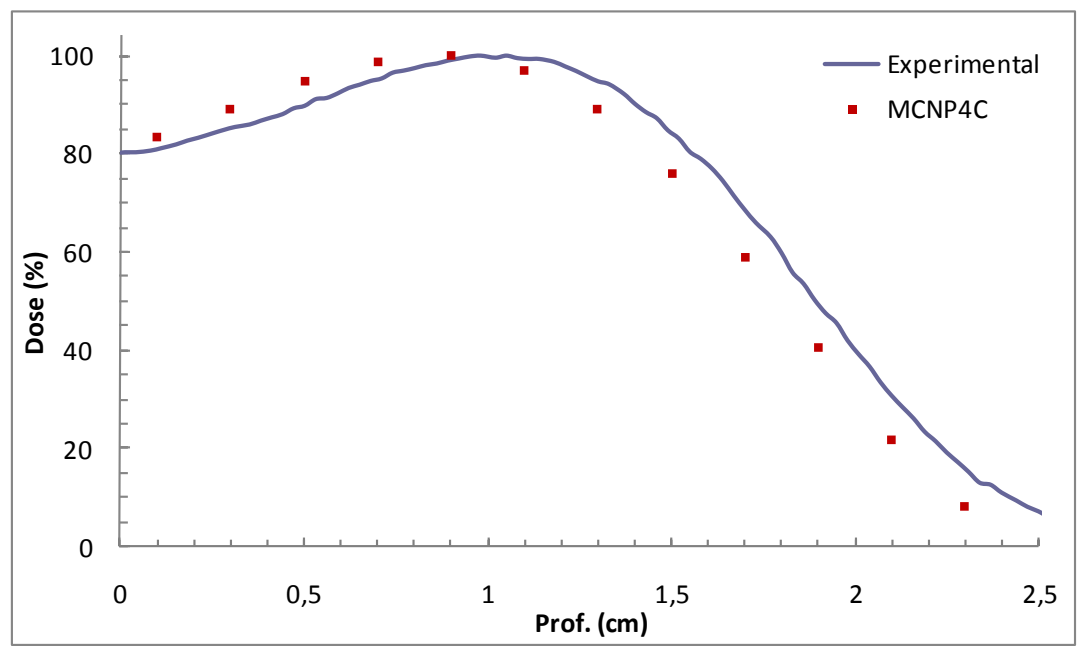

FIGURA 57: PDP (DFS 0,7 m) com uma placa de cobre com 0,8 $\mathrm{mm}$ de espessura posicionada na janela do acelerador. 
Este resultado pode ser justificado pelas irregularidades nas placas de cobre utilizadas. No processo experimental foram utilizadas quatro placas sobrepostas de cobre, com espessura de 0,2 $\mathrm{mm}$ cada, em consequência da espessura reduzida, as placas apresentavam diversas ondulações, ocasionadas pelo manuseio.

Além das irregularidades, não foi possível eliminar as camadas de ar entre as placas, o que pode ter acentuado as diferenças nos resultados.

\subsubsection{Perfil radial de dose}

A distribuição radial de dose foi simulada em duas profundidades (7 e 11 $\mathrm{mm}$ ), em intervalos de $2 \mathrm{~cm}$, com erro relativo inferior a $2 \%$, para cada uma das placas analisadas.

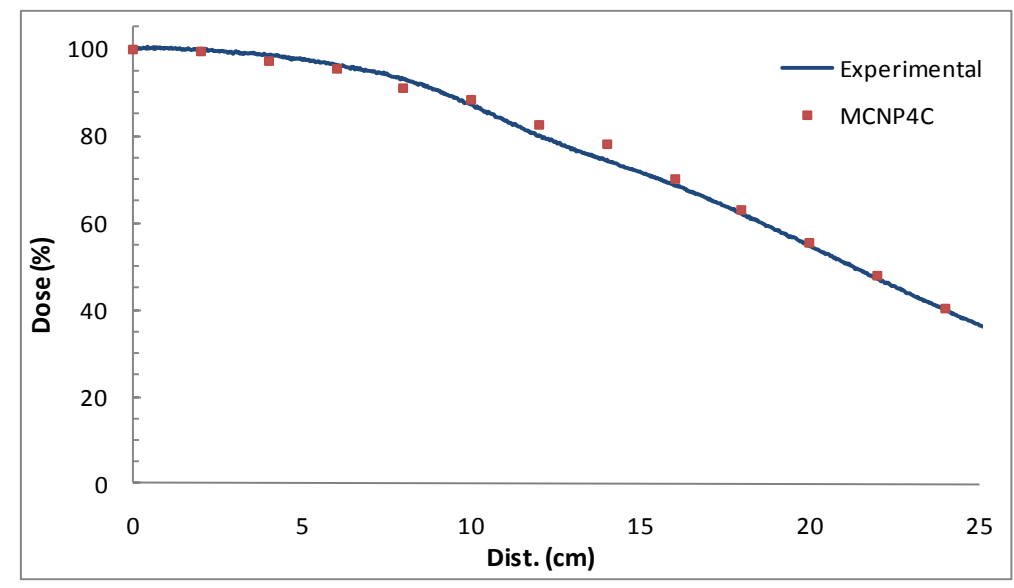

FIGURA 58: Perfil radial (DFS $1 \mathrm{~m}$ ) a $11 \mathrm{~mm}$ de profundidade, com uma placa de alumínio com $1 \mathrm{~mm}$ de espessura posicionada na janela do acelerador.

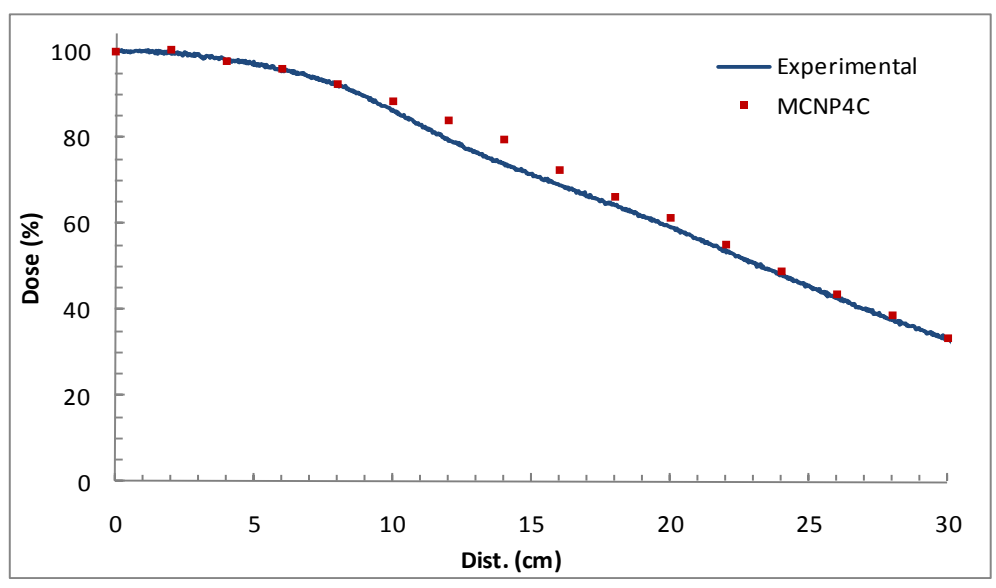

FIGURA 59: Perfil radial (DFS $1 \mathrm{~m}$ ) a $11 \mathrm{~mm}$ de profundidade, com uma placa de alumínio com $3 \mathrm{~mm}$ de espessura posicionada na janela do acelerador. 


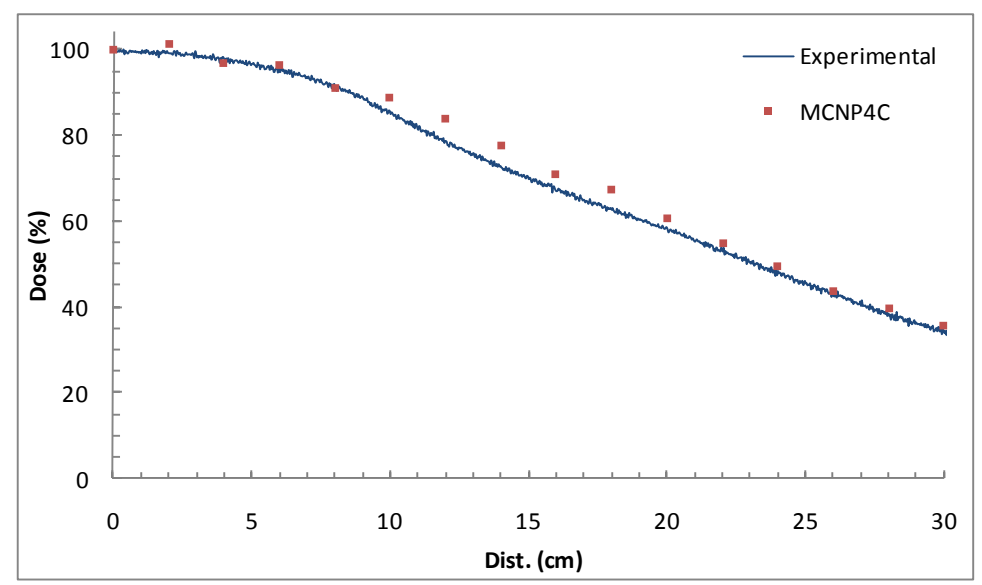

FIGURA 60: Perfil radial (DFS $1 \mathrm{~m}$ ) a $11 \mathrm{~mm}$ de profundidade, com uma placa de alumínio com $5 \mathrm{~mm}$ de espessura posicionada na janela do acelerador.

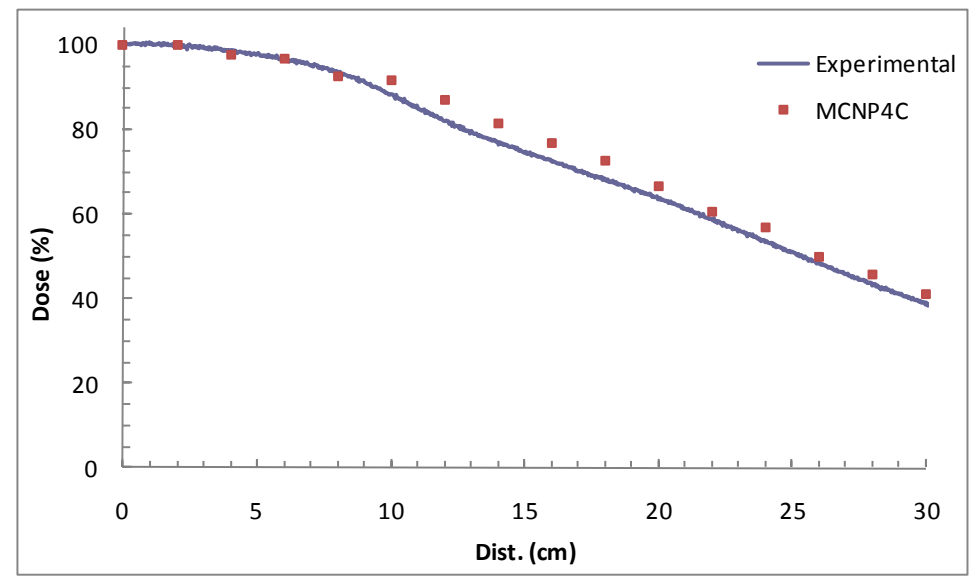

FIGURA 61: Perfil radial (DFS $1 \mathrm{~m}$ ) a $11 \mathrm{~mm}$ de profundidade, com uma placa de cobre com $0,8 \mathrm{~mm}$ de espessura posicionada na janela do acelerador.

Os resultados obtidos a $11 \mathrm{~mm}$ de profundidade por meio de simulações e de medidas experimentais com uma câmara de ionização podem ser observados nas figuras 58 a 61.

O perfil experimental apresenta uma inflexão entre 10 e $20 \mathrm{~cm}$ de distância do eixo central, em todos os resultados, nesta região foram observadas diferenças de $8 \%$ entre o resultado simulado e experimental, ao passo que os demais pontos apresentam diferenças inferiores a $5 \%$, mesmo em regiões de baixa dose relativa.

No processo de caracterização do acelerador não foram observadas grandes variações entre os lados do campo de tratamento. No entanto, a região entre 
10 e $15 \mathrm{~cm}$ de distância do eixo central apresentou à maior divergência, com diferenças de até $2,7 \%$.



FIGURA 62: Comparação entre o perfil radial obtido pelo método de Monte Carlo e os perfis experimentais, nos dois eixos do campo de tratamento, a $11 \mathrm{~mm}$ de profundidade (DFS $1 \mathrm{~m}$ ).

A não uniformidade do campo de tratamento foi acentuada pelas placas espalhadoras. Para confirmar esta hipótese, foi realizada uma medida experimental nos dois eixos do campo e em lados opostos ao eixo y, com uma placa de alumínio de $1 \mathrm{~mm}$ de espessura.

A medida experimental foi realizada em um dos lados do eixo (y’) até 15 $\mathrm{cm}$ de distância do eixo central, em razão da limitação do tamanho do objeto simulador.

Mediante o resultado obtido (figura 62) verificou-se que a diferença percentual observada entre os resultados simulados e experimentais pode ser uma característica do próprio acelerador, intensificada pelo espalhamento do feixe.

A fonte de elétrons utilizada nas simulações apresenta grande similaridade ao espectro experimental, necessitando de correções em virtude da assimetria do campo, que chega a $8 \%$, fora do limite de uniformidade estabelecido pela IEC para tratamentos convencionais.

Embora tenha sido verificada uma boa conformidade entre os resultados, no processo de implementação do tratamento a não uniformidade do campo pode 
causar variações significativas, tornando necessários ajustes na simetria das placas.

\subsection{Folhas espalhadoras e degradadoras de energia}

Utilizando os materiais selecionados foram realizadas inúmeras simulações para determinar a geometria e a composição das placas espalhadoras e produzir duas técnicas distintas de tratamento: a) tratamentos de lesões com extensão máxima de $60 \mathrm{~cm}$ a DFS $1,3 \mathrm{~m}$; b) TSET com feixe único a DFS 2,95 m.

\subsubsection{Feixe único de tratamento para lesões de até $60 \mathrm{~cm}$ (DFS 1,3 m)}

O tratamento de lesões com múltiplos campos necessita de um maior tempo, problema de especial relevância, tratando-se de hospitais públicos que atendem um número de grande de pacientes. Além de apresentar planejamento mais complexo em razão do cálculo de dose nas junções dos campos.

Um campo de tratamento com dimensões de $60 \mathrm{~cm} \times 60 \mathrm{~cm}$ a uma DFS máxima de 1,3 m é uma necessidade real do hospital. Embora a incidência de lesões com comprimento desta ordem seja pequena, um único tratamento deste tipo justifica a produção desta placa, uma vez que um tratamento com junções de campos menores pode apresentar uniformidade muito inferior à obtida com um feixe único.

A distância entre a fonte e a superfície, foi determinada pela máxima distância de posicionamento da mesa de tratamento, uma vez que, outro sistema de suporte poderia acrescentar incertezas significativas na posição do paciente.

A placa desenvolvida, para este tratamento, tem espessura de $1,5 \mathrm{~mm}$ e consiste em duas folhas quadradas de cobre sobrepostas, com 20 e $24 \mathrm{~cm}$ de lado para a folha superior e inferior, respectivamente.

\subsubsection{Percentual de dose em profundidade}

A PDP foi caracterizada experimentalmente com um filme radiocrômico posicionado entre placas de água sólida e simulada pelo MCNP4C. A comparação entre os resultados pode ser observada na figura 63 . 


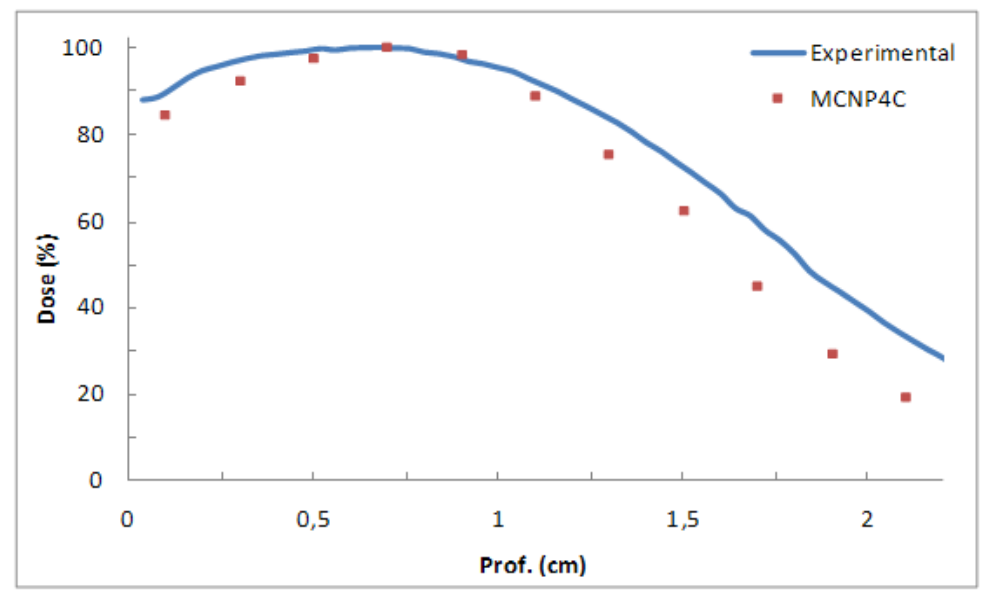

FIGURA 63: PDP (DFS 1,3 m) com uma placa espalhadora de cobre, posicionada $11 \mathrm{~cm}$ abaixo da bandeja de suporte.

A região de tratamento foi estabelecida experimentalmente em $1,4 \mathrm{~cm}$ de profundidade, $1 \mathrm{~mm}$ superior à obtida pelo MCNP4C. A diferença entre os resultados aumenta com a profundidade, atingindo $3 \mathrm{~mm}$ de diferença, na profundidade onde a dose relativa é $30 \%$.

A diferença entre os resultados, simulados e experimentais, pode ser atribuída a um conjunto de fatores, sendo eles, a dificuldade em posicionar o filme na superfície da placa e determinar a posição inicial do filme digitalizado, além de possíveis problemas na representação da fonte, acentuadas pela distância.

Em uma possível implementação futura esta medida será realizada com uma câmara de ionização, para caracterizar a distribuição de dose em profundidade com maior precisão, além de determinar parâmetros, como a dose absoluta.

\subsubsection{Perfil radial}

A medida experimental do perfil radial foi realizada diversas vezes, alterando a distância entre a placa e a janela do acelerador, para ajustar a diferença na posição entre a janela real e a janela simulada, uma vez que o acelerador apresenta uma série de estruturas de suporte que não foram simuladas por não interferirem no feixe de tratamento.

Após as medidas, a correção da distância foi estabelecida em $5 \mathrm{~mm}$, posicionando a placa em relação ao suporte e aproximadamente $15 \mathrm{~mm}$ posicionando a placa em relação à janela do acelerador. 
Na figura 64 é apresentada a comparação entre o resultado de perfil radial em um dos lados do eixo central ( $3 \mathrm{~mm}$ de profundidade), obtido experimentalmente com uma câmara de ionização de placas paralelas, posicionada entre placas de água sólida e movimentada em intervalos de $5 \mathrm{~cm}$, e os resultados simulados com a placa a $11 \mathrm{~cm}$ de distância da bandeja de suporte.

Os resultados foram simulados com erro relativo inferior a $1 \%$, até $30 \mathrm{~cm}$ de distância do eixo central, e apresentam diferenças em relação ao resultado experimental inferiores a $2 \%$, exceto a $25 \mathrm{~cm}$ de distância do eixo central, onde a diferença percentual chega a $10 \%$.

O perfil radial, simulado e experimental, apresenta uma queda na dose relativa entre 15 e $20 \mathrm{~cm}$ de distância do eixo central, esta variação pode ter ocorrido em consequência da junção entre as placas, que forma um degrau de $1 \mathrm{~mm}$. Este efeito pode ser corrigido por meio de pequenos ajustes nas dimensões das placas utilizadas e reduzindo o desnível em sua junção.

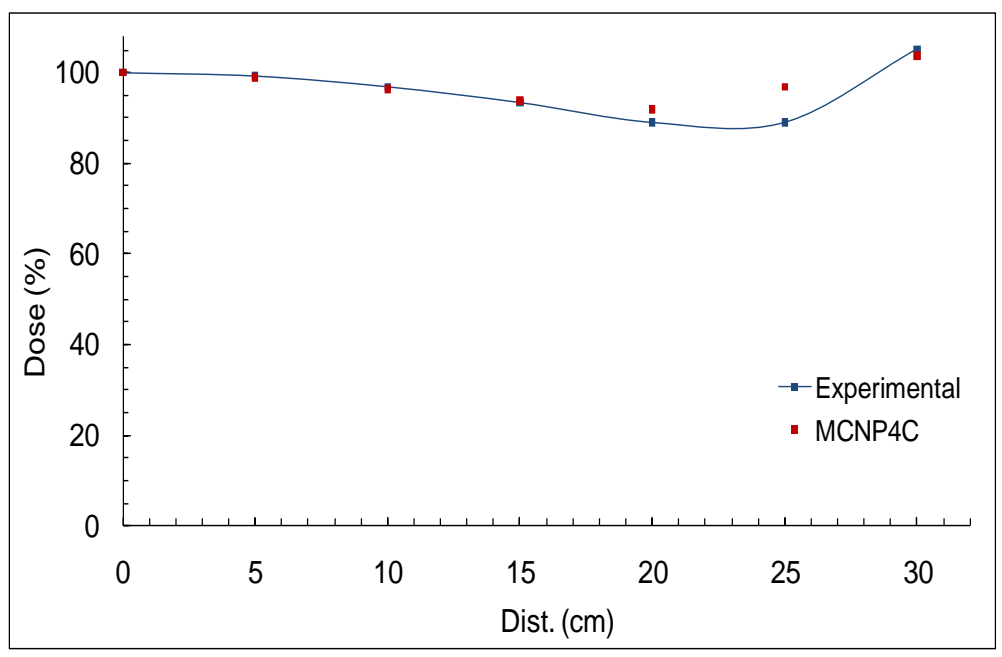

FIGURA 64: Comparação entre o perfil radial simulado e experimental em um dos lados do eixo central, utilizando uma folha espalhadora de cobre, a DFS 1,3 m.

O campo de tratamento experimental apresenta grande similaridade em relação ao campo simulado e uniformidade próxima a $10 \%$, até $25 \mathrm{~cm}$ de distância do eixo central, considerada aceitável pelos critérios do hospital. Embora a placa desenvolvida precise ser aprimorada para realização de tratamentos de lesões com até $60 \mathrm{~cm}$. 
Feixes espalhados apresentam pequeno gradiente de dose fora da região de tratamento, nesta região foram observadas diferenças percentuais de até $18 \%$ entre os resultados simulados e experimentais.

O gradiente de dose pode ocasionar danos aos tecidos sadios adjacentes a lesão, em consequência da alta energia depositada. Para reduzir o efeito da radiação em tecidos sadios adjacentes podem ser utilizados coletes de chumbo.

A atenuação do feixe foi verificada experimentalmente com um colete de chumbo de $1 \mathrm{~mm}$ de espessura posicionado na superfície do objeto simulador, ocasionando uma redução superior a $95 \%$ da energia depositada.

Coletes de chumbo com espessura próxima a $1 \mathrm{~mm}$ podem ser utilizados para delimitar a região de tratamento, tornando possível irradiações de corpo inteiro com translação do paciente.

A translação do paciente pode ser uma alternativa de tratamento em casos onde os pacientes se encontram demasiadamente debilitados e não conseguem ficar na posição de tratamento, inviabilizando o tratamento a longas distâncias.

A técnica consiste em posicionar o paciente sobre a mesa de tratamento (DFS $130 \mathrm{~cm}$ ) irradiar parte da superfície, protegendo as demais áreas com coletes de chumbo e em seguida deslocar a mesa de tratamento, realizando irradiações consecutivas, tratando toda a superfície atingida.

\subsubsection{Feixe único de tratamento para TSET}

O tratamento com um feixe único é uma das técnicas mais simples de tratamento do tipo TSET, embora envolva grandes distâncias, problemas de posicionamento dos pacientes e adaptações no acelerador.

Para atender os requisitos estabelecidos pelo TG 23 em uma sala de tratamento convencional que possui dimensões reduzidas, foram simuladas diversas placas espalhadoras com objetos simuladores em diferentes DFS, com o intuito de obter o maior espalhamento possível em uma distância pequena, quando comparada aos tratamentos convencionais. 
A distância entre a fonte e a superfície foi estabelecida empiricamente, em 2,95 m, nesta distância foram obtidos os resultados simulados, utilizando placas de zinco, cobre e estanho, mais próximos as especificações do TG 23.

O titânio foi descartado nessa fase do trabalho, uma vez que, o espalhamento eletrônico obtido com este material, é insuficiente para obter um campo de tratamento com $200 \mathrm{~cm}$ x $80 \mathrm{~cm}$, a DFS inferior a $3 \mathrm{~m}$.

\subsubsection{Percentual de dose em profundidade}

A espessura das placas foi limitada pela produção de raios- $X$, que corresponde a aproximadamente $1,0 \%$ da energia máxima depositada, para as placas desenvolvidas. Os resultados apresentam erro relativo inferior a $1 \%$ dentro da região de tratamento e erro relativo de $3 \%$ na profundidade máxima analisada.

O cobre e o zinco apresentam espalhamento similar, para ambos os materiais foram desenvolvidas placas com 1,5 $\mathrm{mm}$ de espessura. A folha espalhadora desenvolvida com estanho possui $1,2 \mathrm{~mm}$ de espessura, uma vez que este material apresenta espalhamento superior ao demais.

O perfil axial de dose foi simulado para as placas desenvolvidas de zinco, cobre e acrílico, cobre e estanho. Os resultados obtidos podem ser observados na figura 65 .

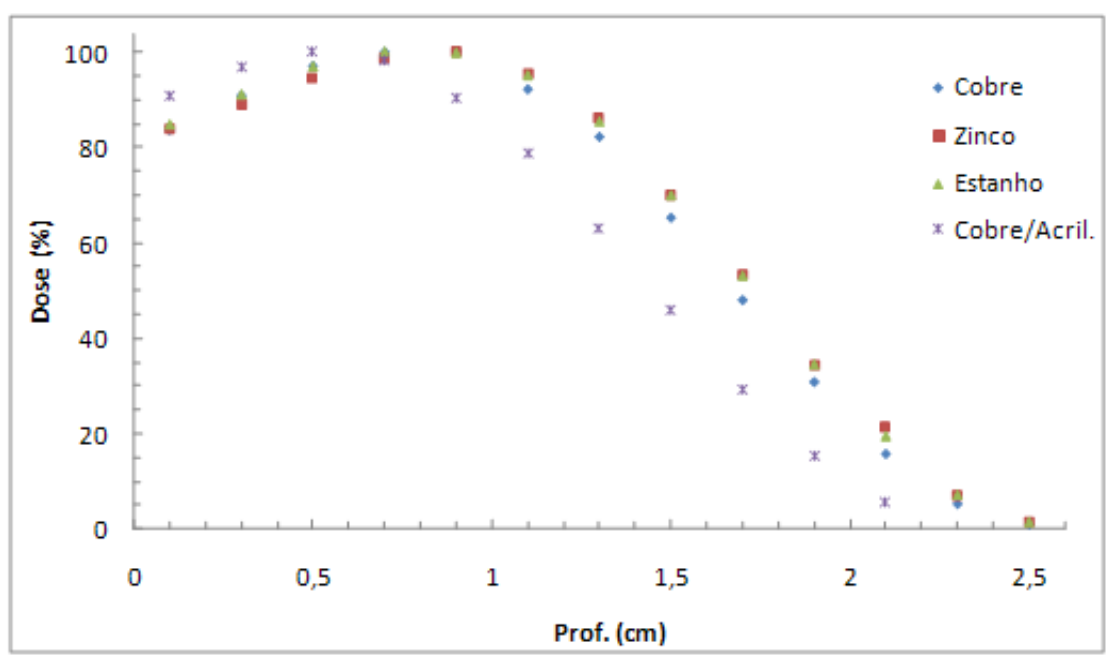

FIGURA 65: PDP utilizando placas espalhadoras de cobre, cobre e acrílico, zinco e estanho. 
Os resultados não apresentam diferenças significativas, em relação aos parâmetros de PDP, com $R_{80}$ entre 12 e $13 \mathrm{~mm}$ de profundidade e $R_{50}$ entre 16 e 17 $\mathrm{mm}$, dentro do estabelecido pelo TG 23.

Uma placa de acrílico com $2 \mathrm{~mm}$ de espessura foi simulada sobre o objeto simulador, degradando a energia do feixe espalhado pela placa de cobre. Por meio do resultado obtido é possível observar a superficialização da energia depositada em 4, 2 e $10 \mathrm{~mm}$ na posição do $R_{100}, R_{80}$ e $R_{50}$, respectivamente.

O alumínio não foi utilizado para degradar a energia do feixe, pois não foram observadas variações significativas na PDP, utilizando placas com espessura próxima a $1 \mathrm{~mm}$.

O alumínio é um material opaco a luz e maleável em espessuras reduzidas, sua utilização em placas com grandes dimensões próximas ao paciente, pode dificultar o posicionamento do paciente e ocasionar variações na distribuição de dose, em razão de imperfeições e ondulações na placa, provocadas pelo manuseio.

Em razão das características do material, as placas de alumínio devem apresentar dimensões reduzidas e ser fixadas próximas ao acelerador. No entanto, pequenas alterações no feixe a uma grande distância do objeto simulador provocam alterações significativas na distribuição radial de dose, inviabilizando o uso de placas degradadoras de alumínio com espessura acima de $2 \mathrm{~mm}$, associadas às placas desenvolvidas.

\subsubsection{Perfil radial de dose}

O perfil radial de dose foi simulado com placas de cobre, zinco e estanho. Todas as placas espalhadoras e degradadoras de energia simuladas são constituídas por duas placas quadradas sobrepostas, a placa superior com $20 \mathrm{~cm}$ de lado e a placa inferior com $24 \mathrm{~cm}$.

Os perfis foram simulados em um objeto simulador, até $1 \mathrm{~m}$ de distância do eixo central, com erro relativo inferior a $1 \%$. Os resultados obtidos apresentam grande similaridade e podem ser observados na figura 66. 


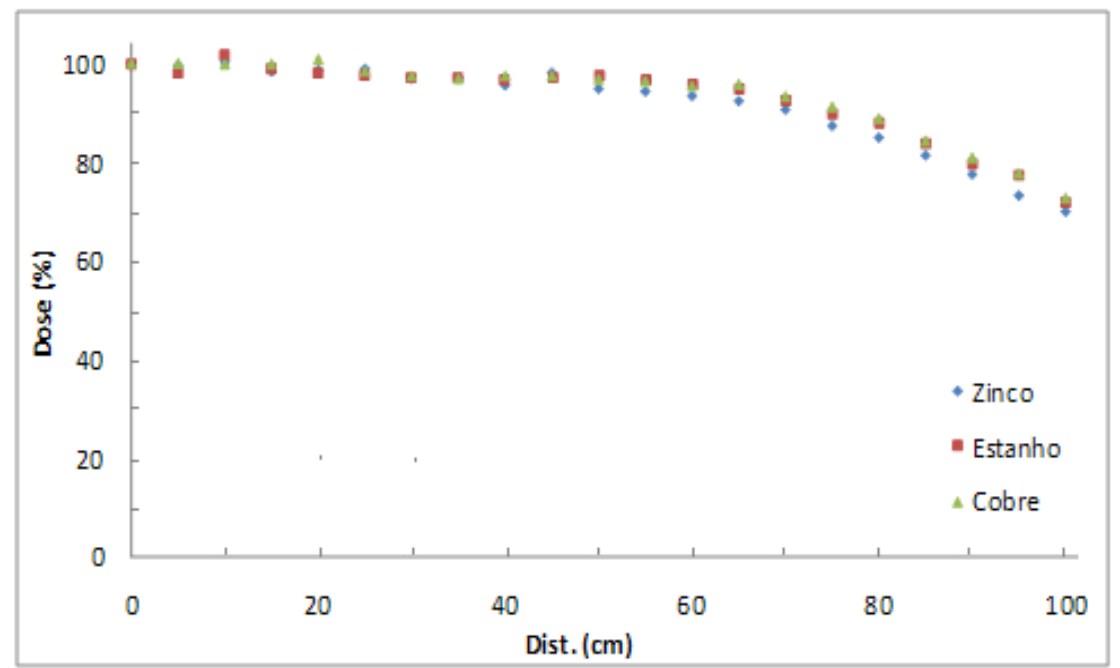

FIGURA 66: Perfil radial de dose simulado, em um dos lados do eixo central, com placas espalhadoras de cobre, zinco e estanho, a DFS 2,95 m.

Como a distribuição angular da fonte é simétrica, assim como as folhas espalhadoras, o perfil radial em um dos lados do eixo central não apresenta diferença em relação às demais regiões do campo de tratamento.

O resultado obtido apresenta uniformidade superior a $4 \%$, até $40 \mathrm{~cm}$ de distância do eixo central (correspondente a $80 \mathrm{~cm}$ no campo de tratamento), e satisfaz os requisitos do TG23 em relação à uniformidade lateral.

A uniformidade do campo de tratamento, em seu maior comprimento, é próxima a $8 \%$, até $75 \mathrm{~cm}$ de distância do eixo central (correspondente a $150 \mathrm{~cm}$ no campo de tratamento). O TG23 estabelece a uniformidade de $8 \%$ em uma região com $160 \mathrm{~cm}$, esse resultado pode ser alcançado aumentando a distância de tratamento ou a espessura das placas.

No entanto, a validação experimental dos resultados (item 8.8.2.3) mostra que o espalhamento foi subestimado, e o tamanho do campo de tratamento é superior ao simulado.

\subsubsection{Validação do perfil radial}

O perfil radial simulado com a placa de cobre foi validado experimentalmente, utilizando dosímetros termoluminescentes do tipo LiF 100 e filmes radiocrômicos, posicionados sobre uma placa de acrílico com $1 \mathrm{~cm}$ de espessura, a DFS 2,95 m. 
Os resultados com dosímetros termoluminescentes foram obtidos com 9 TLDs, em cada ponto de medição. O desvio padrão dos grupos ultrapassa $15 \%$, em alguns pontos. Aplicando os fatores de correção individuais, o desvio padrão é reduzido para valores inferiores a 3,8\%, e a incerteza máxima associada a cada ponto do perfil radial é inferior a $5 \%$.

O processo experimental utilizando filmes radiocrômicos apresenta diversos fatores que influenciam na incerteza dos resultados, tais como, a umidade, temperatura, iluminação do ambiente, além da incerteza associada aos equipamentos de leitura e a resposta do filme. Com base na literatura a incerteza das medidas experimentais foi estabelecida em 3 \% (ANDREAS et al., 2003).

Os resultados obtidos com os filmes e os TLDs apresentam grande similaridade, uma vez que, a diferença entre os resultados obtidos é inferior a um desvio padrão.

Na figura 67 é apresentado o resultado do perfil radial, em um dos lados do eixo central, obtido com dosímetros termoluminescentes, filmes radiocrômicos e simulado pelo MCNP4C.

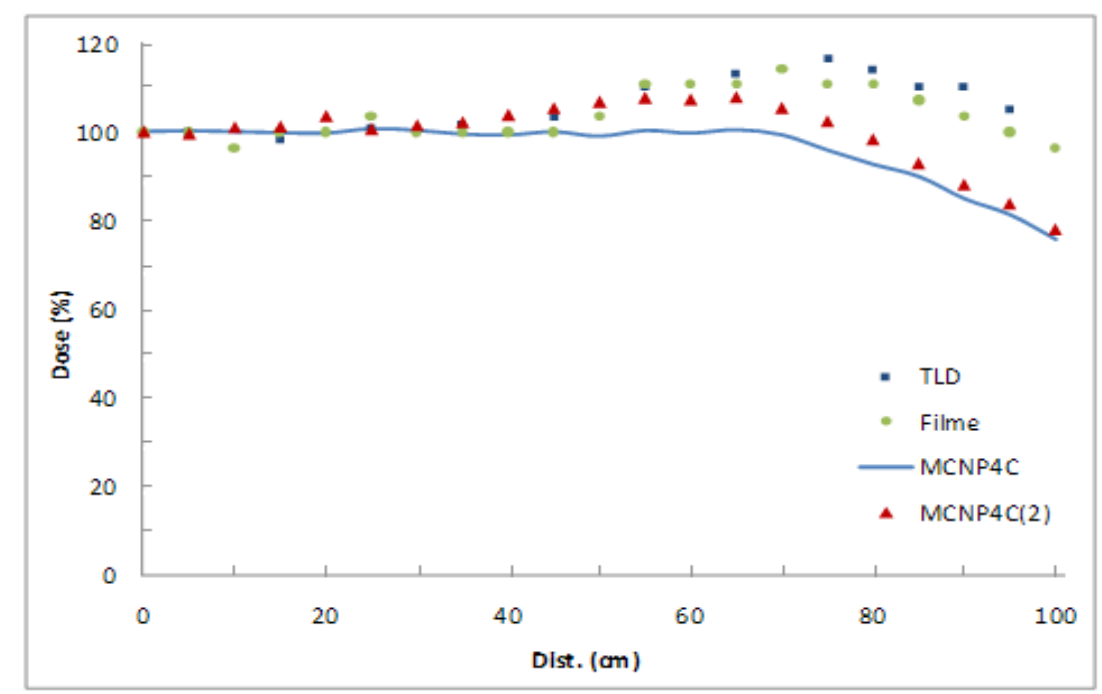

FIGURA 67: Perfil radial de dose em um dos lados do eixo central (DFS 2,95 m), obtido com TLDs, filmes radiocrômicos e simulado pelo MCNP4C.

O resultado obtido pelo MCNP4C (linha azul) apresenta diferença percentual em relação aos resultados experimentais próxima a $20 \%$, na região compreendida entre 0,7 e $1 \mathrm{~m}$ de distância do eixo central. 
Em consequência da grande DFS utilizada, pequenas variações no procedimento experimental, como a distância entre a placa e a bandeja de suporte, podem ocasionar grandes variações no perfil radial.

Assim como as variações experimentais, pequenas modificações na distribuição angular do feixe, embora pouco perceptíveis em pequenas distâncias, podem alterar significativamente o tamanho do campo a DFS 2,95 m.

O resultado MCNP4C(2) na figura 67 , representa o perfil radial simulado, aumentando em $2 \mathrm{~mm}$ a abertura da janela simulada do acelerador. Esta pequena alteração provoca alterações significativas no perfil radial, assim como os fatores mencionados.

Estes efeitos serão verificados em um possível processo de implementação, onde serão realizadas novas medidas experimentais, verificando os possíveis fatores de incerteza, inclusive a distribuição angular da fonte simulada.

O perfil radial experimental apresenta uniformidade próxima a $15 \%$, com maiores intensidades no extremo do campo de tratamento, em consequência do espalhamento eletrônico, maior que o esperado.

No entanto, este efeito foi considerado benéfico, uma vez que, apresenta fácil solução, por meio da redução da espessura das placas espalhadoras, o que também reduz a contaminação por raios- $X$. A maior intensidade nos extremos do campo também pode ser corrigida reduzindo a DFS, o que reduz consideravelmente o tempo de tratamento.

Estas alterações podem ser realizadas sem comprometer o tamanho de campo necessário a esta técnica de tratamento, uma vez que, o tamanho de campo obtido com as placas de cobre é superior ao especificado pelo TG23.

Embora os resultados obtidos com o MCNP4C apresentem diferenças percentuais significativas nos extremos do campo, da ordem de $20 \%$, este resultado apresenta grande conformidade, considerando a extrapolação das distâncias simuladas (a fonte utilizada nas simulações foi obtida a DFS $0,7 \mathrm{~m}$ ) e que pequenos 
ajustes nos experimentos e na fonte utilizada podem reduzir consideravelmente estas diferenças. 


\section{CONCLUSÃO}

A simulação do feixe de tratamento do acelerador linear Varian Clinac 2100C do Serviço de Radioterapia do Hospital das Clínicas pelo programa MCNP4C, foi realizada mediante medidas de perfis radiais e axiais de dose, obtidas com uma câmara de ionização de placas paralelas da PTW.

O programa MCNP4C se mostrou uma importante ferramenta, simulando as características do feixe de elétrons de $6 \mathrm{MeV}$ do acelerador linear Varian Clinac $2100 \mathrm{C}$ com grande aproximação. As diferenças observadas entre a profundidade dos parâmetros clínicos simulados e experimentais, obtidos por meio da PDP, é inferior a $1 \mathrm{~mm}$, dentro da região de tratamento, em todas as DFS simuladas.

A fonte simulada representa com grande aproximação a abertura do feixe e a distribuição radial de dose, como pode ser verificado pelas simulações em diferentes DFS. Sendo este o parâmetro de maior relevância na obtenção de grandes campos de radiação.

Os parâmetros obtidos por meio das simulações numéricas permitiram a análise de feixes com diferentes energias, a análise de diferentes materiais, assim como o desenvolvimento dos campos de tratamento para irradiações de corpo inteiro e de lesões locais.

As técnicas de tratamento desenvolvidas por meio de simulações e validadas experimentalmente apresentam um grande diferencial em relação à maioria das técnicas utilizadas atualmente, no que diz respeito à distância do tratamento. Utilizando folhas de cobre, zinco ou estanho é possível realizar irradiações de lesões com extensão de até $60 \mathrm{~cm}$ utilizando a mesa de suporte do acelerador, além de irradiações de corpo inteiro a DFS 2,95 m, distância muito inferior a empregada em técnicas similares. 
Embora alguns ajustes sejam necessários, os resultados obtidos comprovam a viabilidade de tratamentos do tipo TSET, que atendam as especificações do protocolo da AAPM, em salas de tratamento com dimensões reduzidas e fornecem subsídios para a possível implementação desta técnica de tratamento pelo Serviço de Radioterapia do Hospital das Clínicas da Universidade de São Paulo.

Os resultados obtidos foram validados por meio de medidas experimentais, no entanto as simulações e as medidas experimentais serão revalidadas e aprimoradas, segundo os critérios de aceitação do hospital, para a realização futura de tratamentos.

O trabalho desenvolvido também possibilita a simulação de tratamentos específicos, em diferentes distâncias fonte superfície, utilizando diferentes configurações de placas espalhadoras. A reconstrução e validação da fonte possibilita também o aprimoramento continuo da técnica de tratamento, em razão dos resultados observados durante as aplicações e nas necessidades específicas de cada paciente.

A técnica de tratamento TSET também deve ser implementada no Instituto do Câncer do Estado de São Paulo (ICESP), utilizando a metodologia desenvolvida neste trabalho, possibilitando o tratamento de pacientes pelo sistema único de saúde (SUS), com uma técnica de tratamento disponível apenas em alguns centros médicos e que possibilita tratamentos individuais, de acordo com a extensão e profundidade da lesão de cada paciente. 


\section{REFERÊNCIAS BIBLIOGRÁFICAS}

AGUIAR, A.B.C. Linfomas cutâneos de células $T$ : papel das células $N K$ e $T$ circulantes na defesa anti-tumoral. Dissertação - Universidade do Porto, Portugal, 2009.

American Association of Physicists in Medicine Task Group 30. Total skin electron therapy: Technique and dosimetry. New York: American Institute of Physics, 1987.

ANTUNES,P.C.G.; SIQUEIRA, P.T.D.; YORIYAZ, H.; FONSECA, G.P.; REIS. G.; FURNARI, L. Reconstruction of segmented human voxel phantoms for skin dosimetry. Nuclear Atlantic Conference - INAC, 2009.

ANTUNES,P.C.G.; SIQUEIRA, P.T.D.; YORIYAZ, H.; FONSECA, G.P.; FURNARI, L.; REIS. G.S. Reconstrução de objetos simuladores para dosimetria de pele. XIV Congresso Brasileiro de Física Médica, 2009.

BECKER, M.; HOPPE, R.T.; KNOX, S.J. Multiple Courses of high-dose total skin electrons beam therapy in the management of mycosis fungoides. Int. J. Radiation Oncology Biol. Phys., vol 32, p. 1445-1449, 1995.

BIELAJEW, A.F. Fundamentals of the Monte Carlo method for neutral and charged particle transport. University of Michigan, 2001.

BRIESMEISTER, J.F. MCNP: A general Monte Carlo N-particle transport code, version 4C, LA-13709-M. Los Alamos Scientific Laboratory, Los Alamos, New México, 2000.

BULLA, R.T. Métodos de calibração de câmaras de ionização de placas paralelas para dosimetria de feixes de elétrons. Dissertação - Instituto de Pesquisas Energéticas e Nucleares. São Paulo,1999.

CHEN, Z.; AGOSTINELL, A.G.; LYNN, B.S; Mathing the dosimetry characteristics of a dual-field for stanford technique to a customized single-field stanford technique for total skin electron therapy. Int. J. Radiation Oncology Biol. Physics, vol 59, p 872-885, 2004.

CRISCIONE V.D.; WEINSTOCK M.A. Incidence of cutaneous T-cell lymphoma in the United States:1973-2002. Arch. Dermatol, vol 143, p. 854-859, 2007.

EL-KHATIB, E.; SCRIMGER, J.; MURRAY, B. Reduction of the bremsstrahlung component of clinical electron beams: implications for electron arc therapy and total skin electron irradiation. Phys. Med. Biol, vol 36, p 111-118, 1991. 
EI-KHATIB, E.; SHERALI, H.; NIKOLIC, M.; VOSS, N.J.S.; PARSONS, C. Variation of Electron Beam Uniformity With Beam Angulations and Scatterer Positions for Total Skin Irradiations with the Stanford Technique. Int. J. Radiation Oncology Biol. Physics, vol 33, p. 469-474, 1995.

FILL, U.; REGULLA, D.; SPRUNCK, M. PC-Assisted Dose Assessment in Clinical TL Dosimetry and QA Progammes. GSF report D-85758. Radiation Protection Dosimetry, Nuclear Technology Publishing, Vol 66, pp. 249-253. 1999.

GUR D.; BUKOVITZ A.G.; SERAGA C. Photon contamination in 8-20 MeV electron beams from a linear accelerator. Med. Phys.vol. 6, p. 145-146, 1979.

J. A. Halbleib, R. P. Kensek, G. D. Valdez, T. A. Mehlhorn, S. M. Seltzer and M. J. Berger. ITS: The Integrated TIGER Series of Coupled Electron/Photon Monte Carlo Transport Codes Version 3.0. IEEE Transactions on Nuclear Science, vol 39, p. 1025-1030, 1992.

HOPPE, R.; COX, R. et al. Electrons beam therapy for mycosis fungoides: The Stanford University experience. Cancer Treatment Reports, vol 64, p. 691700, 1979.

INTERNATIONAL ATOMIC ENERGY AGENCY. Absorbed dose determination in external beam radiotherapy. Technical Report Series No. 398. Vienna: IAEA, 2000.

INTERNATIONAL COMMISSION ON RADIATION UNITS AND MEASUREMENTS, Tissue Substitutes in Radiation Dosimetry and Measurement. Rep.44, ICRU, Bethesda, MD, 1989.

JONES, G.W.; ROSENTHAL, D.; WILSON, L. D. Total skin electron radiations for patients with erythrodermic cutaneous T-Cell lymphoma (Mycosis Fungoides and the Sézary Syndrome). American Cancer Society, vol 85, p. 19851995, 1999.

LANSIGAN, FREDERICK.; JAEHYUK, C.; FOSS, M. F. Cutaneos T-Cell lymphoma. Hematology Oncology Clinics, vol 22, p. 979-996, 2008.

MACK A, MACK G, WELTZ D, SCHEIB SG, BÖTTCHER HD, SEIFERT V. High precision film dosimetry with GAFCHROMIC films for quality assurance especially when using small fields. Med. Phys. vol. 30, p. 2399-2409, 2003.

MARIN A.V. Desenvolvimento de um sistema dosimétrico postal para uso em programas de qualidade em radioterapia com feixes de fótons em condição de não referência. Dissertação de Mestrado. Comissão Nacional de Energia Nuclear, 2003.

MCKEEVER, W. S.; MOSCOVITCH, M.; TOWNSEND, P.D. Thermoluminescence Dosimetry Material: Properties and Uses. Nuclear Technology Publishing England, 2005. 
PODGORSAK, E.B. Radiation Oncology Physics: A Handbook for Teachers and Students. International Atomic Energy Agency Vienna, 2005.

PARIDA, D.K.; VERMA. K.K.; CHANDER, S.; JOSHI, R.C.; RATH, G.K. Total skin electron irradiation therapy in mycosis fungoides using high-dose rate mode: A preliminary experience. International Journal of Dermatology, vol. 44, p. 828-830, 2004.

RAVI, A.; NISCE, L.Z.; NORY D. Total Skin Electron Beam Therapy in the Manegement of Cutaneous Malignancies. Clinics in Dermatology, vol 19, p. 354356, 2001.

RODRIGUES, L.N.; CRUZ, J.C.; CECÍLIO, P.J.; CAPRIOGLIO, L. Implementation of TRS-398 protocol for electrons beams at "Hospital Israelita Albert Einstein”, São Paulo, Brazil. Radiol. Bras., vol 39, n 1, 2006.

ROGERS, D.W.O. Fifty years of Monte Carlo simulations for medical physics. Physics in Medicine and Biology, vol. 51, p. R287-R301, 2006.

ROSA, L.A.R.; REGULLA, D.; FILL, U. Reproducibility study of TLD-100 microcubes at radiotherapy dose level. Elsevier Science. 1999.

SAMPAIO, S.A.P. Dermatologia. 3.ed. Artes Médicas, 2007.

SCHOLTZ, W. Ueber den einfluese der roentgenstrahlen auf die haut in gesunden und krankein zustande. Arch. Dermat. Syph (Berlin), vol. 59, p. 421-449, 1902.

SEGRÉ, E. Dos raios-X aos quarks: físicos modernos e suas descobertas. $1^{\text {a }}$ ed. Universidade de Brasília, 1987.

SHULTIS, J.K.; FAW, R.E.; An MCNP Primer. Kansas State University, 2006.

SOMMERVILLE, J. Mycosis fungoides treated with general X-ray bat. Journal Dermatology, vol. 51, p. 323-324, 1939.

TAUHATA, L.; SALATI, I.P.A.; PRINZIO, R. Radioproteção e dosimetria. Instituto de Radioproteção e Dosimetria - CENEN, 3를 ver, 2002.

TRUMP, J.G. High energy electrons for treatment of extensive superficial malignant lesions. Am. J Roentgenol Rad. Ther. Nucl. Med, vol. 69, p. 623-629, 1953.

ULUTIN, H.C.; BEYAN, C.; PAK,Y. Total Skin Electron Beam Therapy for Cutaneous T-Cell Lymphoma: Turkish Experience With Translational Technique. Hoematologia, vol 32, p. 397-403, 2002.

VIEIRA, A.M.M. Dosimetria dos sistemas de radiocirurgia estereotáxica com aceleradores lineares equipados com colimadores micro multi-lâminas. Tese- Instituto de Pesquisas Energéticas e Nucleares. São Paulo. 2008. 
VONDERHEID, E.C, SCOTT, E.J.V, WALLNER, P.E, JOHNSON, W.C. A 10-Year experience with topical mechlorethamine fo mycosis fungoides: Comparison with patients treated by total-skin electron-beam radiation therapy. Cancer Treatment Reports, vol 63, p. 681-689, 1979.

WIESLANDER, E.; KNÖÖS, T. A virtual-accelerator-based verification of a Monte Carlo dose calculation algorithm for electron beam treatment planning in clinical situations. Radiotherapy and Oncology, vol 82, p. 208-217, 2007.

YORIYAZ H, SIQUEIRA PTD, ANDRADE DA, FONSECA GP; GUIMARÃES PA, SOUZA G. Estudos dos Parâmetros Clínicos em Radioterapia com Feixes de Elétrons. Projeto - FAPESP, 2007. 